\author{
UNIVERSIDADE DE SÃO PAULO \\ FACULDADE DE CIÊNCIAS FARMACÊUTICAS \\ Departamento de Alimentos e Nutrição Experimental \\ Programa de Pós-Graduação em Ciências dos Alimentos \\ Área de Concentração - Nutrição Experimental
}

\title{
Efeito da deficiência dietética de magnésio na resistência insulínica e no status inflamatório e oxidativo em ratos alimentados com dieta hiperlipídica
}

\section{Cristiane Hermes Sales}

Tese para obtenção do grau de DOUTOR

Orientadora:

Prof $^{a}$. Dra ${ }^{a}$. Célia Colli 



\author{
UNIVERSIDADE DE SÃO PAULO \\ FACULDADE DE CIÊNCIAS FARMACÊUTICAS \\ Departamento de Alimentos e Nutrição Experimental \\ Programa de Pós-Graduação em Ciências dos Alimentos \\ Área de Concentração - Nutrição Experimental
}

\title{
Efeito da deficiência dietética de magnésio na resistência insulínica e no status inflamatório e oxidativo em ratos alimentados com dieta hiperlipídica
}

Versão corrigida da Tese conforme Resolução CoPGr 5890.

O original encontra-se disponível no Serviço de Pós-Graduação da FCF/USP.

\section{Cristiane Hermes Sales}

Tese para obtenção do grau de DOUTOR

Orientadora:

Prof ${ }^{\mathrm{a}}$. Dr ${ }^{\mathrm{a}}$. Célia Colli

SÃO PAULO

2013 


\section{Ficha Catalográfica}

Elaborada pela Divisão de Biblioteca e

Documentação do Conjunto das Químicas da USP.

\section{Sales, Cristiane Hermes}

S163e Efeito da deficiência dietética de magnésio na resistência insulínica e no status inflamatório e oxidativo em ratos alimentados com dieta hiperlipídica / Cristiane Hermes Sales. -São Paulo, 2013.

220p.

Tese (doutorado) - Faculdade de Ciências Farmacêuticas da Universidade de São Paulo. Departamento de Alimentos e Nutrição Experimental.

Orientador: Colli, Célia.

1. Nutrição experimental : Ciência dos alimentos 2. Nutrição clínica : Ciência dos alimentos I. T. II. Colli, Célia, orientador.

641.1 CDD 
Cristiane Hermes Sales

\title{
Efeito da deficiência dietética de magnésio na resistência insulínica e no status inflamatório e oxidativo em ratos alimentados com dieta hiperlipídica
}

\author{
Comissão Julgadora da \\ Tese para obtenção do grau de Doutor
}

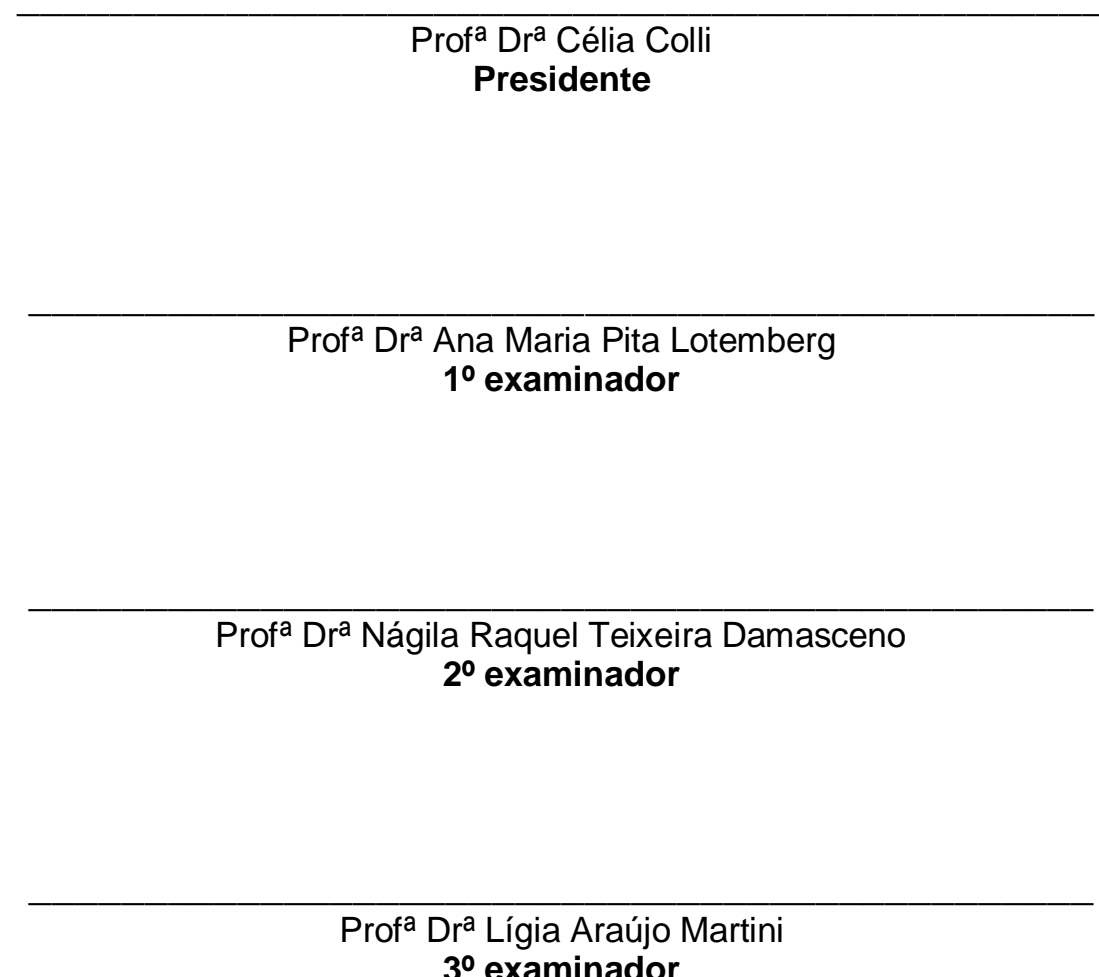

3o examinador

Prof. Titular Fernando Salvador Moreno

4ํ examinador

São Paulo, 27 de junho de 2013 

Ao meu bahuarte:

Eamilson Sales e Célia Hermes, mens exemplos e primeiros mestres, Endmilson Sales, que me ensina a cada dia com sua vivacidade, e Marina Sales, ser encantador... 



\section{AGRADECIMENTOS}

$\mathrm{Na}$ busca de responder os por quês que surgem no nosso caminho, eis que emergem ideias a serem desenvoltas longe do ostracismo, e pessoas acabam entrando na nossa vida, seja por uma "razão", ou por uma "estação", e alguns, decerto, mais que por uma razão, permanecerão para a vida inteira.

“Aqueles que passam por nós não se vão sós, não nos deixam sós. Deixam um pouco de si, e levam um pouco de nós. As tempestades, a bruma e a neve vão incomodá-lo algumas vezes. Pense, então, em todos aqueles que já passaram por isso e diga para si mesmo: o que eles conseguiram eu também posso conseguir. [...] Quando trocamos viris apertos de mão, competimos em corridas, reunimonos para salvar um de nós que está em dificuldade, gritamos pedindo socorro na hora do perigo - só então aprendemos que não estamos sozinhos no mundo."

Antoine de Saint-Exupéry

Agradeço a Deus, pela segurança do Seu amor e a certeza de que está comigo. 
o meu agradecimento especial, ao meu alicerce, MINHA FAMílIA, pela essência que me deram, por me ensinarem a arte do (con)viver. Obrigada por compreenderem a minha ausência física, pela presença constante de vocês em todos os momentos, por me entusiasmarem e impulsionarem a seguir sempre em busca dos meus ideais, buscando aprender com TUDO, para alçar voos em busca das estrelas, mas sem esquecer o que é ter os pés no chão. Sem o auxilio de vocês, e sem as constantes palavras de incentivo, talvez não tivesse chegado aqui... Meu eterno agradecimento!

"Ninguém caminha sem aprender a caminhar, sem aprender a fazer o caminho caminhando, sem aprender a refazer, a retocar o sonho, por causa do qual a gente se pôs a caminhar." 


\begin{abstract}
À professora doutora Célia Colli, minha orientadora, obrigada pelo acolhimento em 2006, pela abertura que me foi dada em continuar no meu caminhar científico sobre as doenças crônicas não transmissiveis, e durante esses anos enveredarmos mais sobre o magnésio. Mais uma semente nossa aqui é lançada! Muito foi o aprendizado durante essa jornada. [...]
\end{abstract}

"Existem momentos na vida da gente, em que as palavras perdem o sentido ou parecem inúteis, e, por mais que a gente pense numa forma de empregá-las elas parecem não servir. Então a gente não diz, apenas sente." 
À professora Lucia de Fátima Campos Pedrosa Schwarzschild, que me inicion cientificamente. Obrigada pelas palavras de incentivo, que em muitos momentos se tornaram impulsos para manter-me na reta. Liberou as asas do 'seu anjo', mas cuidou, ao seu modo, de manter vigilia.

À hoje professora Anna Cecilia Queiroz de Medeiros, que desde os tempos do ginásio participa da construção desta minha jornada científica $e$, principalmente, de vida. Eis uma amostra de que distância geográfica não é nada. Meu sincero agradecimento minha amiga.

"Um amigo é alguém que sabe a canção do seu coração, e pode cantá-la quando você tiver esquecido a letra."

Autor desconhecido 
Aos alunos e técnicos que trilharam no Laboratório de Nutrição (FBA/FCFUSP) durante o desenrolar desta tese, mesmo que por uma estação:

Adriana Rodrigues, Alexandre Lobo, Aline Nogueira, Ana Lina Sales, Beatriz Mastroeni, Camila Torreglosa, Cassiana Ganem, Edna Machado, Eduardo de Carli, Eduardo Gaierski, Fabiana Lima, Fernanda Brunacci, Isabela Saraiva, Ivana Lavanda, Jéssica Silva, Laila Santos, Luciana Setaro, Maria Izabel Giannichi, Natália Nadur, Pryscilla Teixeira, Renata Figueiredo, Renata Kanashiro, Tatiana Garofalo, Vivianne Rocha e William Latorre.

"Quem olha para fora, sonha; quem olha para dentro, desperta."

Carl Jung

Aos colegas de outros laboratórios, que direta ou indiretamente me auxiliaram nesta jornada: Amanda Crisma, Ana Mara Silva, Claudimar de Oliveira, Emídio Matos, Janaína Lombello, Kaluce Gonçalvez, Karina Nakashima, Kátia Callou, Leonardo Torres, Lucas Pantaleão, Marcelo Sousa, Michele Trindade $e$ Tânia Shiga.

Agradeço especialmente as "estrelinhas" especiais providas dos mais sublimes sentimentos, que ao seu modo souberam compartilhar a sua luz. As verdadeiras estrelas encantam pelo seu brilho singelo e próprio, e não necessitam que eu as destaque aqui, pois tem seu espaço muito bem definido na constelação, e não carecem ofuscar para mostrarem o seu valor.

"As pessoas têm estrelas que não são as mesmas. Para uns, que viajam, as estrelas são guias. Para outros, elas não passam de pequenas luzes. Para outros, os sábios, são problemas. Para o meu negociante, eram ouro. Mas todas essas estrelas se calam. Tu, porém, terás estrelas como ninguém... Quando olhares o céu de noite, porque habitarei uma delas, porque numa delas estarei rindo, então será como se todas as estrelas te rissem! E tu terás estrelas que sabem rir! E quando te houveres consolado (a gente sempre se consola), tu te sentirás contente por me teres conhecido. Tu serás sempre meu amigo. Terás vontade de rir comigo. E abrirás às vezes a janela à toa, por gosto... E teus amigos ficarão espantados de ouvir-te rir olhando o céu. Tu explicarás então: 'Sim, as estrelas, elas sempre me fazem rir!' E eles te julgarão maluco. Será uma peça que te prego..." 


\begin{abstract}
À Fátima Arantes Aparecida Sardinha, que se aventurou comigo para territórios longínquos para viver formalidades... Sua companhia fez toda diferença para um marco no meu caminhar. Obrigada por ter-se feito 'presente' em todos os seus significados, dedicando parte do seu precioso tempo comigo, e dando-me a oportunidade de conhecê-la.
\end{abstract}

À Andréa Martos Naccache, por todo apoio imprescindivel! [...] E nas buscas do 'self' somos agraciados por almas perfumadas que encantam com sua singularidade, e nos sustentam nos despertares, ajustando a bússola quando não conseguimos mais entendê-la. Meu muito obrigada querida!

"Fazer o percurso que nos leva do sintoma ao sinthoma, passa por buscar nas sombras que nos movem as luzes que guiarão os nossos caminhos."

Maria Aparecida de Oliveira Ribeiro 
Aos professores que compartilharam um pouquinho dos seus conhecimentos de sala de aula durante o meu estágio no programa de aperfeiçoamento de ensino - PAE: professor titular Fernando Salvador Moreno, professora titular Silvia Maria Franciscato Cozzolino e professor doutor Thomas Prates Ong, junto a professora Célia Colli (supervisora e responsável pela disciplina).

À professora doutora Júlia Maria Pavan Soller, do IME-USP, por sua solicitude desprendida para minimizar nossas dúvidas estatísticas. Obrigada por mais esta contribuição!

À equipe do Laboratório de Sinalização Celular da UNICAMP, em nome do professor doutor Dennys Esper Corrêa Cintra, pela abertura concedida no laboratório de vocês, pela troca de conhecimentos essenciais e pelo auxílio no término das análises de 'western blotting'. Agradeço ainda a Angélica Rossi Sartori Cintra, Erika Anne Roman, Nicole Corrêa Guimarães, Rafaela Benatti e Vanessa Oliveira Lázari, pelo auxillio e troca de conhecimentos.

À professora associada Inar Alves de Castro, a técnica Luciene Lauer e a doutoranda Patrícia Borges, da FCF-USP, por todo auxílio prestado durante as análises de MDA.

À professora titular Mari Cleide Sogayar e sua equipe, do departamento de Bioquímica do Instituto de Química da USP, por compartilharem o conhecimento de vocês e me proporcionarem mergulhar um pouco no mundo das técnicas de biologia molecular. Obrigada pela inigualável atenção dispensada nos momentos que estive com vocês. Conviver com vocês foi um momento impar!

À professora associada Rosa Maria Rodrigues Pereira e a biomédica Liliam Takayama, do Laboratório de Metabolismo Ósseo da FMUSP, pelas análises de densidade óssea de um dos subprojetos desta tese. 
Ao especialista de laboratório Alexandre Mariani Rodrigues, do Laboratório de Tecnologia de Alimentos da FCF-USP, pela assessoria nas análises de resistência óssea de um dos subprojetos desta tese.

À técnica Ivanir Pires, do laboratório de Bioquímica da Nutrição da FCF-USP, pela presteza impar em todos os momentos em que precisamos.

À técnica Tatiana Garofalo do Laboratório de Biotecnologia de Alimentos da FCF-USP, por viabilizar, junto ao professor Flávio Finardi Filho, o uso de uma das capelas do seu laboratório para análises de Soxhlet por praticamente um semestre inteiro...

Ao professor Jorge Mancini Filho e a técnica MSc. Rosângela Pavan Torres, do laboratório de Lípides da FCF-USP, por possibilitar a análise do perfil de ácidos graxos do piloto.

Aos professores Ana Campa, José Donato e Silvia Maria Franciscatto Cozzolino pelas considerações feitas no exame de qualificação.

Aos que sempre nos auxiliam no dia a dia da Faculdade de Ciências Farmacêuticas, seja na parte burocrática ou para manter os nossos ambientes mais agradáveis: Cleonice Estrela, Edilson Feitosa, Elaine Midori, Essy Naira, Joana Santos, Jorge de Lima, Maria de Lourdes Pedrosa, Mirian Lopes, Mônica Perussi e Roberta Uehara.

Aos funcionários do Biotério de Experimentação Animal do Conjunto das Químicas, pelo zelo resguardado nas atividades que desempenham, especialmente à Flávia de Moura Prates Ong, pelos valiosos ensinamentos compartilhados. 
Aos queridos amigos potiguares (legítimos ou de coração), que mesmo longe estão sempre presentes...

Aos pequenos seres Wistar que involuntariamente se doaram em prol do conhecimento científico.

Ao Programa de Pós-Graduação em Ciência de Alimentos, por me proporcionar trilhar um pouco mais no mundo acadêmico.

À Fundação de Amparo a Pesquisa do Estado de São Paulo - FAPESP, pela bolsa de doutorado concedida (Processo: 2009/05624-7) e ao Conselho Nacional de Desenvolvimento Científico e Tecnológico - CNPq, pelo auxílio à pesquisa (Processo: $480487 / 2009-0$ ).

É difícil nominar a todos, mas, enfim, muitos foram os que entraram nesta jornada e deram sua parcela de contribuição nesta etapa em minha vida, seja tecnicamente, emocionalmente, afetivamente... Obrigada!

"A vida me ensinou a dizer adeus às pessoas que amo, sem tirá-las do meu coração." Charles Chaplin

"and now the end is near; and so I face the final curtain..." 

"Todo cientista é eticamente responsável pelo avanço da ciência."

FAPESP

"Por tantas veredas caminhei, entre flores coloridas e perfumadas, colhidas logo cedo, ainda orvalhadas.

E as pedras encontradas no caminho, não foram desprezadas, se tornando lição meditada na derrama da noite em solidão.

Tudo valeu pela intensidade vivida, por ter sempre um escudo amoroso, na passagem do tempo, em cada pouso.

Eis-me aqui, alma em aprendizado, cujo perfume ainda se revela inconstante, em processo de metamorfose ambulante.

Mas haverá um tempo, não sei quando, em que desvelada a sutil fragrância, a alma vagará liberta de qualquer circunstância."

Guida Linhares 



\section{RESUMO}

SALES, C.H. Efeito da deficiência dietética de magnésio na resistência insulínica e no status inflamatório e oxidativo em ratos alimentados com dieta hiperlipídica. 2013. $220 \mathrm{f}$. Tese (Doutorado) - Faculdade de Ciências Farmacêuticas, Universidade de São Paulo, São Paulo, 2013.

O objetivo deste trabalho foi avaliar, em ratos, os efeitos do consumo, em curto prazo, de dieta hiperlipídica e deficiente em magnésio $(\mathrm{Mg})$ na adiposidade, no status de $\mathrm{Mg}$, na sensibilidade à insulina, e no status inflamatório e oxidativo. Foi inicialmente realizado um ensaio piloto $(\mathrm{n}=$ 12), de 24 dias, que permitiu avaliar o padrão alimentar dos animais. A dieta hiperlipídica testada teve sua composição em micronutrientes aumentada proporcionalmente à redução esperada de consumo. A partir desses resultados, delineou-se o ensaio principal, de 32 dias, com os animais alimentados com rações controle (ad libitum [CT; $n=8$ ] e pair-feeding [PF; $n=$ 16]), e hiperlipídica (adequada [HF; $n=12]$ e deficiente em $\mathrm{Mg}$ [HFMg; $n=12]$ ). Foram avaliados a adiposidade, o perfil lipídico, o status de Mg, a resistência insulínica (glicemia e insulinemia de jejum, teste de tolerância à insulina - TTI, fosforilação do receptor de insulina [IR- $\beta$ ], do substrato 1 do IR [IRS-1] e da proteína quinase B [Akt]), e marcadores de inflamação e de estresse oxidativo. O consumo de dieta $\mathrm{HFMg}^{-}$e $\mathrm{HF}$ resultou em maior ganho de peso e adiposidade em relação ao PF. Da mesma forma os grupos $\mathrm{HF}$ e $\mathrm{HFMg}^{-}$apresentaram concentrações séricas de colesterol total, VLDL-c e de triacilgliceróis mais elevadas em relação ao grupo PF. Como esperado, os animais $\mathrm{HFMg}^{-}$apresentaram alterações no status de $\mathrm{Mg}$, evidenciadas pela redução de suas concentrações no osso e na urina. Apesar de não terem sido observadas diferenças na glicemia e na insulinemia entre os grupos, a menor fosforilação das proteínas da via de sinalização de insulina comprovam que a deficiência de Mg agrava os efeitos da dieta hiperlipídica nesta via. Não foram observadas diferenças nos parâmetros de inflamação e de estresse oxidativo. No entanto, observou-se associação inversa do malondialdeído e do inibidor do ativador de plasminogênio-1 com o status de Mg. Os resultados do presente estudo reforçam a importância da análise de micronutrientes em dietas experimentais, a fim de se obter dados reprodutíveis. A utilização do grupo PF permitiu verificar que o consumo de dietas hiperlipídicas predispõem a maior adiposidade, resistência insulínica e dislipidemia, e que a deficiência de Mg pode piorar a resistência insulínica.

PALAVRAS-CHAVE: magnésio, dieta hiperlipídica, estresse oxidativo, inflamação, perfil lipídico, ratos, resistência insulínica 


\section{ABSTRACT}

SALES, C.H. Effect of dietary magnesium deficiency on insulin resistance and on inflammatory and oxidative status in rats fed with high-fat diet. 2013. $220 \mathrm{f}$. Tese (Doutorado) - Faculdade de Ciências Farmacêuticas, Universidade de São Paulo, São Paulo, 2013.

The aim of this study was to assess, in rats, the effects of high-fat and magnesium $(\mathrm{Mg})$ deficient diet, in short-time, on adiposity, magnesium status, insulin sensitivity, and oxidative and inflammatory status. Firstly, it was realized a pilot study $(n=12), 24$ days, which allowed to assess the dietary patterns of the animals. The high-fat diet tested had its micronutrient composition increased proportionally to the expected reduction in consumption. Based in these results, it was outlined the principal study, 32 days, with the animals fed with control diet (ad libitum [CT; $\mathrm{n}=8$ ] and pair-feeding [PF; $\mathrm{n}=16]$ ), and high-fat diet (adequate [HF; $\mathrm{n}=$ 12] and magnesium deficient $\left.\left[\mathrm{HFMg}^{-} ; \mathrm{n}=12\right]\right)$. It was assessed the adiposity, serum lipid profile, Mg status, insulin resistance (fasting glucose and insulin, insulin tolerance test - ITT, phosphorylation of insulin receptor [IR- $\beta$ ], insulin receptor substrate 1 [IRS-1] and protein kinase $\mathrm{B}[\mathrm{Akt}])$, and markers of inflammation and oxidative stress. The consumption of $\mathrm{HFMg}^{-}$and $\mathrm{HF}$ results in greater weight gain and adiposity compared to PF. Likewise, the high-fat groups showed serum total cholesterol, VLDL-C, and triglycerides higher than PF group. As expected, the animals showed changes in magnesium status, as evidenced by lower bone and urine levels. Although no differences were observed in blood glucose and serum insulin levels among the groups, the lowest phosphorylation of the insulin signaling pathway show that $\mathrm{Mg}$ deficiency intensifies the effects of high-fat diet in this pathway. No differences were observed in the inflammatory and oxidative stress parameters. However, it was observed an inverse association of malondialdehyde and plasminogen activator inhibitor-1 with Mg status. The results of this study support the importance of micronutrients analyzes in the experimental diets, in order to obtain reproducible data. With the PF group it was showed that high-fat diets predisposes to greater adiposity, dyslipidemia, insulin resistance, and that $\mathrm{Mg}$ deficiency can worse the effects on insulin resistance.

KEY WORDS: high-fat diet, inflammation, insulin resistance, lipid profile, magnesium, oxidative stress, rats 


\section{LISTA DE FIGURAS}

\section{Parte I}

Figura I- 1 - Mecanismos celulares que predispõem a resistência insulínica na obesidade 38

Figura I- 2 - Participação do magnésio na ação da insulina: célula $\beta$ pancreática e tecidos periféricos.

Figura I- 3 - Inter-relações da obesidade com a deficiência de magnésio

\section{Parte II}

Figura II-1 - Curva de crescimento de ratos Wistar alimentados, durante 32 dias, com dieta controle, hiperlipídica ou hiperlipídica deficiente em magnésio.

Figura II-2 - Status de magnésio de ratos Wistar alimentados, durante 32 dias, com dieta controle, hiperlipídica ou hiperlipídica deficiente em magnésio 78

Figura II-3 - Curva glicêmica durante teste de tolerância à insulina $(A)$, constante do teste de tolerância à insulina $(B)$, glicose sanguínea $(C)$ e insulina sérica $(D)$, HOMA-IR (E) e HOMA- $\beta$ (F) de ratos Wistar alimentados, durante 32 dias, com dieta controle, hiperlipídica ou hiperlipídica deficiente em magnésio .

Figura II-4 - Fosforilação da subunidade $\beta$ do receptor de insulina - IR $\beta(A)$, do substrato 1 do receptor de insulina - IRS-1 [Tyr895] (B) e da proteína quinase B - Akt [Ser473] (C) em extratos totais de fígado de ratos Wistar alimentados, durante 32 dias, com dieta controle, hiperlipídica ou hiperlipídica deficiente em magnésio.

\section{Parte IV}

Figura C-1 - Peso corpóreo (a), evolução do ganho de peso (b), ganho de peso (c), índice de adiposidade (d) e composição corpórea (e) de ratos Wistar alimentados, durante 24 dias, com dieta normolipídica ou hiperlipídica. Resultados expressos em média e desvio padrão ( $n=6$ animais/grupo) .... 153

Figura C-2 - Status de magnésio de ratos Wistar alimentados, durante 24 dias, com dieta normolipídica ou hiperlipídica. ( $\mathrm{n}=6$ animais/grupo)

Figura C-3 - Curva glicêmica durante teste de tolerância à insulina (a), constante do teste de tolerância à insulina (b), e glicose sanguínea (c) e insulina sérica (d) de ratos Wistar alimentados, durante 24 dias, com dieta normolipídica ou hiperlipídica. ( $\mathrm{n}=6$ animais/grupo)

Figura D-1 - Delineamento experimental: ENSAIO PILOTO ........................................ 166

Figura D-2 - Delineamento experimental: ENSAIO PRINCIPAL .................................. 167

Figura D-3 - Fluxograma no dia da eutanásia ............................................................. 169 
Figura D-4 - Reação que ocorre entre o ácido 2-tiobarbitúrico e o MDA, durante o aquecimento em meio contendo ácido ortofosfórico

Figura F-1 - Magnésio plasmático/sérico e eritrocitário de ratos Wistar $(\mathrm{n}=9)$. Avaliação de uso de anticoagulantes. Médias \pm DP $(p>0,05)$.

Figura G-1 - Cromatograma representativo do branco utilizado no método: todos os reagentes sem amostra e sem padrão interno

Figura G-2 - Cromatogramas representativos das análises do branco com padrão $C_{13: 0}$ (A) e das amostras de fígado de ratos Wistar (B)

Figura G-3 - Cromatograma representativo da análises do padrão Lipid Standards: fatty acid methyl ester mixtures (189-19) - Supelco ${ }^{\circledR}$ 


\section{LISTA DE TABELAS}

\section{Parte I}

Tabela I- 1 - Ingestão média de magnésio: estudos desenvolvidos no Brasil 42

Tabela I- 2 - Resultados de estudos experimentais que avaliam os efeitos da deficiência dietética de magnésio sobre alterações lipídicas

\section{Parte II}

Tabela II-1 - Formulação das dietas experimentais.

Tabela II-2 - Composição química das dietasa ofertadas durante o ensaio principal

Tabela II-3 - Consumo dietético e coeficiente de eficácia alimentar de ratos Wistar alimentados, durante 32 dias, com dieta controle, hiperlipídica ou hiperlipídica deficiente em magnésio

Tabela II-4 - Ganho de peso corpóreo, índice de adiposidade e composição corpórea de ratos Wistar alimentados, durante 32 dias, com dieta controle, hiperlipídica ou hiperlipídica deficiente em magnésio

Tabela II-5 - Perfil lipídico de ratos Wistar alimentados, durante 32 dias, com dieta controle, hiperlipídica ou hiperlipídica deficiente em magnésio

Tabela II-6 - Análise de regressão linear múltipla stepwise considerando os parâmetros de perfil lipídico, índice de adiposidade, status de magnésio e de glicemia como variáveis dependentes.

\section{Parte IV}

Tabela C-1 - Formulação das dietas padrão AIN-93G e experimentais do ensaio piloto147

Tabela C-2 - Composição química das dietas ofertadas durante o período experimental (dietas customizadas da Harlan Teklad Laboratories)

Tabela C-3 - Ingestão dietética de ratos Wistar alimentados, durante 24 dias, com dieta normolipídica ou hiperlipídica ${ }^{a}$

Tabela C-4 - Perfil de ácidos graxos no fígado, parâmetros glicêmicos, marcadores de estresse oxidativo e de inflamação de ratos Wistar alimentados, durante 24 dias, com dieta normolipídica ou hiperlipídica

Tabela D-1 - Formulação das dietas usadas no ensaio piloto

Tabela D-2 - Formulação das dietas usadas no ensaio principal

Tabela D-3 - Condições para quantificação de minerais em dietas em espectrofotômetro de absorção atômica Perkin Elmer AAnalyst 100 (Norwalk, CT, EUA)* 
Tabela G-1 - Ácidos graxos quantificados nos brancos avaliados pelo método de hidrólise ácida durante a validação da extração de ácidos graxos em fígado de ratos Wistar.

Tabela G-2 - Precisões intra- e inter-ensaio do método de extração e metilação de ácidos graxos por hidrólise ácida em amostras de fígado de ratos Wistar ${ }^{\star}$

Tabela G-3 - Erro relativo do método de extração e metilação de ácidos graxos em fígados de ratos, por hidrólise ácida. Avaliação feita com padrão interno: triglicerídeo tritridecanoína $\left(\mathrm{C}_{13: 0}\right)$ Sigma ${ }^{\circledR}$ (concentração esperada do padrão

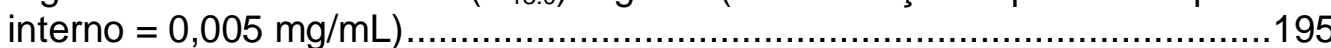

Tabela G-4 - Comparação dos resultados obtidos experimentalmente com o valor do material certificado de referência*

Tabela J-1 - Perfil lipídico e status oxidativo e inflamatório de ratos Wistar alimentados, durante 32 dias, com dieta controle, hiperlipídica ou hiperlipídica deficiente em magnésio

Tabela J-2 - Análise de regressão linear múltipla stepwise considerando os parâmetros de peroxidação lipídica, estresse oxidativo e inflamação como variáveis dependentes 


\section{LISTA DE ABREVIATURAS E SIGLAS}

\begin{tabular}{|c|c|}
\hline ADP & adenosina difosfato \\
\hline AGL & ácidos graxos livres \\
\hline AIN & American Institute of Nutrition (Instituto Americano de Nutrição) \\
\hline AIN-93G & ração recomendada pela AIN para período de crescimento \\
\hline AIN-93G-MX & mix mineral para ração AIN-93G \\
\hline AIN-93G-VX & mix vitamínico para AIN-93G \\
\hline Akt & proteína quinase B \\
\hline AMP & adenosina 3',5'-monofosfato \\
\hline ANOVA & análise de variância \\
\hline AOAC & $\begin{array}{l}\text { Association of Official Analytical Chemists (Associação de Químicos } \\
\text { Analíticos Oficial) }\end{array}$ \\
\hline AP-1 & proteína ativadora 1 \\
\hline aPKC & proteína quinase $\mathrm{C}$ atípica \\
\hline ATP & adenosina trifosfato \\
\hline BRAZOS & the Brazilian osteoporosis study (estudo brasileiro de osteoporose) \\
\hline CAT & catalase \\
\hline CEEA & comitê de ética em experimentação animal \\
\hline CT & grupo controle \\
\hline cox2 & ciclo-oxigenase 2 \\
\hline DCNT & doenças crônicas não transmissíveis \\
\hline EAA & espectrofotometria de absorção atômica \\
\hline EAR & estimated adequate intake (ingestão adequada estimada) \\
\hline ER-estresse & estresse de retículo endotelial \\
\hline ERO & espécies reativas de oxigênio \\
\hline FAS & fatty acid sintase (ácido graxo sintase) \\
\hline FATP-1 & $\begin{array}{l}\text { fatty acid transporter protein } 1 \text { (proteína transportadora de ácidos graxos } \\
\text { 1) }\end{array}$ \\
\hline GLC & glicose \\
\hline GLUT & glucose transporter (transportador de glicose) \\
\hline GSH-Px & glutationa peroxidase \\
\hline GR & glutationa redutase \\
\hline GSH & glutationa \\
\hline GSSG & glutationa oxidada \\
\hline $\mathrm{HbA1c}$ & hemoglobina glicada \\
\hline HDL-C & high density lipoprotein (lipoproteína de alta densidade) \\
\hline $\mathrm{HF}$ & grupo hiperlipídico \\
\hline $\mathrm{HFMg}^{-}$ & grupo hiperlipídico deficiente em magnésio \\
\hline HMG-CoA & 3-hidroxi-3-metil-glutaril-CoA \\
\hline HOMA-IR & homeostasis model assessment insulin resistance \\
\hline HOMA- $\beta$ & homeostasis model assessment $\beta$-cell function \\
\hline HPLC & cromatografia líquida de alta eficiência \\
\hline ICAM & molécula de adesão intracelular \\
\hline IFN- $\gamma$ & interferon gama \\
\hline $\lg G$ & imunoglobulina G \\
\hline IKK & inibidor do fator nuclear kappa B quinase \\
\hline IL & interleucina \\
\hline
\end{tabular}




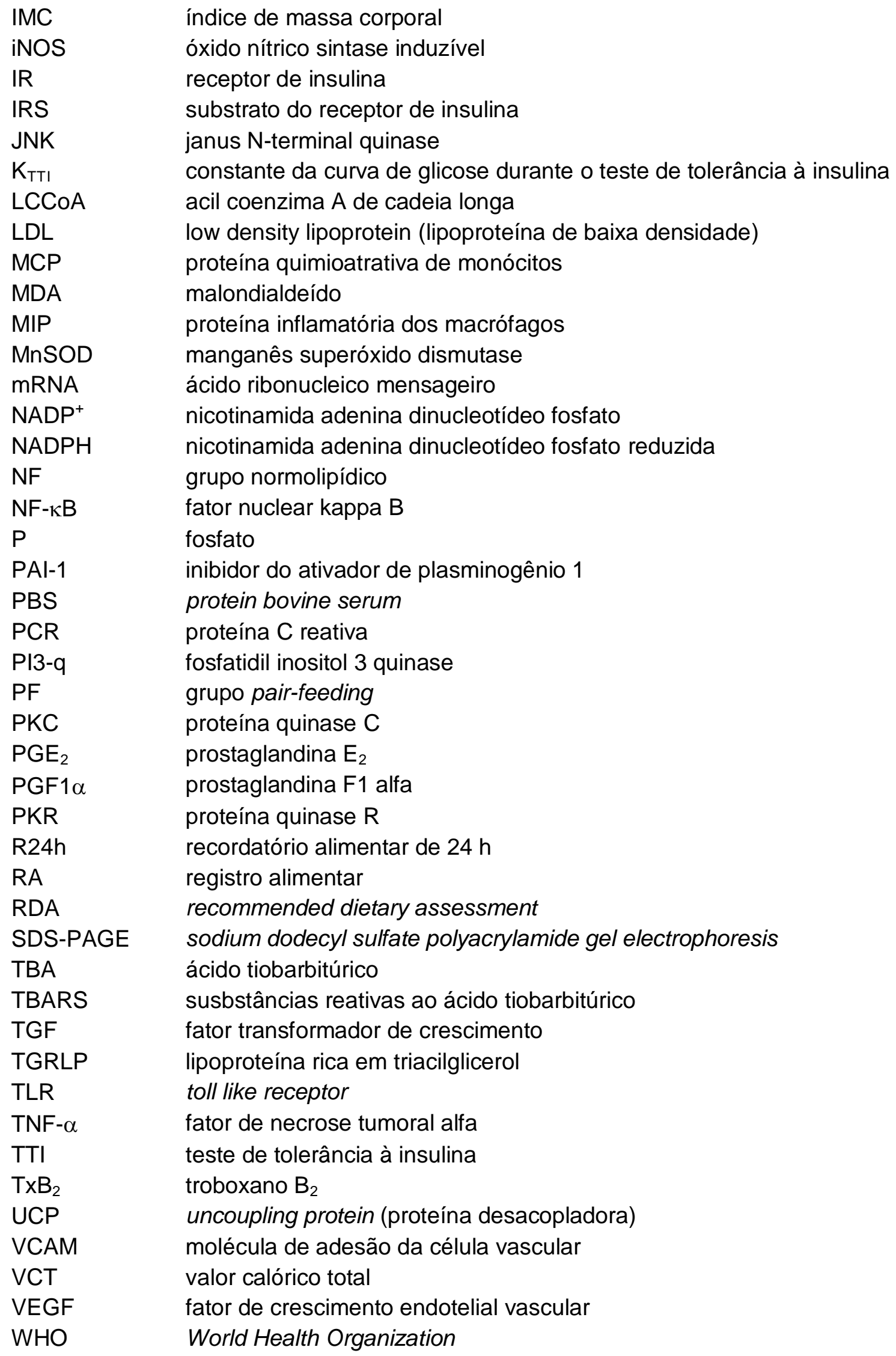




\section{LISTA DE SÍMBOLOS}

\begin{tabular}{|c|c|}
\hline 우 & feminino \\
\hline$\hat{0}$ & masculino \\
\hline$\downarrow$ & diminuição \\
\hline$\uparrow$ & aumento \\
\hline$\%$ & porcento \\
\hline a & anos \\
\hline $\mathrm{BCA}$ & ácido bicincônico \\
\hline $\mathrm{BF}_{3}$ & trifluoreto de boro \\
\hline${ }^{\circ} \mathrm{C}$ & graus Celsius \\
\hline $\mathrm{Ca}$ & cálcio \\
\hline $\mathrm{CaCl}_{2}$ & cloreto de cálcio \\
\hline $\mathrm{cm}$ & centímetro \\
\hline $\mathrm{CuCl}_{2}$ & cloreto de cobre \\
\hline d & dia \\
\hline $\mathrm{dL}$ & decilitro \\
\hline EC & enzyme code (código da enzima) \\
\hline $\mathrm{FeCl}_{3}$ & cloreto de ferro \\
\hline $\mathrm{FNa}$ & fluoreto de sódio \\
\hline$g$ & gramas \\
\hline h & hora \\
\hline $\mathrm{H}_{2} \mathrm{O}$ & água \\
\hline $\mathrm{H}_{2} \mathrm{O}_{2}$ & peróxido de hidrogênio \\
\hline $\mathrm{HCL}$ & ácido clorídrico \\
\hline $\mathrm{HNO}_{3}$ & ácido nítrico \\
\hline K & potássio \\
\hline kcal & quilocalorias \\
\hline $\mathrm{kg}$ & quilograma \\
\hline L & litro \\
\hline $\mathrm{La}_{2} \mathrm{O}_{3}$ & óxido de lantânio \\
\hline $\mathrm{Mg}$ & magnésio \\
\hline $\mathrm{Mg}^{2+}$ & magnésio \\
\hline $\mathrm{mg}$ & miligramas \\
\hline $\mathrm{MgCl}_{2}$ & cloreto de magnésio \\
\hline $\min$ & minuto \\
\hline $\mathrm{mL}$ & mililitros \\
\hline mmol & milimol \\
\hline $\mathrm{n}$ & número \\
\hline$\mu \mathrm{g}$ & micrograma \\
\hline$\mu \mathrm{mol}$ & micromol \\
\hline$\mu \mathrm{U}$ & microunidades \\
\hline $\mathrm{N}$ & nitrogênio \\
\hline $\mathrm{NaCl}$ & cloreto de sódio \\
\hline $\mathrm{Na}_{4} \mathrm{P}_{2} \mathrm{O}_{7}$ & pirofosfato de sódio \\
\hline $\mathrm{Na}_{3} \mathrm{VO}_{4}$ & ortovanadato de sódio \\
\hline
\end{tabular}


xxviii SALES, C.H.

$\begin{array}{ll}\mathrm{nm} & \text { nanometro } \\ \mathrm{nmol} & \text { nanomol } \\ \mathrm{pg} & \text { picograma } \\ \mathrm{pH} & \text { potencial hidrogeniônico } \\ \mathrm{p} / \mathrm{v} & \text { peso/volume } \\ \mathrm{rpm} & \text { rotações por minuto } \\ \mathrm{s} & \text { segundos } \\ \mathrm{sem} & \text { semanas } \\ \mathrm{U} & \text { unidade } \\ \mathrm{UI} & \text { unidades internacionais } \\ \mathrm{v} / \mathrm{v} & \text { volume/volume } \\ \mathrm{ZnCl} & \text { cloreto de zinco }\end{array}$




\section{SUMÁRIO}

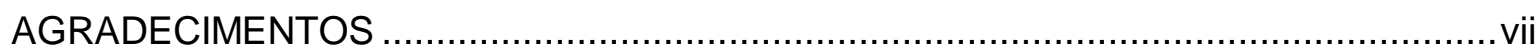

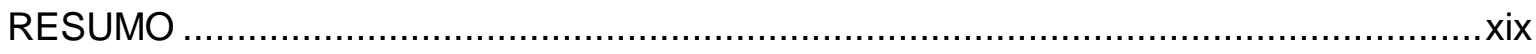

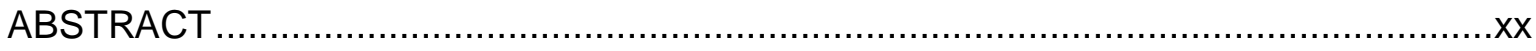

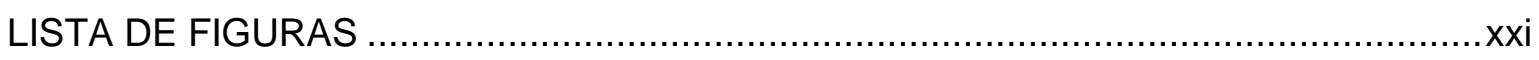

LISTA DE TABELAS ….................................................................................. xxii

LISTA DE ABREVIATURAS E SIGLAS ............................................................xV

LISTA DE SÍMBOLOS........................................................................................ Xxvii

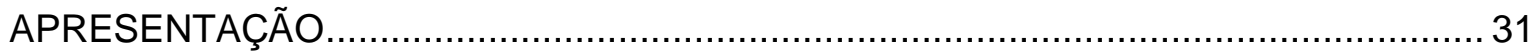

PARTE I

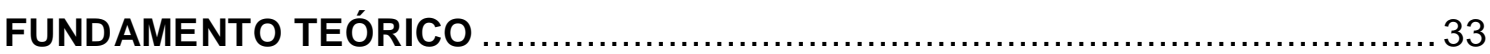

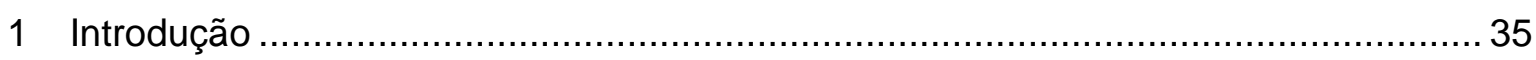

2 Obesidade: caminho para a resistência insulínica ................................................. 36

3 Magnésio e fatores associados à obesidade e a síndrome metabólica...................... 40

4 Evidências do papel do magnésio nos fatores associados à obesidade .................... 44

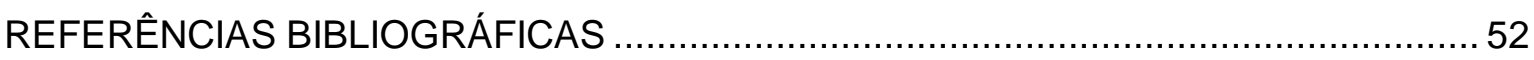

PARTE II

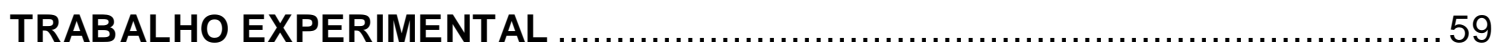

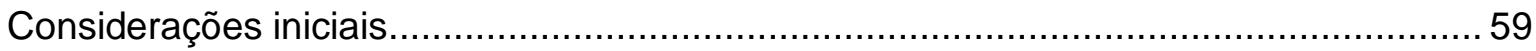

Artigo

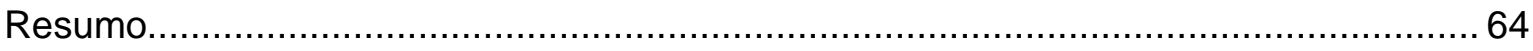

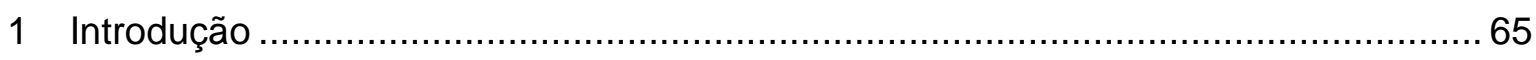

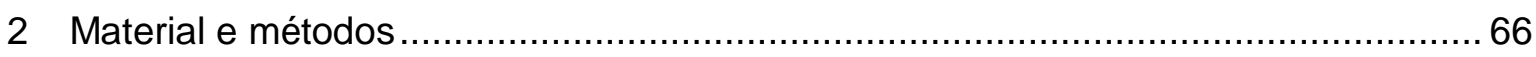

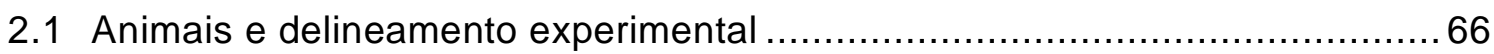

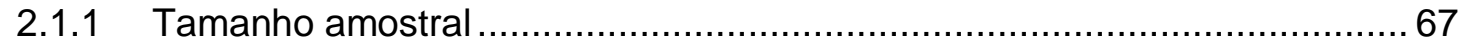

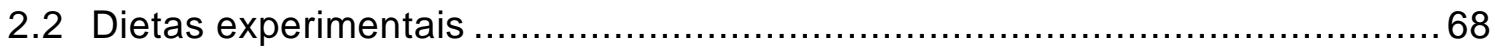

2.3 Composição corporal e índice de adiposidade .................................... 69

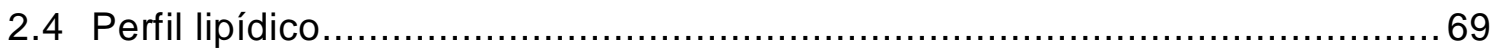

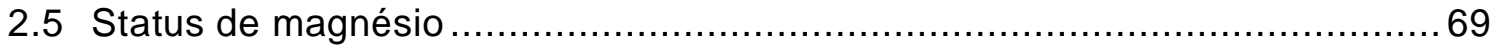

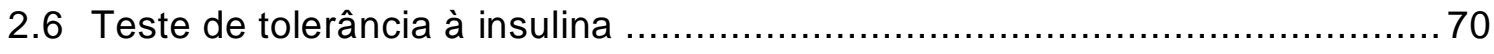

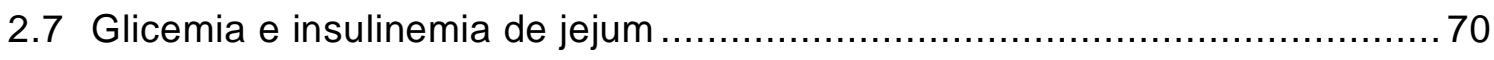


2.8 Fosforilação de proteínas da via de sinalização de insulina ........................72

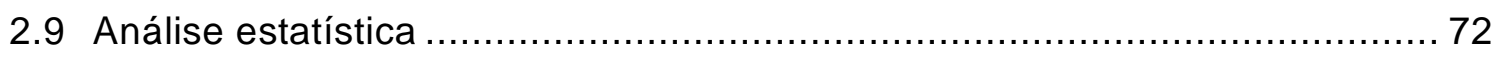

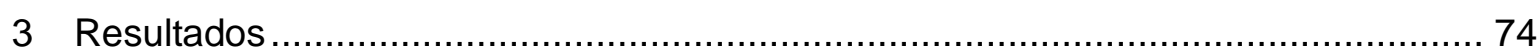

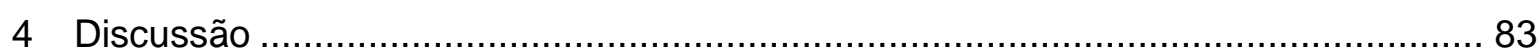

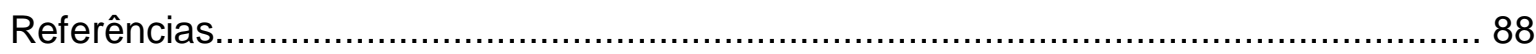

PARTE III

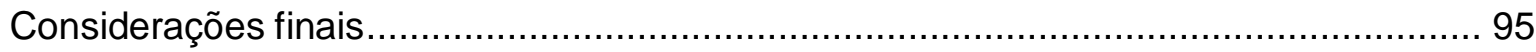

PARTE IV

APÊNDICES

PARTE V

ANEXOS..... 


\section{APRESENTAÇÃO}

Um dos fatores que motivaram o desenvolvimento deste trabalho experimental foram as controvérsias sobre a associação entre o baixo consumo dietético de magnésio (frequente na população) e o risco de desenvolvimento de doenças crônicas não transmissíveis (DCNT). O magnésio está envolvido em alterações metabólicas associadas à obesidade e à síndrome metabólica. Por exemplo, indivíduos com diabetes tipo 2 e hipertensão arterial sistêmica frequentemente apresentam alterações no status do mineral. Além disso, complicações crônicas dessas morbidades também estão associadas à deficiência de magnésio.

Estudo anterior, realizado em nosso laboratório, com pacientes com diabetes tipo 2, mostrou que o baixo consumo de magnésio e alterações no status do mineral associaram-se tanto ao pior controle glicêmico quanto à obesidade. ${ }^{1}$

Diante disso, a hipótese desse trabalho foi que ratos jovens alimentados com dietas hiperlipídicas podem ter a resistência insulínica, a inflamação e o estresse oxidativo agravados quando ingerem dieta deficiente em magnésio, e assim tem aumentado o risco do surgimento de DCNT mais precocemente.

O trabalho aqui apresentado foi dividido em cinco partes: I- revisão da literatura que fundamenta a hipótese; II- trabalho experimental (ensaio principal); III- considerações finais; IV- apêndices, em que são apresentados trabalhos e dados complementares à tese; e V-anexos.

\footnotetext{
${ }^{1}$ SALES, C.H. Avaliação do status de magnésio em pacientes com diabetes mellitus tipo 2. 2008. $180 \mathrm{f}$. Dissertação (Mestrado em Ciência de Alimentos) - Faculdade de Ciências Farmacêuticas, Universidade de São Paulo, São Paulo, 2008. and magnesium intake on the blood glucose control in patients with type 2 diabetes. Clin Nutr, v. 30, p. 359364, 2011.
} 



\section{FUNDAMENTO TEÓRICO²}

"Um novo olhar sobre o papel do magnésio na gênese da obesidade"

"A tarefa não é tanto ver aquilo que ninguém viu, mas pensar o que ninguém ainda pensou sobre aquilo que todo mundo vê."

Arthur Schopenhauer

\footnotetext{
${ }^{2}$ Nos Apêndices A e B estão disponíveis dois capítulos sobre magnésio, elaborados em paralelo a esta tese, e que complementam o conteúdo aqui abordado.
} 



\section{Introdução}

O sobrepeso e a obesidade são o quinto maior fator de risco para morte na população mundial, tendo em vista que, tanto em adultos quanto em crianças, a presença do acúmulo excessivo de tecido adiposo, característico da obesidade, aumenta o risco de alterações metabólicas como resistência periférica à insulina, dislipidemias e aumento dos níveis pressóricos. Essas alterações podem ter como desfechos outras doenças crônicas não transmissíveis (DCNT) como o diabetes tipo 2, hipertensão, doenças cardiovasculares e alguns cânceres (mama, endométrio e cólon), doenças estas igualmente tidas como problemas de saúde pública (WORLD HEALTH ORGANIZATION - WHO, 2011).

Fato que chama atenção é o crescente número de casos de obesidade infantil nos países em desenvolvimento (GUPTA, 2012; 2013) e, no mundo, de diabetes tipo 2 infantil (KADIKI; REDDY; MARZOUK, 1996; GABBAY; CESARINI; DIB, 2003; KIESS et al., 2003; LIBMAN; ARSLANIAN, 2003; GUPTA, 2012).

A obesidade resulta principalmente do desequilíbrio entre o consumo e o gasto de energia, consequência da ingestão de dietas com alta densidade energética e sedentarismo, interagindo com fatores ambientais, biológicos e genéticos. Nesse panorama nutricional, o excesso de ingestão de lipídios e de açúcares, frequentemente vem atrelado ao baixo consumo de micronutrientes, devido às escolhas alimentares, e pode levar indivíduos obesos e com sobrepeso a déficits nutricionais (KAIDAR-PERSON et al, 2008).

A baixa ingestão de magnésio vem sendo positivamente associada ao maior risco de desenvolvimento de doenças crônicas não transmissíveis (HE et al., 2006; MORRELL et al., 2012; COLLI; SALES; ROCHA, 2013), e, alterações na sua distribuição no organismo, associadas ao maior risco de complicações de algumas morbidades (GUERRERO-ROMERO; RODRÍGUEZ-MORÁN, 2002a; 2002b; GUERRERO-ROMERO; RODRÍGUEZ-MORÁN, 2006; GUERRERO-ROMERO; BERMUDEZ-PEÑA; 
36 SALES, С.H.

RODRÍGUEZ-MORÁN, 2011), especialmente o diabetes tipo 2 (SALES et al., 2011; LECUBE et al., 2012).

Diante dessas considerações, buscou-se, através dessa revisão, compreender melhor os mecanismos que estão envolvidos com a predisposição a doenças crônicas não transmissíveis e sua relação com o magnésio. 



\section{REFERÊNCIAS BIBLIOGRÁFICAS}

ALTURA, B.M.; KOSTELLOW, A.B.; ZHANG, A.; LI, W.; MORRILL, G.A.; GUPTA, R.K.; ALTURA, B.T. Expression of the nuclear factor- $\kappa B$ and proto-oncogenes cfos and $c$-jun are induced by low extracellular $\mathrm{Mg}^{2+}$ in aortic and cerebral vascular smooth muscle cells: possible links to hypertension, atherogenesis, and stroke. Am J Hypertens, v. 16, p. 701-707, 2003.

ARAUJO, M.C.; BEZERRA, I.N.; BARBOSA, F.S.; JUNGER, W.L.; YOKOO, E.M.; PEREIRA, R.A.; SICHIERI, R. Macronutrient consumption and inadequate micronutrient intake in adults. Rev Saúde Pública, v. 47, p. 177S-89S, 2013 (Suppl 1).

BANAS, S.M.; ROUCH, C.; KASSIS, N.; MARKAKI, E.M.; GEROZISSIS, K. A dietary fat excess alters metabolic and neuroendocrine responses before the onset of metabolic diseases. Cell Mol Neurobiol, v. 29, p. 157-168, 2009.

BARNES, P.J.; KARIN, M. Nuclear factor- $\kappa B$ - a pivotal transcription factor in chronic inflammatory diseases. N Engl J Med, v. 336, n. 15, p. 1066-1071, 1997.

BELIN, R.J.; HE, K. Magnesium physiology and pathogenic mechanisms that contribute to the development of the metabolic syndrome. Magn Res, v. 20, p. 107-129, 2007.

BLACHE, D.; DEVAUX, S.; JOUBERT, O.; LOREAU, N.; M., S.; DURAND, P.; et al. Long-term moderate magnesium-deficient diet shows relationships between blood pressure, inflammation and oxidant stress defense in aging rats. Free Rad Biol Med, v. 41, n. 2, p. 277-284, 2006.

BOPARAI, R.K.; KIRAN, R.; BANSAL, D.D. Insinuation of exacerbated oxidative stress in sucrose-fed rats with a low dietary intake of magnesium: evidence of oxidative damage to proteins. Free Radic Res, v. 41, n. 9, p. 981-9, 2007.

BRIAUD, I.; KELPE, C.L.; JOHNSON, L.M.; TRAN, P.O.; POITOUT, V. Differential effects of hyperlipidemia on insulin secretion in islets of Langerhans from hyperglycemic versus normoglycemic rats. Diabetes, v. 51, p. 662- 668, 2002.

BUETTNER, R.; PARHOFER, K.G.; WOENCKHAUS, M.; WREDE, C.E.; KUNZ-

SCHUGHART, L.A.; SCHÖLMERICH, J.; BOLLHEIMER, J.C. Defining hig-fat-diet rat models: metabolic and molecular effects of different fat types. J Mol Endocrionol, v. 36, p. 485-501, 2006.

BUSSEROLLES, J.; GUEUX, E.; ROCK, E.; MAZUR, A.; RAYSSIGUIER, Y. High fructose feeding of magnesium deficient rats is associated with increased plasma triglyceride concentration and increased oxidative stress. Magnes Res, v. 16, n. 1, p. 7-12, 2003.

CAMPANHOLO, J.M. Efeito da suplementação com magnésio sobre o desempenho em jogadores de futebol. 2008. Dissertação (Mestrado em Ciência de Alimentos) - Faculdade de Ciências Farmacêuticas, Universidade de São Paulo, São Paulo, 2008.

ÇELIK, N.; ANDIRAN, N.; YILMAZ, A.E. The relationship between serum magnesium levels with childhood obesity and insulin resistance: a review of the literature. J Pediatr Endocr Met, v. 24, n. $9-10$, p. 675-678, 2011.

CHAUDHARY, D.P.; BOPARAI, R.K.; SHARMA, R.; BANSAL, D.D. Studies on the development of an insulin resistant rat model by chronic feeding of low magnesium high sucrose diet. Magnes Res, v. 17, n. 4, p. 293-300, 2004.

CHAUDHARY, D.D., BOPARAI, R.K., BANSAL, D.D. Effect of a low magnesium diet on in vitro glucose uptake in sucrose fed rats. Magnes Res, v. 20, n. 3, p. 187-195, 2007.

CINTRA, D.E.; ROPELLE, E.R.; PAULI, J.R. Obesidade e diabetes: fisiopatologia e sinalização celular. São Paulo: Sarvier, 2011. 405p. 
CONG, P.; ZHONG, J.; ZHANG, J.; SUN, J.; LI, L. Effects of magnesium intake on expression of insulin receptor in type 2 diabetes rats. Wei Sheng Yan Jiu, v. 41, n. 2, p. 264-7, 2012.

COLLI, C.; SALES, C.H.; ROCHA, V.S. Assessment of magnesium status. In: BERHARDT, L.V. (Org.). Advances in medicine and biology. Hauppauge: Nova Science Publishers Inc, 2013. v. 40, p. 191-216.

CORICA, F.; CORSONELLO, A.; IENTILE, R.; CUCINOTTA, D.; BENEDETTO, A.D; PERTICONE, F.; DOMINGUEZ, L.J.; BARBAGALLO, M. Serum ionized magnesium level in relation to metabolic syndrome in type 2 diabetic patients. J Am Coll Nutr, v. 25, n. 3, p. 210215, 2006.

CUNNANE, S.C.; SOMA, M.; MCADOO, K.R.; HORROBIN, D.F. Magnesium deficiency in the rat increases tissue levels of docosahexaenoic acid. J Nutr, v. 115, p. 1498-503, 1985.

EVANGELOPOULOS, A.A.; VALLIANOU, N.G.; PANAGIOTAKOS, D.B.; GEORGIOU, A.; ZACHARIAS, G.A.; ALEVRA, A.N.; ZALOKOSTA, G.J.; VOGIATZAKIS, E.D.; AVGERINOS, P.C. An inverse relationship between cumulating components of the metabolic syndrome and serum magnesium levels. Nutr Res, v. 28, p. 659-663, 2008.

FEROLLA, S.M.; FERRARI, T.C.A.; LIMA, M.L.P.; REIS, T.O.; TAVARES Jr., W.C.; COUTO, O.F.M.; VIDIGAL, P.V.T.; FAUSTO, M.A.; COUTO, C.A. Dietary patterns in Brazilian patients with non alcoholic fatty liver disease: a cross-sectional study. Clinics v. 68, n. 1, p. 11-17, 2013.

FOOD AND NUTRITION BOARD; INSTITUTE OF MEDICINE. Magnesium. In: _. Dietary reference intakes for calcium, phosphorus, magnesium, vitamin $D$, and fluoride. W ashinghton, DC: National Academy Press, 1997. Cap. 6, p. 190-249.

FORD, E.S.; MOKDAD, A.H. Dietary magnesium intake in a national sample of U.S. adults. $\mathbf{J}$ Nutr, v. 133, p. 2879-2882, 2003.

GABBAY, M.; CESARINI, P.R.; DIB, S.A. Diabetes melito do tipo 2 na infância e adolescência: revisão da literatura. J Pediatr 2003;79(3):201-8.

GALANTE, A.P. Desenvolvimento e validação de um método computadorizado para avaliação do consumo alimentar, preenchido por indivíduos adultos utilizando a web. 2007. 114 f. Tese (Doutorado em Nutrição Humana Aplicada) - FSP/FCF/FEA, Universidade de São Paulo, São Paulo, 2007.

GOTTSCHALL, C.B.A.; ÁLVARES-DA-SILVA, M.R.; CAMARGO, A.C.R.; BURTETT, R.M.; da SILVEIRA, T.R. Avaliação nutricional de pacientes com cirrose pelo vírus da hepatite C: a aplicação da calorimetria indireta. Arq Gastroenterol, v. 41, n. 4, p. 22, 2004.

GUERRERO-ROMERO, F.; RODRÍGUEZ-MORÁN, M. Relationship between serum magnesium levels and C-reactive protein concentration, in non-diabetic, non-hypertensive obese subjects. Int J Obes, v. 26, p. 469-474, 2002.

GUERRERO-ROMERO, F.; RODRÍGUEZ-MORÁN, M. Low serum magnesium levels and metabolic syndrome. Acta Diabetol, v. 39, p. 209-213, 2002.

GUERRERO-ROMERO, F.; RODRÍGUEZ-MORÁN, M. Hypomagnesemia, oxidative stress, inflammation, and metabolic síndrome. Diabetes Metab Res Rev, v. 22, n. 6, p. 471-476, 2006.

GUERRERO-ROMERO, F.; BERMUDEZ-PEÑA, C.; RODRÍGUEZ-MORÁN, M. Severe hypomagnesemia and low-grade inflammation in metabolic síndrome. Magnes Res, v. 24, n. 2, p. 45-53, 2011. 
GUEUX, E.; MAZUR, A.; CARDOT, P.; RAYSSIGUIER, Y. Magnesium deficiency affects plasma lipoprotein composition in rats. J Nutr, v. 121, p. 1222-7, 1991.

GUPTA, N.; GOEL, K.; SHAH, P.; MISRA, A. Childhood obesity in developing countries: epidemiology, determinants, and prevention. Endocr Rev 33: 48-70, 2012.

GUPTA, N.; GOEL, K.; SHAH, P.; MISRA, A. Childhood obesity and the metabolic syndrome in developing countries. Indian J Pediatr, v. 80, p. S28-37, 2013. (Suppl 1)

HAFFNER, S.M. Abdominal obesity, insulin resistance, and cardiovascular risk in pre-diabetes and type 2 diabetes. Eur Heart J Supp, v. 8, p. B20-B25, 2006.

HANS, C., CHAUDHARY, D., BANSAL, D. Magnesium deficiency increases oxidative stress in rats. India J Exp Biol, v. 40, n. 11, p. 1275-1279, 2002.

HE, K.; LIU, K.; DAVIGLUS, M.L.; MORRIS, S.J.; LORIA, C.M.; HORN, L.V.; JACOBS, D.R.; SAVAGE, P.J. Magnesium intake and incidence of metabolic syndrome among young adults. Circulation, v. 113, p. 1675-1682, 2006.

HIROSUMI, J.; TUNCMAN, G.; CHANG, L.; GÖRGÜN, C.Z.; UYSAL, K.T.; MAEDA, K.; KARIN, M.; HOTAMISLIGIL, G.S. A central role for JNK in obesity and insulin resistance. Nature, v. 420, p. 333-336, 2002.

HOTMAMISLIGIL, G.S.; SHARGILL, N.S.; SPIEGELMAN, B.M. Adipose expression of tumor necrosis factor- $\alpha$ : direct role in obesity-linked insulin resistance. Science, v. 259, p. 87-91, 1993.

HUERTA, M.G.; ROEMMICH, J.N.; KINGTON, M.L.; BOVBJERG, V.E.; WELTMAN, A.L.; HOLMES, V.F.; PATRIE, J.T.; ROGOL, A.D.; NADLER, J.L. Magnesium deficiency is associated with insulin resistance in obese children. Diabetes Care, v. 28, p. 1175-1181, 2005.

HUMMASTI, S.; HOTAMISLIGIL, G.S. Endoplasmic reticulum stress and inflammation in obesity and diabetes. Circ Res, v. 107, p. 579-591, 2010.

ITANI, S.I.; RUDERMAN, N.B.; SCHMIEDER, F.; BODEN, G. Lipid-induced insulin resistance in human muscle is associated with changes in diacilglycerol, protein kinase $\mathrm{C}$, and $\mathrm{I}_{\kappa} \mathrm{B}-\beta$. Diabetes, v. 51, p. 2005-2011, 2002.

KADIKI, O.A.; REDDY, M.R.S.; MARZOUK, A.A. Incidence of insulin-dependent diabetes (IDDM) and non-insulin-dependent diabetes (NIDDM) (0-34 years at onset) in Benghazi, Libya. Diabetes Res Clin Pract v. 32, p. 165- 17, 1996.

KAIDAR-PERSON, O.; PERSON, B.; SZOMSTEIN, S.; ROSENTHAL, R.J. Nutritional deficiencies in morbidly obese patients: a new form of malnutrition? Part B: minerals. Obes Surg, v. 18, p. 1028-1034, 2008.

KALUPAHANA, N.S.; CLAYCOMBE, K.J.; MOUSTAID-MOUSSA, N. (n-3) fatty acids alleviate adipose tissue inflammation and insulin resistance: mechanistic insights. Adv Nutr, v. 2, p. 304-316, 2011.

KASUGA, M. Insulin resistance and pancreatic $\beta$ cell failure. J Clin Invest, v. 116, p. 17561760, 2006.

KIESS, W.; BÖTTNER, A.; RAILE, K.; KAPELLEN, T.; MÜLLER, G.; GALLER, A.; PASCHKE, R.; WABITSCH, M. Type 2 diabetes mellitus in children and adolescents: a review from a Europe perspectives. Horm Res, v. 59, p. 77-84, 2003. (suppl 1) 
KIM, D.J.; XUN, P.; LIU, K.; LORIA, C.; YOKOTA, K.; JACOBS-JR, D.R.; HE, K. Magnesium intake in relation to systemic inflammation, insulin resistance, and the incidence of diabetes.

Diabetes Care, v. 33, p. 2604-2610, 2010.

KIRII, K.; ISO, H.; DATE, C.; FUKUI, M.; TAMAKOSHI, S.; JACC STUDY GROUP. Magnesium intake and risk of self-reported type 2 diabetes among Japanese. J Am Coll Nutr, v. 29, 99-106, 2010.

LA FLEUR, S.E.; VANDERSCHUREN, L.J.M.J.; LUIJENDIJK, M.C.; KLOEZE, B.M.; TIESJEMA, B.; ADAN, R.A.H. A reciprocal interaction between food-motivated behavior and diet-induced obesity. Internat J Obes, v. 31, p. 1286-1294, 2007.

LECUBE, A.; BAENA-FUSTEGUERAS, J.A.; FORT, J.M.; PELEGRÍ, D.; HERNÁNDEZ, C.; SIMÓ, R. Diabetes is the main factor accounting for hypomagnesemia in obese subjects.

PLoS One, v. 7, n. 1, p. e30599, 2012.

LEE, Y.S.; LI, P.; HUH, J.Y.; HWANG, I.J.; LU, M.; KIM, J.I.; HAM, M.; TALUKDAR, S.; CHEN, A.; LU, W.J.; BANDYOPADHYAY, G.K.; SCHWENDENER, R.; OLEFSKY, J.; KIM, J.B. Inflammation is necessary for long-term but not short-term high-fat diet - induced insulin resistance. Diabetes, v. 60, p. 2474-2483, 2011.

LERMA, A.; PLANELLS, E.; ARANDA, P.; LLOPIS, J. Effect of magnesium deficiency on fatty acid composition of the erythrocyte membrane and plasma lipid concentration in rats. $\mathbf{J}$ Nutr Biochem, v. 6, p. 577:81, 1995.

LIBMAN, I.; ARSLANIAN, S. Type 2 diabetes in childhood: the American perspective. Horm Res, v. 59, p. 69-76, 2003.

LIMA, M.L.; CRUZ, T.; RODRIGUES, L.E.; BOMFIM, O.; MELO, J.; CORREIA, R.; PORTO, M.; CEDRO, A.; VICENTE, E. Serum and intracellular magnesium deficiency in patients with metabolic syndrome - evidences for its relation to insulin resistance. Diabetes Res Clin Pract, v. 83, n. 2, p. 257-262, 2009.

LIN, Y; SUN, Z. Current views on type 2 diabetes. J Endocrinol, v. 204, n.1, p. 1-11, 2010.

LOURENÇO, B.H.; VIEIRA L.P.; MACEDO, A.; NAKASATO, M.; MARUCCI, M.F.; BOCCHI, E.A. Nutritional status and adequacy of energy and nutriente intakes among heart failure patients. Arq Bras Cardiol, v. 93, n. 5, p. 501-7, 2009.

MAHFOUZ, M.M.; KUMMEROW, F.A. Effect of magnesium deficiency on $\Delta 6$ desaturase activity and fatty acid composition of rat liver microsomes. Lipids, v. 24, p. 727-32, 1989.

MAK, I.T.; DICKENS, B.F.; KOMAROV, A.M.; WAGNER, T.L.; PHILLIPS, T.M.; WEGLICKI, W.B. Activation of the neutrophils and loss of plasma glutathione during Mg-deficiency modulation by nitric oxide synthase inhibition. Mol Cell Biochem, v. 176, p. 35-39, 1997.

MARI, E.T.L. Análises uni e multivariada na avaliação do estado nutricional de atletas de pólo aquático feminino: enfoque em minerais. $97 \mathrm{f}$. Dissertação (Mestrado em Nutrição Humana Aplicada) - FCF/FEA/FSP, Universidade de São Paulo, São Paulo, 2002.

MAZUR, A.; MAIER, J.A.M.; ROCK, E.; GUEUX, E., NOWACKI, W. RAYSSINGUIER, Y. Magnesium and the inflammatory response: potential physiopathological implications. Arch Biochem Biophys, v. 458, p. 48-56, 2007.

MOLES, K.W.; MCMULLEN, J.K. Insulin resistance and hypomagnesaemia: case report. Brit Med J, v. 285, p. 262, 1982. 
MORRELL, J.S.; LOFGREN, I.E.; BURKE, J.D.; REILLY, R.A. Metabolic syndrome, obesity, and related risk factors among college men and women. J Am Coll Health, v. 60, n. 1, p. 8289, 2012.

NASSIR, F.; MAZUR, A.; GIANNONI, F.; GUEUX, E.; DAVIDSON, N.O.; RAYSSIGUIER, Y. Magnesium deficiency modulates hepatic lipogenesis and apolipoprotein gene expression in the rat. Biochim Biophys Acta, v. 1257, p. 125-32, 1995.

PICKERING, C.; ALSIÖ, J.; HULTING, A.L.; SCHIÖTH, H.B. Withdrawal from free-choice high-fat high-sugar craving only in obesity-prone animals. Psychopharmacology (Berl), v. 204, n. 3, p. 431-443, 2009.

PINHEIRO, M.M., SCHUCH, N.J., GENARO, P.S., CICONELLI, R.M., FERRAZ, M.B., MARTINI, L.A. Nutrient intakes related to osteoporotic fractures in men and women - The Brazilian Osteoporosis Study (BRAZOS). Nutr J, v. 8, n. 6, 2009. doi:10.1186/1475-2891-8-6.

RAYSSIGUIER, Y.; GUEUX, E.; WEISER, D. Effect of magnesium deficiency on lipid metabolism in rats fed a high carbohydrate diet. J Nutr, v. 111, p. 1876-83, 1981.

RAYSSIGUIER, Y.; GUEUX, E.; NOWACKI, W.; ROCK, E.; MAZUR, A. High fructose consumption combined with low dietary magnesium intake may increase the incidence of the metabolic syndrome by inducing inflammation. Magnes Res, v. 19, n. 4, p. 237-243, 2006.

RIBEIRO FILHO, F.F.; MARIOSA, L.S.; FERREIRA, S.R.G; ZANELLA, M.T. Gordura visceral e síndrome metabólica: mais que uma simples associação. Arq Bras Endocrinol Metab, v. 50, n. 2, p. 230-238, 2006.

RIBEIRO, B.G.; SOARES, E.A. Avaliação do estado nutricional de atletas de ginástica olímpica do Rio de Janeiro e São Paulo. Rev Nutr, v. 15, n. 2, p. 181-91, 2002.

RODEN, M. How free fatty acids inhibit glucose utilization in human skeletal muscle. News Physiol Sci, v. 19, p. 92-96, 2003.

ROCHA, V.S; LAVANDA, I. NAKANO, E.Y.; RUANO, R.; ZUGAIB, M.; COLLI, C. Calcium and magnesium status is not impairad in pregnant women. Nutr Res, v. 32, n. 7, p. 542-6, 2012.

ROSANOFF, A.; SEELING, M.S. Comparison of mechanism and functional effects of magnesium and statin pharmaceuticals. J Am Coll Nutr, v. 23, n. 5, p. 501S-505S, 2004.

SAJAN, M.P.; FARESE, R.V. Insulin signaling in hepatocytes of humans with type 2 diabetes: excessive production and activity of protein kinase $\mathrm{C}-1$ (PKC- -1$)$ and dependent processes and reversal by PKC-ı inhibitors. Diabetologia, v. 55, n. 5, p. 1446-57, 2012.

SALES, C.H. Avaliação do status de magnésio em pacientes com diabetes mellitus tipo 2. 2008. 180 f. Dissertação (Mestrado em Ciência de Alimentos) - Faculdade de Ciências Farmacêuticas, Universidade de São Paulo, São Paulo, 2008.

SALES, C.H.; PEDROSA, L.F.C. Magnesium and diabetes mellitus: their relation. Clin Nutr, v. 25, p. 554-62, 2006.

SALES, C.H.; PEDROSA, L.F.C.; LIMA, J.G.; LEMOS, T.M.A.M.; COLLI, C. Influence of magnesium status and magnesium intake on the blood glucose control in patients with type 2 diabetes. Clin Nutr, v. 30, p. 359-364, 2011.

SAM, S.; HAFFNER, S.; DAVIDSON, M.H.; DAVIDSON, M.H.; D'AGOSTINO, R.B.; FEINSTEIN, S.; KONDOS, G.; PEREZ, A.; MAZZONE, T. Relation of abdominal fat depots to systemic markers of inflammation in type 2 diabetes. Diabetes Care, v. 32, p. 932-937, 2009. 
SARIS, N.E.L.; MERVAALA, E.; KARPPANEM, H.; KHAWAJA, J.A.; LEWENSTAM, A. Magnesium. An update on physiological, clinical and analytical aspects. Clin Chim Acta, v.294, p. 1-26, 2000.

SETARO, L. Efeito da suplementação com magnésio no desempenho físico em atletas de voleibol profissional. $95 \mathrm{f}$. Tese (Doutorado em Ciência dos Alimentos) - FCF/FEA/FSP, Universidade de São Paulo, São Paulo, 2009.

SMITH, J.D.; BOREL, A.L.; NAZARE, J.A.; HAFFNER, S.M.; BALKAU, B.; ROSS, R.; MASSIEN, C.; ALMÉRAS, N.; DESPRÉS, J.P. Visceral adipose tissue indicates the severity of cardiometabolic risk in patients with and without type 2 diabetes: results from the INSPIRE ME IAA study. J Clin Endocrinol Metab, v. 97, n. 5, p. 1517-25, 2012.

SOLINAS, G.; KARIN, M. JNK1 and IKK $\beta$ : molecular links between obesity and metabolic dysfunction. FASEB J, v. 24, p. 2596-2611, 2010.

SOMA, M.; CUNNANE S.C.; HORROBIN, D.F.; MANKU, M.S.; HONDA, M.; HATANO, M. Effects of low magnesium diet on the vascular prostaglandin and fatty acid metabolism in rats. Prostaglandins, v. 36, n. 4, p. 431-41, 1988.

SONG, Y.; RIDKER, P.M.; MANSON, J.E.; COOK, N.R.; BURING, J.E.; LIU, S. Syndrome in middle-aged and older U.S. women. Diabetes Care, v. 28, p. 1438-1444, 2005.

SUÁREZ, A.; PULIDO, N.; CASLA, A.; CASANOVA, B.; ARRIETA, F.J.; ROVIRA, A. Impaired tyrosine-kinase activity of muscle insulin receptors from hypomagnesemic rats. Diabetologia, v. 38, p. 1262-70, 1995.

TAKAYA, J.; HIGASHINO, H.; KOBAYASHI, Y. Intracellular magnesium and insulin resistance. Magnes Res, v. 17, n. 2, p. 126-136, 2004.

VASKONEN, T. Dietary minerals and modification of cardiovascular risk factors. J Nutr Biochem, v. 14, n. 9, p. 492-506, 2003.

VENU, L.; HARISHANKAR, N.; KRISHNA, T.P.; RAGHUNATH, M. Does maternal dietary mineral restriction per se predispose the offspring to insulin resistance? Eur $\mathbf{J}$ Endocrinol, $v$. 151, p. 287-294, 2004.

VENU, L.; KISHORE, Y.D.; RAGHUNATH, M. Maternal and perinatal magnesium restriction predisposes rat pups to insulin resistance and glucose intolerance. J Nutr, v. 135, p. 13531358, 2005.

VENU, L.; PADMACATHI, I.J.N.; KISHIRE, Y.D.; BHANU, N.V.; RAO, K.R.; SAINATH, P.B.; GANESHAN, M.; RAGHUNATH, M. Long-term effects of maternal magnesium restriction on adiposity and insulin resistance in rat pups. Obesity, v. 16, p. 1270-1276, 2008.

WITHERS, D.J.; GUTIERREZ, J.S.; TOWERY, H.; BURKS, D.J.; REN, J.M.; PREVIS, S.; ZHANG, Y.; BERNAL, D.; PONS, S.; SHULMAN, G.L.; BONNER-WEIR, S.; WHITE, M.F. Disruption of IRS-2 causes type 2 diabetes in mice. Nature, v. 391, p. 900-904, 1998.

WORLD HEALTH ORGANIZATION. Obesity and overweight. Genebra, 2011. Disponível em: http://www.who.int/mediacentre/factsheets/fs311/en/. Acesso em: 18 jan 2012 

ENSAIO PRINCIPAL

"El deseo de aliviar o prevenir los males á que está sujeto el hombre desde que nace, ha creado el arte por el cual se conocen en la naturaleza las sustancias que simples o mezcladas, puras 0 modificadas pueden servir de remedio." 



\section{Considerações iniciais}

Após realização de ensaio piloto (Apêndice C), desenvolvido no intuito de avaliar os efeitos de uma ração comercial obesogênica (hiperlipídica), neste ensaio introduzimos em nossos experimentos a deficiência de magnésio, cerne desse trabalho, com o objetivo de avaliar, em ratos Wistar em crescimento, os efeitos do consumo da dieta hiperlipídica e deficiente em magnésio sobre o status deste mineral, a resistência insulínica, o perfil lipídico e o status inflamatório e oxidativo.

Com base nos resultados do ensaio piloto, em que o ajuste de nutrientes da dieta resultou em consumo de minerais superior ao esperado, optou-se por trabalhar com grupos controle pair-feeding aos hiperlipídicos para equiparar o consumo de proteína e de micronutrientes, como uma forma de melhor controlar o ensaio. A princípio haviam sido delimitados dois grupos pair-feeding para cada grupo hiperlipídico, porque a deficiência de magnésio poderia levar a maiores restrições de consumo; no entanto, como não foram observadas diferenças estatísticas entre os controles pair-feeding nos parâmetros avaliados, agruparam-se os animais dos dois grupos pair-feeding em um só grupo.

Os dados deste ensaio são apresentados na forma de artigo, segundo as normas da revista Clinical Nutrition. No Apêndice D é apresentada a metodologia usada com mais detalhes, e nos Apêndices H, I e J são apresentados resultados complementares. 

Dieta hiperlipídica e deficiente em magnésio: efeito na adiposidade, no perfil lipídico e na sensibilidade à insulina de ratos em crescimento

Título curto: dieta hiperlipídica e deficiente em magnésio 


\section{Referências}

1. Suárez A, Pulido N, Casla A, Casanova B, Arrieta FJ, Rovira A. Impaired tyrosinekinase activity of muscle insulin receptors from hypomagnesemic rats. Diabetologia 1995; 38: 1262-70.

2. Chaudhary DP, Boparai RK, Sharma R, Bansal DD. Studies on the development of an insulin resistant rat model by chronic feeding of low magnesium high sucrose diet. Magnes Res 2004; 17(4): 293-300.

3. Venu L, Harishankar N, Krishna TP, Raghunath M. Does maternal dietary mineral restriction per se predispose the offspring to insulin resistance? Eur J Endocrinol $2004 ; 151: 287-94$.

4. Sales CH, Pedrosa LFC, Lima JG, Lemos TMAM, Colli C. Influence of magnesium status and magnesium intake on the blood glucose control in patients with type 2 diabetes. Clin Nutr 2011; 30: 359-64.

5. Nielsen FH, Milne DB, Klevay LM, Gallagher S, Johnson L. Dietary magnesium deficiency induces heart rhythm changes, impairs glucose tolerance, and decreases serum cholesterol in post menopausal women. J Am Coll Nutr 2007; 26(2): 121-32.

6. Huerta MG, Roemmich JN, Kington ML, Bovbjerg VE, Weltman AL, Holmes VF, Patrie JT, Rogol AD, Nadler JL. Magnesium deficiency is associated with insulin resistance in obese children. Diabetes Care 2005; 28: 1175-81.

7. Takaya J, Higashino H, Kotera F, Kobayashi Y. Intracellular magnesium of platelets in children with diabetes and obesity. Metabolism 2003; 52(4): 468-71.

8. Takaya J, Yamato F, Kuroyanagi Y, Higashino H, Kaneko K. Intracellular magnesium of obese and type 2 diabetes mellitus children. Diabetes Ther 2010; 1(1): 25-31.

9. Çelik N, Andiran N, Yilmaz AE. The relationship between serum magnesium levels with childhood obesity and insulin resistance: a review of the literature. J Pediatr Endocr Met 2011; 24(9-10): 675-8. 
10. Rosanoff A, Weaver CM, Rude R. Suboptimal magnesium status in the United States: are the health consequences underestimated? Nutr Rev 2012; 70(3):153-64.

11. Colli C, Sales $\mathrm{CH}$, Rocha VS. Assessment of magnesium status. In: Berhardt LV. Ed. Advances in medicine and biology. Hauppauge: Nova Science Publishers Inc, 2013; 40: 191-216.

12. Pham PC, Pham PM, Pham PT, Pham SV, Pham PA, Pham PT. The link between lower serum magnesium and kidney function in patients with diabetes mellitus type 2 deserves a closer look. Clin Nephrol 2009; 71: 375-9.

13. Chaudhary DP, Boparai RK, Bansal DD. Effect of a low magnesium diet on in vitro glucose uptake in sucrose fed rats. Magnes Res 2007; 20 (3): 187-95.

14. Boparai RK, Kiran R, Bansal DD. Insinuation of exacerbated oxidative stress in sucrose-fed rats with a low dietary intake of magnesium: evidence of oxidative damage to proteins. Free Radic Res. 2007; 41(9): 981-9. doi: $10.1080 / 10715760701447892$

15. Rayssiguier Y, Gueux E, Weiser D. Effect of magnesium deficiency on lipid metabolism in rats fed a high carbohydrate diet. J Nutr 1981; 111: 1876-83.

16. Venu L, Kishore YD, Raghunath M. Maternal and perinatal magnesium restriction predisposes rat pups to insulin resistance and glucose intolerance. J Nutr 2005; 135 : 1353-8.

17. Venu L, Padmavathi IJN, Kishore YD, Bhanu NV, Rao KR, Sainath PB, Ganeshan M, Raghunath M. Long-term effects of maternal magnesium restriction on adiposity and insulin resistance in rat pups. Obesity 2008; 16: 1270-6.

18. Buettner R, Schölmerich J, Bollheimer C. High-fat diets: modeling the metabolic disorders of human obesity in rodents. Obesity $2007 ; 15(4)$ : 708-808.

19. Cintra DE, Ropelle ER, Moraes KC, Pauli JR, Morari J, De Souza CT, Grimaldi R, Stahl M, Carvalheira JB, Saad MJ, Velloso LA. Unsaturated fatty acids revert diet- 
induced hypothalamic inflammation in obesity. Plos One 2012; 7(1): e30571. doi:10.1371/journal.pone.0030571

20. Blaedel M, Raun K, Boonen HCM, Sheykhzade M, Sams A. Early onset inflammation in pre-insulin-resistant diet-induced obese rats does not affect the vasoreactivity of isolated small mesenteric arteries. Pharmacology. 2012; 90(3-4): 125-32.

21. de Moura LP, Dalia RA, de Araújo MB, Sponton ACS, Pauli JR, Moura RF, et al. Alterações bioquímicas e hepáticas em ratos submetidos à uma dieta hiperlipídica/hiperenergética. Rev Nutr 2012; 25(6): 685-93.

22. Neter, J.; Kutner, M.; Nachtsheim, C.J.; Li, W. Applied linear statisctical models. $5^{\text {th }}$ edn. New York: McGral-Hill//rwin, 2004.

23. Reeves P, Nielsen F, Fahey Jr G. Purified diets for laboratory rodents: final report of the American Institute of Nutrition ad hoc writing comittee on reformulation of the AIN76A rodent diet. J Nutr 1993; 123(2): 1939-51.

24. Association of Official Analytical Chemists. Official methods of analysis of Association of Official Analytical Chemists. $18^{\text {th }}$ edn. Maryland: Current through Revision 1, 2006.

25. Fiske $\mathrm{CH}$, Subbarow $\mathrm{Y}$. The colorimetric determination of phosphorus. J Biol Chem 1925; 66: 375-400.

26. Donato Jr J, Pedrosa RG, Cruzat VF, Pires ISO, Chem B, Tirapegui J. Effects of leucine supplementation on the body composition and protein status of rats submitted to food restriction. Nutr 2006; 22: 520-7.

27. Matthews D, Hosker J, Rudenski A, Naylor B, Treacher D, Turner R. Homeostasis model assessment: insulin resistance and $\beta$-cell function from fasting plasma glucose and insulin concentrations in man. Diabetologia 1985; 28: 412-9. 
28. Buettner R, Parhofer KG, Woenckhaus M, Wrede CE, Kunz-Schughart LA, Schölmerich J, Bollheirmer LC. Defining high-fat-diet rat models: metabolic and molecular effects of different fat types. J Mol Endocrinol 2006; 36:485-501.

29. Legrand C, Okitolonda W, Pottier AM, Lederer J, Henquin JC. Glucose homeostasis in magnesium-deficient rats. Metabolism 1987; 36(2): 160-4.

30. Malpuech-Brugère C, Nowacki W, Daveau M, Gueux E, Linard C, Rock E, et al. Inflammatory response following acute magnesium deficiency in the rat. Biochim Biophys Acta 2000; 1501(2-3): 91-8.

31. Dourmashkin JT, Chang GQ, Gayles EC, Hill JO, Fried SK, Julien C, Leibowitz SF. Different forms of obesity as a function of diet composition. Int J Obes 2005; 29:136878.

32. Mazur A, Maier JAM, Rock E, Gueux E, Nowacki W, Rayssiguier Y. Magnesium and the inflammatory response: potential physiopathological implications. Arch Biochem Biophys 2007; 458: 48-56.

33. Tadayyon B, Lutwak L. Interrelationship of triglycerides with calcium, magnesium and phosphorus in the rat. J Nutr 1969; 97:246-54.

34. Nielsen FH. Dietary fatty acid composition alters magnesium metabolism, distribution, and marginal deficiency response in rats. Magnes Res 2009; 22(4):280-8.

35. Wells IC. Evidence that the etiology of the syndrome containing type 2 diabetes mellitus results from abnormal magnesium metabolism. Can J Physiol Pharmacol 2008; 86:16-24.

36. Lartigue G, de la Serre CB, Espero E, Lee J, Raybould HE. Leptin resistance in vagal afferent neurons inhibits cholecystokinin signaling and satiation in diet induced obese rats. Plos One 2012; 7(3): e32967. doi:10.1371/journal.pone.0032967

37. Pantaleão LC, Teodoro GFR, Torres-Leal FL, Vianna D, de Paula TD, de Matos-Neto EM, et al. Maternal postnatal high-fat diet, rather than gestational diet, affects 
morphology and mTOR pathway in skeletal muscle of weaning rat. J Nutr Biochem 2013.

38. Zecchin HG, Carvalhera JBC, Saad MJA. Mecanismos moleculares de resistência à insulina na síndrome metabólica. Rev Soc Cardiol Estado de São Paulo 2004; 14(4): 574-89. 
III 



\section{Considerações finais}

O ensaio piloto serviu para definirmos melhor o delineamento do ensaio principal, e, por outro lado, reforçou a importância de se avaliar as dietas experimentais, a fim de se obter resultados reprodutíveis e confiáveis.

No ensaio principal pudemos inferir que a presença da deficiência de magnésio associada à dieta hiperlipídica, a qual é tida como uma dieta obesogênica, pode anteceder eventos comuns à obesidade e a síndrome metabólica, especificamente na via de sinalização de insulina, e assim piorar a resistência insulínica, e aumentar o risco de morbidades.

O fato de não ter havido alteração no status inflamatório e oxidativo, que eventualmente se deu pelo curto período de tempo do ensaio, que simula algo mais agudo, não nos permite afirmar que não estejam havendo alterações em nível molecular que modulem a inflamação e o estresse (supressão ou ativação de proteínas e/ou da expressão gênica), e que possam contribuir para a menor sensibilidade à insulina, identificada em nível molecular nos animais dos grupos hiperlipídicos.

O laboratório atualmente tem o propósito de seguir investigando os efeitos da deficiência de magnésio na gênese de processos envolvidos na obesidade (síndrome metabólica), em diferentes modelos experimentais, e sua associação com outros minerais, como o ferro.

A avaliação in vitro dos efeitos da deficiência e da suplementação de magnésio em adipócitos e em células $\beta$-pancreáticas podem dar maior suporte as hipóteses aqui testadas, podendo ser avaliados mecanismos que auxiliem na compreensão das alterações que ocorrem nestas síndromes - obesidade e síndrome metabólica -, e dar mais ferramentas que possam subsidiar estudos em humanos, bem como a aplicação desse conhecimento na prática clínica e em nível de saúde pública. 
A ação do magnésio vem despertando cada vez mais interesse na comunidade científica, e, por outro lado, não se tem tanto embasamento de como está o consumo deste mineral em alguns países. No Brasil, estudos pontuais apontam que o nosso panorama não difere muito dos demais países, cuja baixa ingestão de magnésio já é considerada um problema, e um possível fator associado ao aumento de doenças crônicas não transmissíveis.

Com nosso primeiro trabalho no âmbito da avaliação do status de magnésio em pacientes com diabetes tipo 2 , já tivemos a oportunidade de apresentar as autoridades públicas e a comunidade científica um problema que pode ser recorrente aqui no Brasil, e que pode estar contribuindo para as morbidades e mortalidades constatadas em nosso país. Esperamos continuar avançando nessa área de conhecimento, para, quem sabe, ver sua aplicação prática, e, assim, o objetivo maior deste trabalho foi cumprido. 
IV 

APÊnDICE A - Capítulo publicado no livro Advances in medicine and biology (v. 40), organizado por Leon V. Berhardt. p. 191-216. 

APÊNDICE B - Capítulo publicado no livro Bioquímica da nutrição, nas diferentes fases da vida, na saúde e na doença, organizado por Cristiane Cominetti e Silvia Maria Franciscato Cozzolino. Cap. 9, p. 213-227. 

APÊNDICE C - Ensaio piloto.

Artigo escrito segundo as normas da revista Biological Trace Element Research

\section{Efeito em curto tempo do consumo de dieta hiperlipídica} comercial no status de magnésio e na sensibilidade insulínica de ratos Wistar em crescimentos: estudo piloto

Título curto: Consumo de dieta hiperlipídica e status de magnésio

\section{Apresentação em conferência}

Parte deste estudo foi apresentada no $11^{\text {th }}$ European Nutrition Conference - FENS (Madri, Espanha, outubro de 2011).

SALES, C.H.; GAIEVSKI, E.H.S.; LOBO, A.R.; SANTOS, L.A.S.; COLLI, C. Effects of high-fat diet on magnesium status and insulin sensitivity in rats. In: 11th European Nutrition Conference FENS, 2011, Madri. Annals of Nutrition \& Metabolism. Basel: Karger Medical and Scientific Publishers, 2011. v. 58. p. 82-83. 


\section{Referências bibliográficas}

1. Kiess W, Böttner A, Raile K, Kapellen T, Müller G, Galler A, Paschke R, Wabitsch M (2003) Type 2 diabetes mellitus in children and adolescents: a review from a Europe perspectives. Horm Res 59:77-84. (suppl 1)

2. Libman I, Arslanian S (2003) Type 2 diabetes in childhood: the American perspective. Horm Res 59:69-76.

3. Kaidar-Person O, Person B, Szomstein S, Rosenthal RJ (2008) Nutritional deficiencies in morbidly obese patients: a new form of malnutrition? Part B: minerals. Obes Surg 18:1028-34.

4. Buettner R, Schölmerich J, Bollheimer C (2007) High-fat diets: modeling the metabolic disorders of human obesity in rodents. Obesity 15(4):708-808.

5. Speakman J, Hambly C, Mitchell S, Król E. The contribution of animal models to the study of obesity. Lab Anim. 2008 Oct;42(4):413-32

6. Suárez A, Pulido N, Casla A, Casanova B, Arrieta FJ, Rovira A (1995) Impaired tyrosine kinase activity of muscle insulin receptors from hypomagnesaemic rats. Diabetologia 38:1262-70.

7. Chaudhary DP, Boparai RK, Bansal DD. Effect of a low magnesium diet on in vitro glucose uptake in sucrose fed rats. Magnes Res 2007; 20 (3): 187-95.

8. Colli C, Sales CH, Rocha VS (2013) Assessment of magnesium status. In: Berhardt LV (ed) Advances in medicine and biology. Nova Science Publishers Inc, Hauppauge, v.40, pp 191-216.

9. Smith GP (2000) The controls of eating: a shift from nutritional homeostasis to behavioral neuroscience. Nutr 16:814-20.

10. Mazur A, Maier JAM, Rock E, Gueux E, Nowacki, W (2007) Rayssinguier, Y. Magnesium and the inflammatory response: potential physiopathological implications. Arch Biochem Biophys 458:48-56. 
11. Tadayyon B, Lutwak L (1969) Interrelationship of triglycerides with calcium, magnesium and phosphorus in the rat. J Nutr 97:246-54.

12. Nielsen FH (2009) Dietary fatty acid composition alters magnesium metabolism, distribution, and marginal deficiency response in rats. Magnes Res 22(4):280-8.

13. Wells IC (2008) Evidence that the etiology of the syndrome containing type 2 diabetes mellitus results from abnormal magnesium metabolism. Can $\mathrm{J}$ Physiol Pharmacol 86:16-24.

14. Reeves P, Nielsen F, Fahey Jr G (1993) Purified diets for laboratory rodents: final report of the American Institute of Nutrition ad hoc writing comittee on reformulation of the AIN-76A rodent diet. J Nutr 123(2):1939-51.

15. Association of Official Analytical Chemists (2006) Official methods of analysis of Association of Official Analytical Chemists. 18. ed. Maryland, Current through Revision 1.

16. Donato Jr J, Pedrosa RG, Cruzat VF, Pires ISO, Chem B, Tirapegui J (2006) Effects of leucine supplementation on the body composition and protein status of rats submitted to food restriction. Nutr 22:520-7.

17. Cintra DE, Ropelle ER, Moraes KC, Pauli JR, Morari J, De Souza CT, Grimaldi R, Stahl M, Carvalheira JB, Saad MJ, Velloso LA (2012) Unsaturated fatty acids revert diet-induced hypothalamic inflammation in obesity. Plos One 7(1):e30571.

18. Lundbaek K (1962) Intravenous glucose tolerance as a tool in definition and diagnosis of diabetes mellitus. Br Med J 3:1507-13.

19. Ward WE, Kim S, Bruce WR (2003) A western-style diet reduces bone mass and biomechanical bone strength to a greater extent in male compared with female rats during development. Brit J Nutr 90:589-95.

20. Xu RY, Wan YP, Tang QY, Wu J, Cai W (2008) The effects of high fat on central appetite genes in Wistar rats: a microarray analysis. Clin Chim Acta 397:96-100. 
21. Banas SM, Rouch C, Kassis N, Markaki EM, Gerozissis K (2009) A dietary fat excess alters metabolic and neuroendocrine responses before the onset of metabolic diseases. Cell Mol Neurobiol 29:157-168.

22. Jacqmain M, Doucet E, Després JP, Bouchard C, Tremblay A (2003) Calcium intake, body composition, and lipoprotein-lipid concentrations in adults. Am J Clin Nutr 77:1448-1452.

23. Parikh SJ, Yanovski JA (2003) Calcium intake and adiposity. Am J Clin Nutr 77:2817.

24. Dos Santos LC, Cintra IP, Fisberg M, Martini LA (2008) Calcium intake and its relationship with adiposity and insulin resistance in post-pubertal adolescents. J Hum Nutr Diet 21:109-16.

25. Loss RJF, Rankinen T, Leon AS, Skinner KS, Wilmore JH, Rao DC, Bouchard C (2004) Calcium intake is associated with adiposity in black and withe men and white women of the HERITAGE family study. J Nutr 134(7):1772-8.

26. Yanovski JA, Parikh SJ, Yanoff LB, Denkinger BI, Calis KA, Reynolds JC, Sebring NG, Mchugh T (2009) Effects of calcium supplementation on bosy weight and adiposity in overweight and obese adults. A randomized trial. Ann Intern Med 150:821-99.

27. Renaud S, Ciavatti M, Thevenon C, Ripoll JP (1983) Protective effects of dietary calcium and magnesium on platelet function and atherosclerosis in rabbits fed saturated fat. Atherosclerosis 47:187-98.

28. Scholz-Ahrens Ke, Schrezenmeir J (2006) Milk minerals and the metabolic syndrome. Int Dairy J 16:1399-407.

29. Zemel MB, Shi H, Greer B, Dirienzo D, Zemel PC (2000) Regularion of adiposity by dietary calcium. FASEB J 14:1132-8.

30. Vaskonen T (2003) Dietary minerals and modification of cardiovascular risk factors. J Nutr Biochem 14(9):492-506.

31. Mccarty MF (2005) Magnesium may mediate the favorable impact of whole grains on insulin sensitivity by acting as a mild calcium antagonist. Med Hypotheses 64:619-27. 
32. Parra P, Bruni G, Palou A, Serra F (2008) Dietary calcium attenuation of body fat gain during high-fat feedind in mice. J Nutr Biochem 19:109-17.

33. Pérez-Gallardo L, Gómez M, Parra P, Sánchez J, Palou A, Serra F (2009) Effect of calcium-enriched high-fat diet on calcium, magnesium and zinc retention in mice. Brit $\mathrm{J}$ Nutr 101:1463-6.

34. Ferrari G, Lambertini P, Manzini D, Marchetti A, Sighinolfi S, Della Casa G (2007) Evaluation of the oxidation state and metal concentration in the adipose tissue of Parma ham. Meat Sci 75:337-42.

35. Dourmashkin JT, Chang GQ, Gayles EC, Hill JO, Fried SK, Julien C, Leibowitz SF (2005) Different forms of obesity as a function of diet composition. Int J Obes 29:136878.

36. Takaya J, Higashino $\mathrm{H}$, Kobayashi $\mathrm{Y}$ (2004) Intracellular magnesium and insulin resistance. Magnes Res 17(2):126-36.

37. Storlien LH, Kriketos AD, Jenkins AB, Baur LA, Pan DA, Tapsell LC, Calvert GD (1997) Does dietary fat influence insulin action? Ann N Y Acad Sci 827:287-301.

38. Wilkes JJ, Bonen A, Bell RC (1998) A modified high-fat diet induces insulin resistance in rat skeletal muscle but not adipocytes. Am J Physiol Endocrinol Metab 275:E679-86.

39. Briaud I, Kelpe CL, Johnson LM, Tran PO, Poitout V (2002) Differential effects of hyperlipidemia on insulin secretion in islets of Langerhans from hyperglycemic versus normoglycemic rats. Diabetes 51:662-8.

40. La Fleur S, Vanderschuren LJMJ, Luijendick MC, Loeze BM, Tiesjema B, Adan RAH (2007) A reciprocal interaction between food-motivated behavior and diet-induced obesity. Intern J Obes 31:1286-94.

41. Buettner R, Parhofer KG, Woenckhaus M, Wrede CE, Kunz-Schughart LA, Schölmerich J, Bollheimer JC (2006) Defining high-fat-diet rat models: metabolic and molecular effects of different fat types. J Mol Endocrionol 36:485-501. 
42. Pickering C, Alsiö J, Hulting AL, Schiöth HB (2009) Withdrawal from free-choice highfat high-sugar craving only in obesity-prone animals. Psychopharmacology (Berl) 204(3):431-43.

43. Roden M (2003) How free fatty acids inhibit glucose utilization in human skeletal muscle. News Physiol Sci 19:92-96.

44. Morrell JS, Lofgren IE, Burke JD, Reilly RA (2012) Metabolic syndrome, obesity, and related risk factors among college men and women. J Am Coll Health 60(1): 82-9. 
APÊNDICE D - Detalhamento da metodologia utilizada na execução da tese

\section{Material e métodos}

O projeto foi aprovado pelo Comitê de Ética em Experimentação Animal da Faculdade de Ciências Farmacêuticas da USP (Protocolo CEEA n²009/221) ${ }^{3}$, e seguiu os princípios adotados pelo Colégio Brasileiro de Experimentação Animal.

A princípio foi realizado um ensaio piloto para avaliar a resposta dos animais a ração hiperlipídica formulada, e em seguida foi realizado o ensaio principal, em que a redução da oferta de magnésio foi associada à dieta hiperlipídica, e se incluiu um grupo pair feeding.

\subsection{Animais e delineamento experimental}

Ratos (Rattus novergicus, var. albinus) machos da linhagem Wistar Hannover,

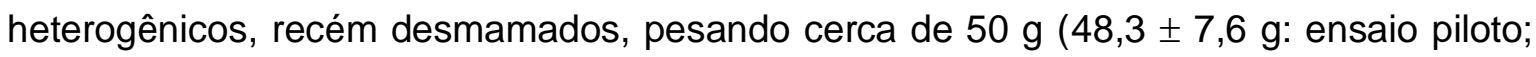
52,0 \pm 3,6 g: ensaio principal), provenientes do Biotério de Produção e Experimentação da Faculdade de Ciências Farmacêuticas e do Instituto de Química da Universidade de São Paulo - USP, foram agrupados, aleatoriamente, após aclimatação de 7 dias, em grupos experimentais: 1) ENSAIO PILOTO - controle $(n=6)$ e hiperlipídico $(n=6)$ (Figura D- 1); 2) ENSAIO PRINCIPAL - controle ad libitum ( $\mathrm{G} 1, \mathrm{n}=8)$, controle com alimentação pareada em gramas aos hiperlipídicos [controle pair feeding] $(\mathrm{G} 2, \mathrm{n}=16)^{4}$, hiperlipídico (G3, $n=12$ ) e hiperlipídico deficiente em magnésio (G4, $n=12$ ) (Figura D-2). Os animais foram alojados individualmente, em gaiolas semimetabólicas de aço inoxidável e mantidos a $22 \pm 2{ }^{\circ} \mathrm{C}$, com 50 a $60 \%$ de umidade, e ciclo claro de 7 as $19 \mathrm{~h}$. Ração e água desmineralizada foram ofertadas ad libitum, sendo realizado o monitoramento diário, e os animais pesados a cada dois dias. Diariamente se observou ainda se os animais apresentavam algum sinal relacionado à deficiência de magnésio, como

\footnotetext{
${ }^{3}$ Aprovação no Anexo A.

${ }^{4}$ A princípio havia sido estabelecido um grupo pareado para cada grupo hiperlipídico, uma vez que a deficiência de magnésio poderia alterar o consumo, mas em virtude de não ter havido diferença entre o consumo de ração e água entre os grupos pareados, e entre os grupos hiperlipídicos, agrupou-se os animais dos grupos pareados em um único grupo pareado.
} 
presença de hiperemia das orelhas e pés, hiperirritabilidade, convulsão, alopecia, lesões na pele e edema. ${ }^{5}$

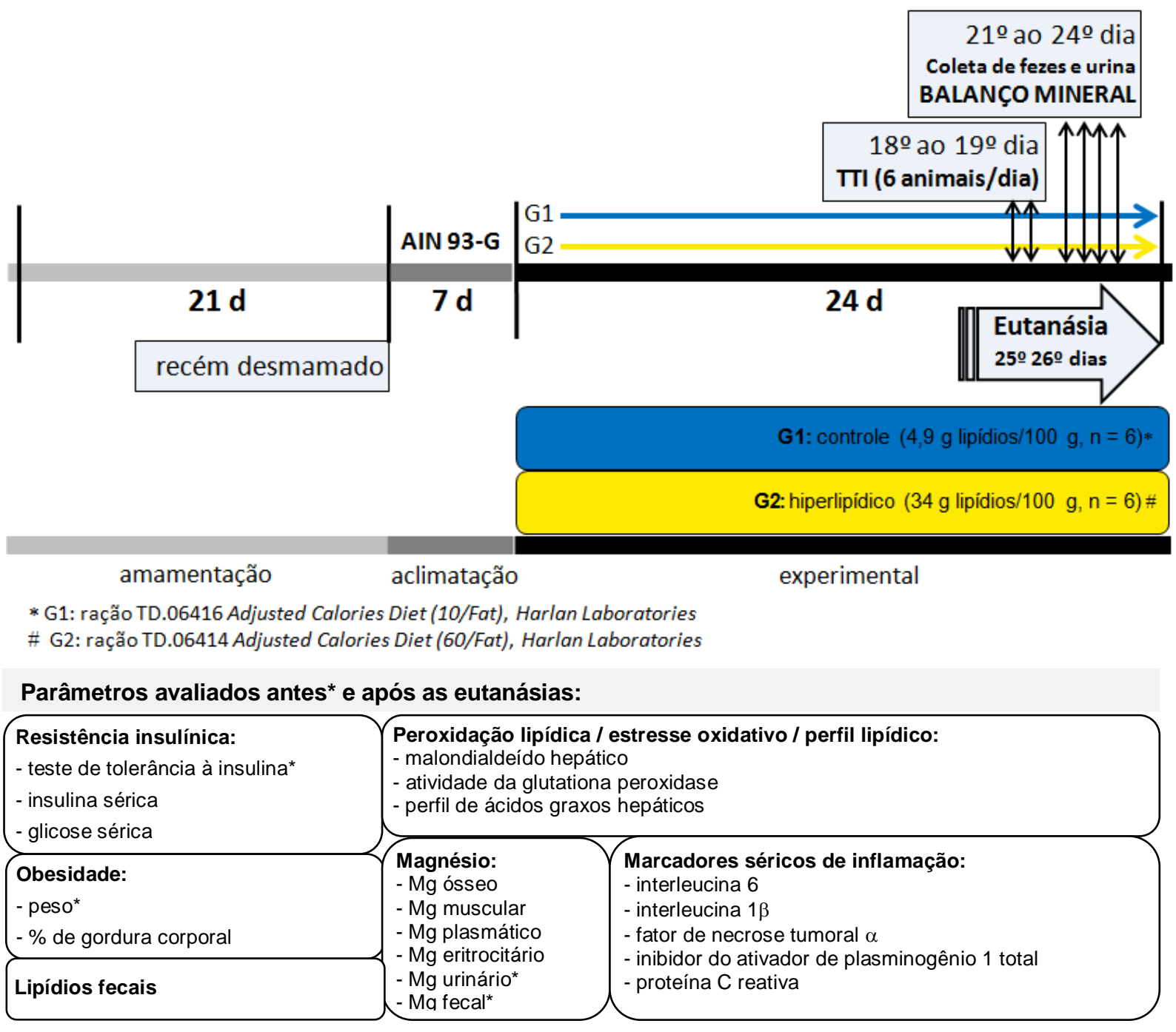

Figura D- 1 - Delineamento experimental: ENSAIO PILOTO

\footnotetext{
${ }^{5}$ Formulário usado consta no Apêndice $\mathrm{E}$
} 


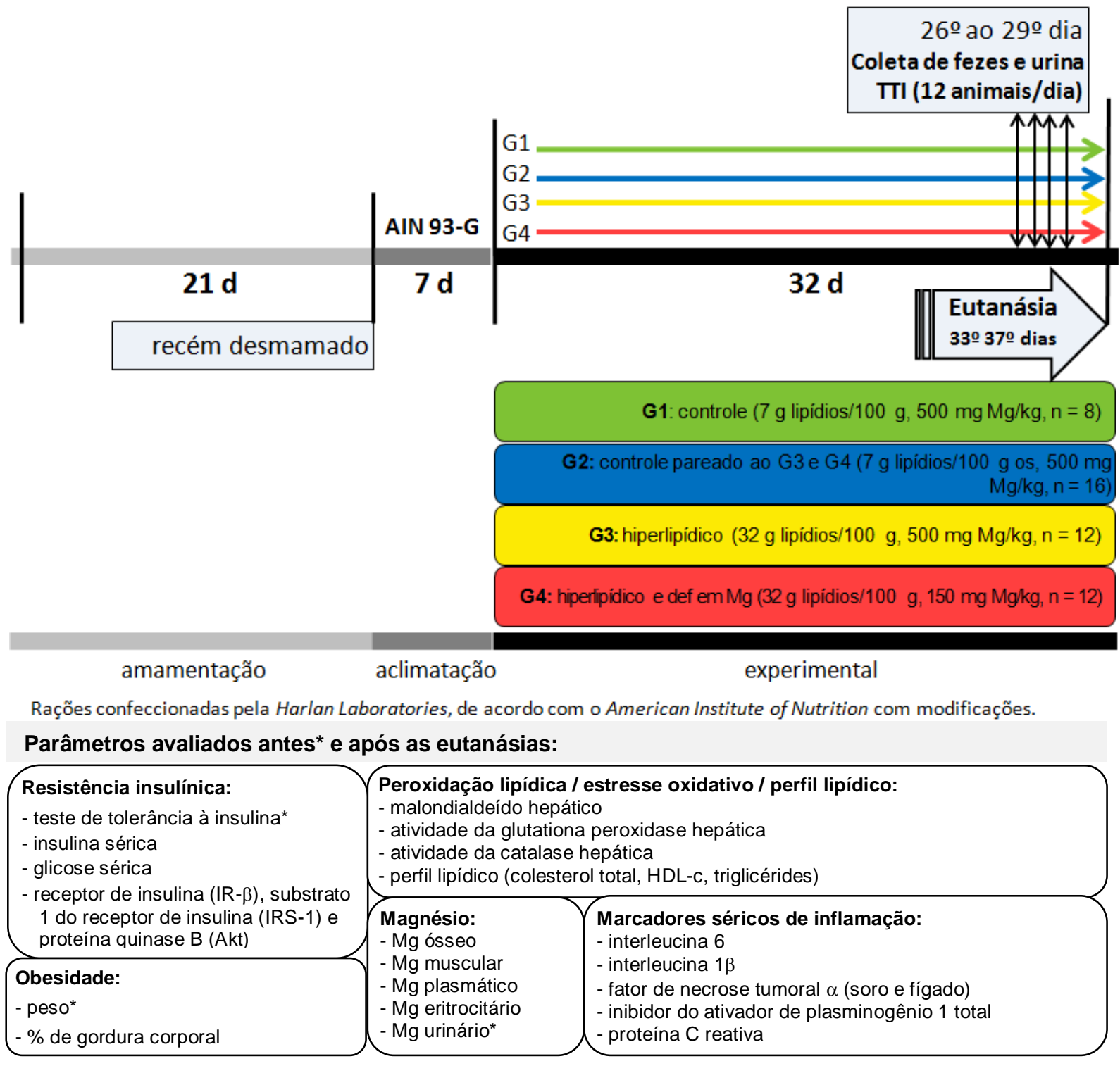

Figura D- 2 - Delineamento experimental: ENSAIO PRINCIPAL

Na semana anterior às eutanásias, foi realizado o teste de tolerância à insulina, e os animais transferidos para gaioleiros metabólicos, durante $24 \mathrm{~h}$, para coleta de urina e de fezes, para dosagem de magnésio. No ensaio piloto, os animais foram mantidos por quatro dias nos gaioleiros metabólicos para avaliação do balanço mineral. Durante o períodos em que os animais ficaram nas gaiolas metabólicas, diariamente foi avaliado o volume urinário, separado alíquota para dosagem de creatinina, e o restante da urina foi acidificado ( $\mathrm{pH} 1$ a 2) com ácido clorídrico $(\mathrm{HCl}) 3 \mathrm{~mol} / \mathrm{L}$ e posteriormente armazenado a - 
$80 \stackrel{\circ}{ } \mathrm{C}$. As amostras de fezes foram separadas de qualquer conteúdo de pelo ou ração eventualmente presentes, e armazenadas a $-20 \stackrel{\circ}{ } \mathrm{C}$, até análise.

Concluídos os períodos experimentais, após jejum de 12 a 14 h, os animais foram anestesiados por via intraperitoneal, com dose de $0,2 \mathrm{~mL} / \mathrm{kg}$ de peso corporal de solução anestésica de - xilazina (25 mg/kg; Virbaxil $2 \%$, Virbac, São Paulo, Brasil) e quetamina (10 mg/kg; Vetaset, Fort Dodge, lowa, EUA) $(1: 2 ; \mathrm{v} / \mathrm{v})$. Na ausência de reflexo de pinçamento plantar, o abdômen foi aberto por incisão na linha média, cortados um fragmento de fígado para quantificação das proteínas IR, IRS-1 e Akt, os quais foram colocados imediatamente em nitrogênio líquido. Para análise da ativação dessas mesmas proteínas, administrou-se, pela veia cava, 0,75 U de insulina/kg de peso corporal e, após $30 \mathrm{~s}$, foi coletado outro fragmento de fígado. O sangue foi coletado pela veia porta, e distribuído em tubos com anticoagulante ${ }^{6}$, para quantificação de magnésio, e sem anticoagulante, para as demais dosagens (Figura D-3).

Após esses procedimentos, os órgãos foram perfundidos por via intracardíaca com solução de cloreto de sódio $(\mathrm{NaCl})$ 0,85 \% até total exsanguinação. Em seguida, foram dissecados o fígado, os fêmures, as tíbias, os músculos gastrocnêmios, rins e os depósitos adiposos epididimal direito e retroperitoneal direito. Os órgãos dissecados foram removidos de qualquer tecido aderente, pesados, colocados em nitrogênio líquido e depois acondicionados a $-80^{\circ} \mathrm{C}$. Ao final, foi feita a limpeza do trato gastrointestinal, que foi devolvido, junto com os depósitos adiposos, ao restante da carcaça, armazenada a $-20{ }^{\circ} \mathrm{C}$ até análise da composição corporal (Figura D-3).

\subsubsection{Tamanho amostral}

A definição do tamanho da amostra baseou-se no estudo de probabilidades de erros envolvidos em testes de hipóteses para comparar as médias dos grupos para uma

\footnotetext{
${ }^{6}$ ENSAIO PILOTO: 50 UI de heparina sódica/mL de sangue, ENSAIO PRINCIPAL: $10 \mu \mathrm{L}$ de citrato de sódio $30 \% / \mathrm{mL}$ de sangue. Não utilizamos o mesmo anticoagulante porque não havia mais disponível para comercialização. Antes da decisão fizemos alguns testes para verificar possíveis diferenças com o uso destes anticoagulantes, não sendo verificadas diferenças nos parâmetros de magnésio. Dados apresentados no Apêndice F.
} 
variável de interesse, considerando quatro grupos, e valores de delta e estimativas de desvio padrão (NETER et al., 2004). Para os grupos em que se supôs que poderia haver maior variabilidade, e eventualmente morte de animais, o $\mathrm{n}$ foi aumentado. $\mathrm{O}$ tamanho amostral foi definido utilizando como variável de interesse a sensibilidade à insulina, e assumindo poder de $80 \%$ e alfa de $5 \%$.

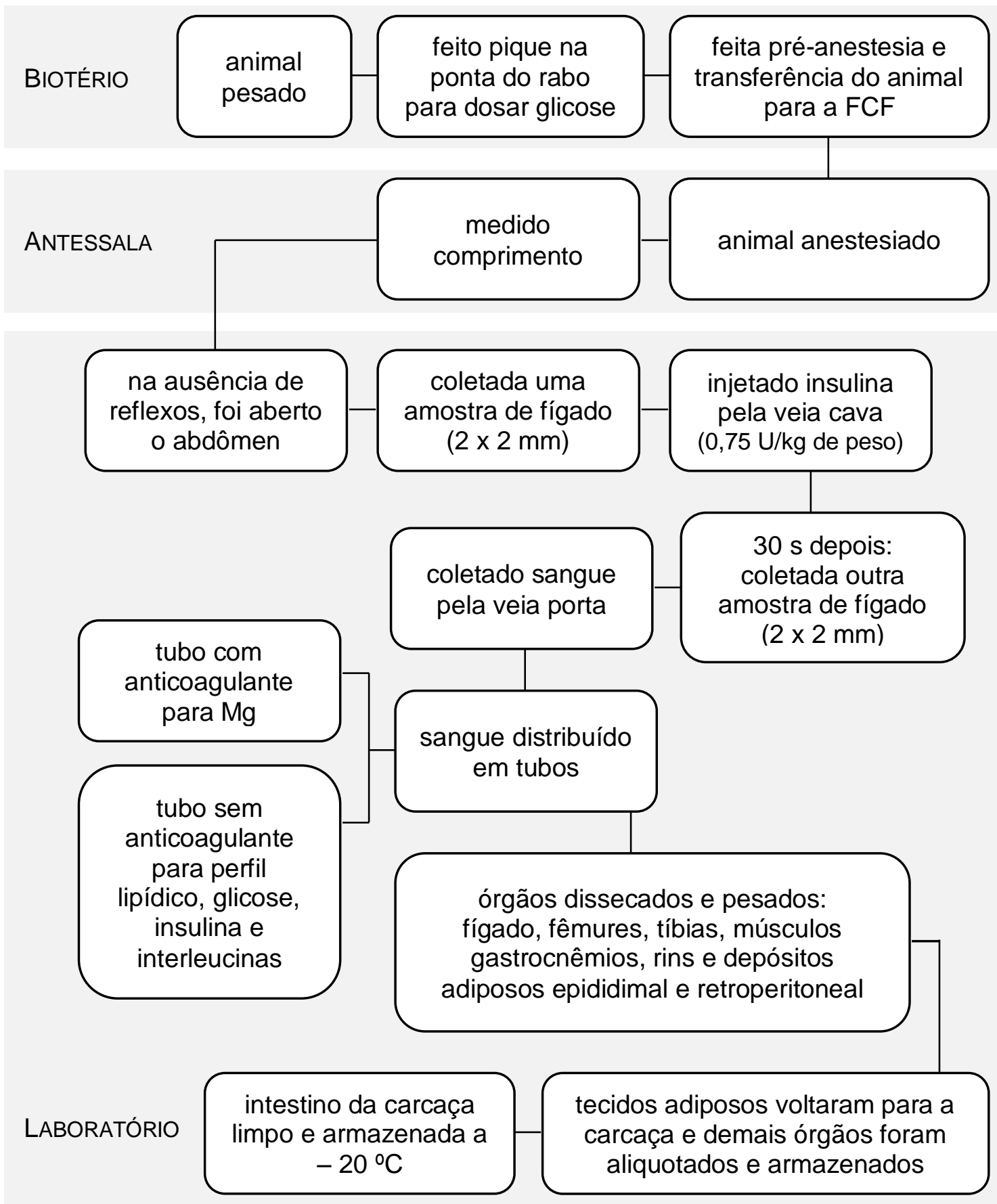

Figura D- 3 - Fluxograma no dia da eutanásia 


\subsection{Dietas experimentais}

- ENSAIO PILOTO

Durante o período de aclimatação foi ofertado dieta controle padrão AIN-93G peletizada (REEVES; NIELSEN; FAHEY, 1993), preparada em nosso laboratório. Durante o período experimental foram ofertadas dietas customizadas da empresa Harlan Teklad Laboratories (Madison, WI, EUA), as quais eram semipurificadas e peletizadas (Tabela D-1). Ambas as dietas foram acondicionadas sob refrigeração ( $\left.4{ }^{\circ} \mathrm{C}\right)$. As dietas experimentais adquiridas da Harlan, normolipídica (TD.06416) e hiperlipídica (TD.06414), tem como ponto de referência para sua formulação o padrão sugerido pelo AIN (American Institute of Nutrition), e são indicadas para estudos de indução de obesidade e síndrome metabólica.

Assumindo-se que o consumo de ração é menor nos grupos que consomem dietas com maior densidade energética, as dietas são formuladas, pela empresa, com maior concentração de nutrientes (proteínas, minerais, vitaminas) para garantir o consumo igual ao do grupo normolipídica, sendo o ajuste feito pela energia. 
Tabela D- 1 - Formulação das dietas usadas no ensaio piloto ${ }^{7}$

\begin{tabular}{|c|c|c|c|}
\hline \multirow{3}{*}{ Ingredientes } & \multicolumn{3}{|c|}{ Dietas } \\
\hline & \multirow{2}{*}{$\begin{array}{c}\text { Aclimatação } \\
\text { Padrão } \\
\text { AIN 93G* }^{*}\end{array}$} & \multicolumn{2}{|c|}{ Experimentais $^{\dagger}$} \\
\hline & & Normolipídica & Hiperlipídica \\
\hline caseína $^{\ddagger}$ (g/100 g da dieta $)$ & 20,00 & 21,0 & 26,5 \\
\hline L-cistina (g/100 g da dieta) & 0,30 & 0,30 & 0,40 \\
\hline amido de milho (g/100 g da dieta) & 52,95 & 28,0 & - \\
\hline maltodextrina ( $\mathrm{g} / 100 \mathrm{~g}$ da dieta) & - & 5,00 & 16,00 \\
\hline sacarose ( $\mathrm{g} / 100 \mathrm{~g}$ da dieta) & 10,00 & 32,5 & 9,00 \\
\hline celulose ( $\mathrm{g} / 100 \mathrm{~g}$ da dieta) & 5,00 & 3,72 & 6,50 \\
\hline óleo de soja (g/100 g da dieta) & 7,00 & 2,00 & 3,00 \\
\hline banha (g/100 g da dieta) & - & 2,00 & 31,00 \\
\hline mistura salina ${ }^{\S}(\mathrm{g} / 100 \mathrm{~g}$ da dieta $)$ & 3,50 & 3,50 & 4,80 \\
\hline fosfato de cálcio dibásico (g/100 g dieta) & - & 0,20 & 0,34 \\
\hline mistura vitamínicall (g/100 g da dieta) & 1,00 & 1,50 & 2,10 \\
\hline bitartarato de colina $^{\#}$ (g/100 g da dieta) & 0,25 & 0,28 & 0,30 \\
\hline $\begin{array}{l}\text { antioxidante terc-butil hidroquinona (g/100 } \\
\text { g da dieta) }\end{array}$ & 0,0014 & - & - \\
\hline
\end{tabular}

* Dieta formulada em nosso laboratório, utilizada no período de aclimatação dos animais

† Controle (TD.06416 - adjusted calories diet (10/fat), Harlan Teklad Laboratories); hiperlipídica (TD.06414

- adjusted calories diet (60/fat), Harlan Teklad Laboratories)

$\S$ Formulação baseada na AIN-93G-MX (REEVES; NIELSEN; FAHEY, 1993) sem modificações, sendo feito ajuste na dieta hiperlipídica

"| Formulação baseada na AIN-93G-VX (REEVES; NIELSEN; FAHEY, 1993) sem modificações, sendo feito ajuste na dieta hiperlipídica

\section{- ENSAIO PRINCIPAL}

As dietas experimentais usadas no ensaio principal, semipurificadas e peletizadas, foram elaboradas pela empresa Harlan Teklad Laboratories (Madison, WI, EUA), de acordo com nossas recomendações, e acondicionadas sob-refrigeração $\left(\sim{ }^{\circ} \mathrm{C}\right)$ (Tabela D-2). Suas formulações também se basearam no padrão sugerido pela AIN (REEVES; NIELSEN; FAHEY, 1993), com modificações nas concentrações de lipídios nas dietas hiperlipídicas, em que foi acrescida banha às expensas de amido, adicionado menor quantidade de óxido de magnésio na mistura mineral da dieta hiperlipídica deficiente em magnésio. A mistura mineral adicionada nas dietas foi elaborada sem magnésio, de maneira que o sal foi adicionado posteriormente de acordo com a concentração esperada para cada dieta.

\footnotetext{
${ }^{7}$ Ficha de dados das rações experimentais no Anexo B.
} 
Tabela D- 2 - Formulação das dietas usadas no ensaio principal ${ }^{8}$

\begin{tabular}{|c|c|c|c|}
\hline \multirow[b]{2}{*}{ Ingredientes } & \multicolumn{3}{|c|}{ Dietas experimentais $^{*}$} \\
\hline & Controle & Hiperlipídica & $\begin{array}{l}\text { Hiperlip def } \\
\text { Mg }\end{array}$ \\
\hline caseína $^{\dagger}(\mathrm{g} / 100 \mathrm{~g}$ da dieta $)$ & 20,00 & 20,0 & 20,0 \\
\hline L-cistina ( $\mathrm{g} / 100 \mathrm{~g}$ da dieta) & 0,30 & 0,30 & 0,30 \\
\hline amido de milho ( $\mathrm{g} / 100 \mathrm{~g}$ da dieta) & 39,66 & 7,86 & 7,92 \\
\hline maltodextrina (g/100 g da dieta) & 13,20 & 20,00 & 20,00 \\
\hline sacarose ( $\mathrm{g} / 100 \mathrm{~g}$ da dieta) & 10,00 & 10,0 & 10,0 \\
\hline celulose ( $\mathrm{g} / 100 \mathrm{~g}$ da dieta) & 5,00 & 5,00 & 5,00 \\
\hline óleo de soja (g/100 g da dieta) & 7,00 & 7,00 & 7,00 \\
\hline banha $(\mathrm{g} / 100 \mathrm{~g}$ da dieta) & - & 25,00 & 25,00 \\
\hline mistura salina $^{\ddagger}$ (g/100 g da dieta) & 3,50 & 3,50 & 3,50 \\
\hline óxido de magnésio (g/100 g dieta) & 0,085 & 0,085 & 0,026 \\
\hline mistura vitamínica ${ }^{\S}$ (g/100 g da dieta) & 1,00 & 1,00 & 1,00 \\
\hline bitartarato de colinall (g/100 g da dieta) & 0,25 & 0,25 & 0,25 \\
\hline $\begin{array}{l}\text { antioxidante terc-butil hidroquinona }(\mathrm{g} / 100 \mathrm{~g} \text { da } \\
\text { dieta) }\end{array}$ & 0,0014 & 0,0014 & 0,0014 \\
\hline \multicolumn{4}{|c|}{$\begin{array}{l}\text { * Controle (TD. - } 7 \% \text { soybean oil diet (500 Mg), Harlan Teklad Laboratories); hiperlipídica (TD.110297 - } \\
25 \% \text { lard, } 7 \% \text { soybean oil diet (500 Mg), Harlan Teklad Laboratories); hiperlipídica deficiente em } \\
\text { magnésio (TD.110299 - } 25 \% \text { lard, } 7 \% \text { soybean oil diet (150 Mg), Harlan Teklad Laboratories) } \\
\text { † Formulação baseada na AIN-93G-MX (REEVES; NIELSEN; FAHEY, 1993) com modificações apenas no } \\
\text { magnésio, o qual foi adicionado posteriormente de acordo com o esperado para cada dieta } \\
\text { § Formulação baseada na AIN-93G-VX (REEVES; NIELSEN; FAHEY, 1993) sem modificações }\end{array}$} \\
\hline
\end{tabular}

No ensaio principal preferiu-se não realizar o ajuste de nutrientes (proteína, vitaminas e minerais), como nas dietas usadas no ensaio piloto, e optou-se por incluir um grupo pair-feeding aos hiperlipídicos, cujo pareamento foi feito diariamente pelo consumo da dieta em gramas, para equiparar o consumo de proteínas, minerais e vitaminas.

\subsubsection{Definição do tempo e das concentrações de magnésio e de lipídios das dietas experimentais}

Uma vez que o desenvolvimento de doenças crônicas vem ocorrendo cada vez mais precocemente, em diferentes grupos populacionais (FORD e MOKDAD, 2003; KIM et al., 2010; KIRII et al., 2010; SALES et al., 2011) optou-se por avaliar os efeitos do consumo de dietas hiperlipídicas e deficientes em magnésio por cerca de 30 dias, nos ratos com cerca de 60 dias de idade, período no qual estão sexualmente maduros (ADAMS; BOICE, 1983).

\footnotetext{
${ }^{8}$ Ficha de dados das rações experimentais no Anexo C
} 
Estima-se que ratos, tanto em período de crescimento quanto adultos (não gestastes), tenham necessidade dietética de magnésio de 7,5 mg Mg/d, o que equivale, para a dieta AIN 93G, a aproximadamente $500 \mathrm{mg} / \mathrm{kg}$ de ração (REEVES, NIELSEN, FAHEY, 1993; NATIONAL RESEARCH COUNCIL, 1995). Esse valor foi adotado para as dietas controle e hiperlipídica do presente estudo.

Já para a dieta hiperlipídica deficiente em magnésio, embora aquém do que é observado na população adulta (FORD e MOKDAD, 2003; KIM et al., 2010; KIRII et al., 2010; SALES et al., 2011), optou-se por ofertar $150 \mathrm{mg} \mathrm{Mg/g}$ dieta aos animais do grupo deficiente, que equivale a aproximadamente $2,3 \mathrm{mg} \mathrm{Mg} / \mathrm{d}$ (30 \% recomendação). Este valor, de acordo com a literatura, equivale ao que seria uma dieta marginalmente deficiente neste mineral para modelos animais (FEILLET-COUDRAY et al., 2000), e foi adotada para que fosse possível avaliar melhor os efeitos do baixo consumo dietético de magnésio em curto espaço de tempo, associado a dieta hiperlipídica, uma vez que percentuais por volta de $60 \%$ da RDA do rato nem sempre é responsivo a maioria dos parâmetros de magnésio em estudos com animais (NATIONAL RESEARCH COUNCIL, 1995), por representar uma deficiência leve.

Por outro lado, o percentual de lipídios das dietas hiperlipídicas baseou-se especialmente em estudos desenvolvidos com ratos Wistar alimentados com banha, no intuito de desenvolver obesidade e fatores relacionados a esta síndrome (GUSTAFSON et al., 2002; BUETTNER et al., 2006; BANAS et al., 2009; PICKERING et al., 2009; SOGAWA et al., 2009).

\subsubsection{Composição química das dietas experimentais}

Foram determinadas as concentrações de umidade [estufa $105^{\circ} \mathrm{C}$ ], lipídios totais [Soxhlet], proteína [micro-Kjeldahl], minerais e cinzas (AOAC, 2006). Os minerais foram analisados por espectrofotometria de absorção atômica (Perkin Elmer AAnalyst 100 Norwalk, CT, EUA), após digestão por via úmida $\left(\mathrm{HNO}_{3}: \mathrm{H}_{2} \mathrm{O}_{2}, 5: 1 ; \mathrm{v} / \mathrm{v}\right)$ e diluição com 
$\mathrm{HNO}_{3}$ a $1 \%(\mathrm{v} / \mathrm{v})$, nas condições apresentadas na Tabela D-3. Para análise de cálcio e de magnésio foi adicionada, às amostras, ao final das diluições, solução de óxido de lantânio a 5 \%, como $\mathrm{La}_{2} \mathrm{O}_{3} \cdot 7 \mathrm{H}_{2} \mathrm{O}$ (Merck, Darmstadt, Alemanha), de modo a se obter concentração final de lantânio de $0,1 \%(\mathrm{p} / \mathrm{v})$. Foram preparadas curvas padrão a partir das soluções padrão de $\mathrm{CaCl}_{2}, \mathrm{MgCl}_{2}, \mathrm{FeCl}_{3}, \mathrm{ZnCl}_{2}$ e $\mathrm{CuCl}_{2}$ (Titrisol, Merck, Darmstadt, Alemanha). O fósforo foi analisado pelo método de Fiske e Subarrow (1925) em espectrofotômetro Genesys 10 Vis (Thermo Fisher Scientific Inc, Waltham, MA, USA).

Tabela D- 3 - Condições para quantificação de minerais em dietas em espectrofotômetro de absorção atômica Perkin Elmer AAnalyst 100 (Norwalk, CT, EUA)*

\begin{tabular}{lccc}
\hline Mineral & Comprimento de onda $(\mathbf{n m})$ & Fenda $(\mathbf{n m})$ & Limite de quantificação $(\mu \mathbf{g} / \mathbf{m L})$ \\
\hline cálcio & 422,7 & 0,7 & 1,301 \\
magnésio & 202,6 & 0,7 & 1,919 \\
ferro & 248,3 & 0,2 & 0,458 \\
zinco & 213,9 & 0,7 & 0,694 \\
cobre & 324,8 & 0,7 & 0,000 \\
\hline
\end{tabular}

${ }^{*}$ Em todos os métodos foram usados lâmpada de catodo oco e chama oxidante de ar-acetileno

\subsection{Composição corporal e índice de adiposidade}

A avaliação da composição corporal dos animais (umidade, gordura, proteína e resíduo fixo [cinzas]) foi determinada por análise química das carcaças como descrito por DONATO Jr. et al. (2006). Inicialmente as carcaças dos animais foram desidratadas (60 ${ }^{\circ} \mathrm{C}$, estufa ventilada), desengorduradas [Soxhlet], e moídas (moinho lka M20 grinder, Labortechnik, Wasserburg, Alemanha). Após remoção dos pelos, removidos no intuito de melhorar a homogeneidade do pó da carcaça, a porcentagem de proteína [Kjeldahl] $(\mathrm{N} \times$ 6,25 ) e de cinzas (mufla, $540^{\circ} \mathrm{C}$ ) foram determinadas. A massa livre de gordura foi calculada por diferença.

O índice de adiposidade foi calculado pela relação da soma dos tecidos adiposos epididimal e retroperitoneal pelo peso corporal final, em gramas, e este valor foi multiplicado por 100 . 
Índice de adiposidade $(\%)=\frac{\text { tec. adiposo epididimal }(\mathrm{g})+\text { tec. adiposo retroperitoneal }(\mathrm{g})}{\text { peso corporal final }(\mathrm{g})} \times 100$

\subsubsection{Lipídios fecais ${ }^{9}$}

As amostras de fezes foram secas em estufa a $105^{\circ} \mathrm{C}$ por $12 \mathrm{~h}$, moídas e os lipídios totais foram determinados pelo método Soxhlet (AOAC, 2006). A absorção aparente de lipídios da dieta foi calculada pela relação a seguir:

$$
\text { Absorção }(\%)=\frac{\text { ingestão }(\mathrm{mg} / \mathrm{d})-\text { excreção fecal }(\mathrm{mg} / \mathrm{d})}{\text { ingestão }(\mathrm{mg} / \mathrm{d})} \times 100
$$

\subsubsection{Status de magnésio}

O status de magnésio foi avaliado pela quantificação do mineral por espectrofotometria de absorção atômica - EAA (Perkin Elmer AAnalyst 100, EUA) no plasma, eritrócitos, urina (por método direto - SALES et al. [artigo em tramitação]) e nas fezes, músculo gastrocnêmio, tíbia e fêmur nas amostras desidratadas e abertas com $\mathrm{HNO}_{3}: \mathrm{H}_{2} \mathrm{O}_{2}$ (5:1). A curva padrão foi preparada com $\mathrm{MgCl}_{2}$ Titrisol (Merck, Darmstadt, Alemanha). Óxido de lantânio foi acrescentado de modo a se ter concentração final de $0,1 \%$ de lantânio.

Toda a vidraria usada para análise de minerais foi previamente desmineralizada, e a precisão e exatidão dos métodos verificada usando padrões certificados (trace elements serum L-I e urine blank; Seronorm, Billingstad, Norway) e padrões secundários (pool de plasma, eritrócitos, urina e AIN-93G para as amostras que foram digeridas), sendo verificadas precisões de 96 a $100 \%$ e exatidões de 95 a $103 \%$.

A absorção aparente ${ }^{6}$ de magnésio da dieta foi calculada pela mesma relação mencionada para lipídios, e o balanço de magnésio calculado pela relação a seguir.

\footnotetext{
${ }^{9}$ Avaliação feita apenas no ENSAIO PILOTO
} 
Balanço $(\mathrm{mg} / \mathrm{d})=\frac{\text { (ingestão }(\mathrm{mg} / \mathrm{d})-\text { excreção fecal }(\mathrm{mg} / \mathrm{d}))- \text { excreção urinária }(\mathrm{mg} / \mathrm{d})}{\text { ingestão }(\mathrm{mg} / \mathrm{d})}$

\subsection{Resistência insulínica}

\subsubsection{Teste de tolerância à insulina}

O teste de tolerância à insulina curto (TTI) foi realizado seis dias antes da eutanásia. Após $4 \mathrm{~h}$ de jejum, solução de insulina recombinante humana $(0,75 \mathrm{U} / \mathrm{kg}$; Humulin R; Lilly Elly, Indianapolis, EUA) foi injetada, por via intraperintoneal. Amostras de sangue foram colhidas, após pequena secção da cauda, nos tempos 0, 4, 8, 12 e 16 min. A glicose foi mensurada utilizando-se glicosímetro portátil (Accu-Chek ${ }^{\circledR}$ Performa, Roche diagnóstica Ltda, São Paulo, Brasil) (CINTRA et al., 2012). A sensibilidade à insulina foi estimada pela constante $K_{I T T}$, da equação exponencial $y=y_{0} \cdot e^{-k t}$, em que y é a concentração de glicose e t o tempo em minutos (LUNDBAEK, 1962).

\subsubsection{Glicemia e insulinemia de jejum}

Antes da eutanásia foram determinadas a glicemia de jejum (Accu-Chek ${ }^{\circledR}$ Performa, Roche diagnóstica Ltda, São Paulo, Brasil) por incisão na ponta da cauda, e a insulina sérica (kit para multiplex rat serum adipokine - Cat. $n^{\circ}$ RADPK-81K, Millipore Corporation; Billerica, MA, EUA) com o sangue coletado durante a eutanásia.

Com os dados de glicose e de insulina foram aplicadas as fórmulas empíricas dos índices HOMA-IR (homeostasis model assessment insulin resistance) e HOMA- $\beta$ (homeostasis model assessment $\beta$-cell function), que predizem, respectivamente, a sensibilidade à insulina e a função das células $\beta$ pancreáticas: HOMA-IR = insulina de jejum $(\mu \mathrm{U} / \mathrm{mL}) \times$ glicemia de jejum $(\mathrm{mmol} / \mathrm{L}) / 22,5 ;$ HOMA $-\beta=20 \times$ insulina de jejum $(\mu \mathrm{U} / \mathrm{mL}) /($ glicemia de jejum (mmol/L) - 3,5) (MATTHEWS et al., 1985). 


\subsubsection{Fosforilação de proteínas da via de sinalização de insulina ${ }^{10}$}

No intuito de avaliar alguns passos da sinalização da insulina, foram avaliadas, por western blotting, a expressão, no fígado, do receptor de insulina (IR- $\beta$ ), do substrato 1 do receptor de insulina (IRS-1) e da proteína quinase B (Akt).

Aos fragmentos de fígado foi adicionado tampão específico para extração de proteína total $\left(3,2 \mathrm{mM} \mathrm{FNa}, 0,5 \mathrm{mM} \mathrm{Na}_{4} \mathrm{P}_{2} \mathrm{O}_{7}, 0,3 \mathrm{mM} \mathrm{Na}_{3} \mathrm{VO}_{4}, 1: 100\right.$ protease inhibitor cocktail [Thermo Scientific, Rockford, IL, EUA] e T-PER tissue protein [Thermo Scientific, Rockford, IL, EUA]), sendo os tecidos homogeneizados com auxílio de homogeneizador polytron à velocidade máxima, por 20 segundos. Após centrifugação (40 min, 4ํ C, 1200 rpm), foi retirada uma alíquota do sobrenadante para determinação da concentração de proteína (BCA protein assay kit, Pierce, Cat. nำ23225, Rockford, IL, EUA), e alíquotas armazenadas a $-80{ }^{\circ} \mathrm{C}$ até determinação do extrato total com anticorpo específico. No momento do uso foi adicionado a cada alíquota tampão Laemmli 4x, e submetido a banho-maria por 5 min.

Amostras contendo $50 \mu \mathrm{g}$ de extratos protéicos totais foram submetidos à eletroforese em gel desnaturante de poliacrilamida (SDS-PAGE, bis-acrilamida $8 \%$ ) em aparato MiniProtean da Bio-Rad (Hercules, CA, EUA) e transferidos em célula de transferência semi-seca - 25 V, 20 min (BioRad; Hercules, CA, EUA), para membranas de nitrocelulose (Whatman Schleicher \& Schuell Protran Nitrocellulose Transfer Membrane, Dassel, Germany). O bloqueio das membranas foi feito durante $2 \mathrm{~h}$ com solução de leite em pó desnatado a 0,5\%, em solução salina tamponada com fosfato pH 7,3. Em seguida, foram incubadas overnight, a $4 \stackrel{\circ}{\mathrm{C}}$, com anticorpos primários para antiIR (1:500; insulin receptor $\beta$-subunit [C-19; № SC-711]; $1: 500$; phospho-insulin receptor $\beta$ subunit [10C3; no SC-81500] - Santa Cruz Biotechnology (Santa Cruz, CA, EUA)), 1:1000; anti-IRS-1 (IRS-1 [no 2382]; 1:1000; phospho-IRS-1 [Tyr895; no 3070] - Cell

\footnotetext{
${ }^{10}$ Análise realizada apenas nas amostras do ENSAIO PRINCIPAL. Amostras do piloto foram usadas apenas para padronizações.
} 
Signaling Technology, Beverly, MA, EUA), e anti-Akt (1:500; Akt1 [C-20; no SC-1618]; 1:500; anti-phospho [Ser473, no sc-7985-R] - Santa Cruz Biotechnology (Santa Cruz, CA, EUA)), e, posteriormente, incubados ( 2 h) com anticorpos secundários adequados para cada anticorpo primário (1:6667; anti-rabbit ou anti-mouse lgG-horseradish peroxidase, GE Healthcare Lifesciences, Freiburg, Alemanha). Os complexos antígeno-anticorpo foram identificados utilizando substrato quimioluminescente para a enzima peroxidase (SuperSignal West Pico chemiluminescent substrate - Thermo Scientific, Rockford, IL, EUA) e detectados com filme fotossensível (Kodak XAR - Rochester, NY). Após densitometria utilizando um scanner (HP 3400) e o programa Scion Image V. Alpha 4.0.3.2 (Scion Corporation, Frederick, MD, USA), as proteínas fosforiladas foram normalizadas pelo conteúdo de proteína total.

\subsection{Lipídios}

\subsubsection{Perfil de ácidos graxos no fígado ${ }^{11}$}

Cerca de 1,25 g do fígado (50 mg de gordura), foi submetido à hidrólise ácida, sendo adicionado o ácido pirogálico para minimizar a degradação oxidativa dos ácidos graxos durante a análise. Os lipídios foram extraídos com éter etílico, e então metilados para ésteres metílicos de ácidos graxos, com trifluoreto de boro $\left(\mathrm{BF}_{3}\right)$ em metanol $(7 \%)$. Após remoção do solvente sob fluxo de nitrogênio $\left(\mathrm{N}_{2}\right)$, os ácidos graxos metilados foram ressuspendidos em clorofórmio e injetados em cromatógrafo a gás CG17A (Shimadzu, Kyoto, Japão), equipado com detector de ionização de chama ligado a um processadorintegrador C-30021 (CG Instrumentos Científicos Ltda, São Paulo, Brasil), nas seguintes condições: coluna cromatográfica de sílica fundida - Supelcowax 10 de $30 \mathrm{~m}$ x 0,25 mm de diâmetro e 0,2 $\mu \mathrm{m}$ de espessura da fase estacionária (Supelco Park, Bellefonte, Palo Alto, CA, EUA); gás de arraste: hélio (1 mL/min); programação de temperatura da coluna: aquecimento a $1{ }^{\circ} \mathrm{C} / \mathrm{min}$ de $170{ }^{\circ} \mathrm{C}$ até $225^{\circ} \mathrm{C}$, permanecendo nesta temperatura por 10

\footnotetext{
${ }^{11}$ Avaliação feita apenas no ENSAIO PILOTO. No Apêndice G consta a validação feita para este método.
} 
min; temperatura do vaporizador: $250{ }^{\circ} \mathrm{C}$; temperatura do detector: $270{ }^{\circ} \mathrm{C}$; tempo total de análise: 65 min; razão de divisão da amostra no injetor de 1/100.

A identificação dos ésteres metílicos dos ácidos graxos foi realizada comparandose os tempos de retenção das amostras com os de padrões de ácidos graxos (mistura de padrões Sigma - Cat. no 189.19). Relacionaram-se as áreas dos picos e a área total, e os valores foram expressos em percentual de ácidos graxos (AOAC, 2006).

\subsubsection{Perfil lipídico ${ }^{12}$}

Para avaliação do perfil lipídico determinou-se, no soro, o colesterol total pela reação de Trinder (colesterol oxidase), a lipoproteína de alta densidade (HDL-c) pela precipitação com fosfotungstato-magnésio, e os triacilgliceróis pela reação glicerol fosfato oxidase, todos se utilizando de reagentes da Labtest Diagnóstica (Lagoa Santa, MG, Brasil).

\subsection{Estresse oxidativo}

\subsubsection{Malondialdeído}

A peroxidação lipídica foi avaliada pela quantificação da concentração de malondialdeído (MDA) no fígado, por cromatografia líquida de alta eficiência (HPLC) (Agilent Technologies 1200 series - Santa Clara, EUA). No método usado, durante o aquecimento em meio ácido, o MDA é liberado do peróxido do lipídio, e um mol deste composto reage com dois moles de ácido tiobarbitúrico (TBA-MDA), formando um complexo cromogênio (TBA-MDA - Figura D-4) que é detectado a 532 nm (LÄRSTAD et al., 2001; CHENG; WU; HUANG, 2008).

\footnotetext{
${ }^{12}$ Análise realizada apenas no ENSAIO PRINCIPAL
} 


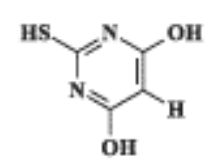

TBA

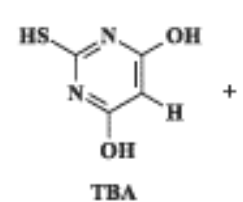

TBA

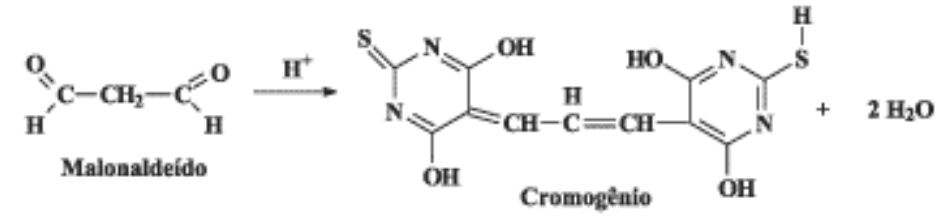

Figura D- 4 - Reação que ocorre entre o ácido 2-tiobarbitúrico e o MDA, durante o aquecimento em meio contendo ácido ortofosfórico

Para leitura, o cromatógrafo foi equipado com coluna reversa Phenomenex C18 de $250 \mathrm{~mm}$ x 4,6 mm com partículas de $5 \mu \mathrm{m}$ (Phenomenex, Torrance, EUA) e pré-coluna Phenomenex LC8-D8 AJ0-1287 (Phenomenex, Torrance, EUA), e mantido nas seguintes condições: temperatura do mostrador de $4{ }^{\circ} \mathrm{C}$; temperatura da coluna de $25^{\circ} \mathrm{C}$; fase móvel de $60 \%$ de tampão fosfato de potássio $(50 \mathrm{mM}, \mathrm{pH} 6,0)$ e $40 \%$ de metanol; volume de injeção de $20 \mu \mathrm{L}$; taxa de fluxo de $1 \mathrm{~mL} / \mathrm{min}$; tempo de corrida de $10 \mathrm{~min}$, mais 10 min para limpeza da coluna com acetonitrila e água e $5 \mathrm{~min}$ de pós-corrida. A detecção foi realizada fluorimetricamente a excitação de $515 \mathrm{~nm}$ e emissão de $543 \mathrm{~nm}$. O tempo de retenção do MDA foi aproximadamente de 8,5 min. A concentração de MDA foi calculada a partir da equação da reta gerada pela curva de calibração, cujas concentrações variaram de 0,5 a $10 \mu \mathrm{mol} / \mathrm{L}$.

\subsubsection{Atividade da glutationa peroxidase}

No método usado a atividade da glutationa peroxidase (GSH-Px) é indiretamente medida por reação atrelada com a glutationa redutase (GR), em que a glutationa oxidada (GSSG), produzida com a redução de hidroperóxidos (terc-butil hidroperóxido) pela GPx, é reciclada para o seu estado reduzido (GSH) pela GR e NADPH (SIES et al., 1979; FLOHÉ; GUNZLER, 1984; TORRES, 2009).

$$
\begin{aligned}
& 2 \cdot \mathrm{GSH}+\mathrm{ROOH} \stackrel{\text { glutationa peroxidase }}{\longrightarrow} \mathrm{GSSG}+\mathrm{H}_{2} \mathrm{O}+\mathrm{ROH} \\
& \mathrm{GSSG}+\mathrm{NADPH}+\mathrm{H}^{+} \stackrel{\text { glutationa reduzida }}{\longrightarrow} 2 \cdot \mathrm{GSH}+\mathrm{NADP}^{+}
\end{aligned}
$$

A atividade da glutationa peroxidase (GSH-Px) foi determinada, a partir de amostras de fígado, homogeneizadas em tampão fosfato de potássio $0,1 \mathrm{M}+$ EDTA 0,1 
$\mathrm{M}, \mathrm{pH}$ 7,0, na proporção de 1:4. Após centrifugação a $10.000 \mathrm{rpm}$, durante $15 \mathrm{~min}$, a 4 ${ }^{\circ} \mathrm{C}$, o sobrenadante foi separado e novamente diluído (1:10).

Em microplacas, acrescentou-se em cada poço $30 \mu \mathrm{L}$ do homogenato de fígado (1:10) e $160 \mu \mathrm{L}$ de meio de reação (tampão fosfato $0,1 \mathrm{M} \mathrm{pH} \mathrm{7,0;} \mathrm{glutationa} \mathrm{redutase}$ $0,08 \mathrm{M}$; glutationa oxidase $9,6 \mathrm{U} / \mathrm{mL}$; NADPH 1,2mM). A placa foi incubada a $30 \stackrel{\circ}{\mathrm{C}}$ por 5 min, e em seguida foi feita uma leitura prévia ( $\lambda=340 \mathrm{~nm}, 30^{\circ} \mathrm{C}, 6 \mathrm{~min}$, sob agitação) para se certificar de que as concentrações das amostras estavam adequadas $(\triangle A B S / m i n$ deve estar entre 0,02 e 0,135/min) e não havia oxidação não específica do NADPH. Após essa certificação foi pipetado rapidamente $10 \mu \mathrm{L}$ de solução de terc-butil $0,46 \%$ a cada poço, e realizada de imediato nova leitura. A atividade da GSH-Px foi medida pela quantidade da enzima que causou a oxidação de $1 \mathrm{nmol}$ de $\mathrm{NADPH}$ para $\mathrm{NADP}^{+}$por minuto à $30^{\circ} \mathrm{C}$. A oxidação do $\mathrm{NADPH}$ a $\mathrm{NADP}^{+}$foi monitorada durante 6 min, no comprimento de onda de $340 \mathrm{~nm}$, e a atividade da GSH-Px determinada pela equação a seguir, derivada da lei de Lambert e Beer:

$$
\text { atividade da GSH-Px (nmol/min/mL) }=\frac{k}{\xi \times b} \times \frac{0,2 \mathrm{~mL}}{\mathrm{Y} \mathrm{mL}} \times \text { diluição da amostra }
$$

onde,

$\mathrm{k}=$ inclinação da curva de crescimento

$\mathrm{b}=$ caminho óptico da placa de Elisa $\therefore 0,524(\mathrm{~cm})$

$\xi_{\mathrm{NADPH}^{*}}=0,00622\left(\mu \mathrm{M}^{-1} \cdot \mathrm{cm}^{-1}\right)$, que corresponde ao coeficiente de extinção do NADPH

$\mathrm{Y}=$ volume de amostra adicionada

Para expressar os resultados em mg de proteína do tecido, determinou-se a concentração de proteína nos homogenatos usando-se o kit BCA protein assay da Pierce (Cat. nำ 23225, Rockford, IL, EUA). 


\subsubsection{Atividade da catalase ${ }^{13}$}

A atividade da catalase foi determinada em amostras de fígado homogeneizadas em tampão fosfato de potássio $0,1 \mathrm{M}+$ EDTA $0,1 \mathrm{M}$, pH 7,0, na proporção de 1:5. Após centrifugação a $10.000 \mathrm{rpm}$, durante $15 \mathrm{~min}$, a $4{ }^{\circ} \mathrm{C}$, o sobrenadante foi separado e novamente diluído (1:10).

Em microplacas foi adicionado $20 \mu \mathrm{L}$ do homogenato de fígado (1:50) em cada poço, e pipetado $180 \mu \mathrm{L}$ de meio reacional (tris-HCl 1M, EDTA $5 \mathrm{mM}, \mathrm{pH}$ 8,0 e peróxido de hidrogênio $30 \mathrm{mM}$ ). Em seguida a placa foi lida imediatamente (6 min, a $30{ }^{\circ} \mathrm{C}$ e a 230 $\mathrm{nm}$ ), sendo verificada a decomposição do peróxido de hidrogênio pela catalase (BEUTLER, 1975). Sua atividade foi determinada pela equação a seguir, derivada da lei de Lambert e Beer:

$$
\text { atividade da CAT }(\mathrm{nmol} / \mathrm{min} / \mathrm{mL})=\frac{\mathrm{k}}{\xi \times \mathrm{b}} \times \frac{0,2 \mathrm{~mL}}{\mathrm{Y} \mathrm{mL}} \times \text { diluição da amostra }
$$

onde,

$\mathrm{k}=$ inclinação da curva de crescimento

$\mathrm{b}=$ caminho óptico da placa de Elisa $\therefore 0,524(\mathrm{~cm})$

$\xi_{\mathrm{H} 202}=0,071\left(\mu \mathrm{M}^{-1} \cdot \mathrm{cm}^{-1}\right)$, que corresponde ao coeficiente de extinção do $\mathrm{H}_{2} \mathrm{O}_{2}$

$\mathrm{Y}=$ volume de amostra adicionada

Para expressar os resultados em mg de proteína do tecido, determinou-se a concentração de proteína do homogenato de fígado usando-se o kit BCA protein assay da Pierce (Cat. no 23225, Rockford, IL, EUA).

\subsection{Status inflamatório}

Foram dosados no soro dos animais as interleucinas 6 e $1 \beta$, o fator de necrose tumoral alfa (TNF- $\alpha$ ), o fator ativador do plasminogênio 1 (PAl-1 total) e a proteína C reativa $(\mathrm{PCR})$. Estas análises foram realizadas utilizando-se o kit rat serum adipokine

\footnotetext{
${ }^{13}$ Análise realizada apenas no ENSAIO PRINCIPAL
} 
(Cat. $\mathrm{n}^{\circ}$ RADPK-81K, Millipore Corporation; Billerica, MA, EUA), por multiplex, e rat $C$ reactive protein (Cat. $n^{\circ}$ CYT294, Millipore Corporation, Billerica, MA, EUA), por ELISA. Foi dosado ainda o TNF- $\alpha$ no fígado, utilizando-se o kit Rat TNF- $\alpha$ Immunoassay (Cat. $n^{\circ}$ RTA00, R\&D Systems, Minneapolis, MN, EUA).

\subsection{Análise estatística}

Os dados são apresentados como média \pm desvio padrão. A normalidade dos dados foi testada usando o teste de Shapiro-Wilk e a homogeneidade de variâncias pelo teste de Levene. Assumidas as condições para aplicação de testes estatísticos paramétricos, as médias dos grupos do ENSAIO PILOTO foram comparadas pelo teste tStudent e do ENSAIO PRINCIPAL foram comparadas pela análise de variância unidimensional (one-way ANOVA) seguido do teste de Tukey. Quando não foi observada distribuição normal, e principalmente homogeneidade de variâncias, as medianas foram comparadas pelo teste de Mann-Whitney (ENSAIO PILOTO) ou pelo teste não-paramétrico de Kruskal-Wallis, seguido de Games-Howell (ENSAIO PRINCIPAL).

Para comparação das médias dos dados de western blotting, além da normalidade, verificada pelo teste de Shapiro-Wilk, verificou-se a esfericidade dos dados nos diferentes grupos pelo teste de Mauchly. Quando esse pressuposto não foi atendido $(p<0,05)$ foi utilizado o fator de correção Huynh-Feldt. As médias dos dados foram comparadas pelo teste ANOVA em dois fatores: estímulo com insulina (negativo e positivo) e grupo (CT, PF, HF, $\mathrm{HFMg}^{-}$), com medidas repetidas em um fator (grupo). As diferenças entre os grupos foram verificadas pelo ajuste de Bonferroni. Para esses dados o software Statistical Package for the Social Sciences (SPSS - Chicago, IL, EUA), versão 15.0 foi utilizado e a significância considerada foi de $\alpha$ de $5 \%$.

A análise de regressão linear múltipla stepwise foi feita para avaliar a relação entre o perfil glicídico e lipídico com o status de magnésio, o consumo de magnésio e de lipídios e o índice de adiposidade. Para isso, foram definidas como variáveis dependentes os parâmetros usados para avaliar a homeostase da glicose (glicemia, insulinemia e $\mathrm{K}_{\mathrm{ITT}}$ ), 
perfil lipídico (triacilgliceróis, colesterol total, HDL-c, VLDL), status oxidativo (MDA, GSHPx) e inflamatório (IL-1 $\beta$, TNF- $\alpha$, PAI-1 e PCR), e como variáveis independentes: magnésio plasmático, magnésio eritrocitário, magnésio urinário, magnésio muscular, magnésio ósseo, consumo de magnésio e de lipídios e índice de adiposidade. Foi testado ainda o efeito do índice de adiposidade e do consumo de lipídios e de magnésio (variáveis independentes) sobre o status de magnésio (variável dependente), e do consumo de lipídios e do status de magnésio (variáveis independentes) no índice de adiposidade (variável dependente). Os valores iniciais incluíram todas as variáveis independentes, e a seleção stepwise foi usada subsequentemente para adicionar ou remover as variáveis. Os modelos finais retiveram apenas aquelas variáveis que mantinham associação com as variáveis dependentes com nível de significância menor do que $5 \%$.

\section{REFERÊNCIAS BIBLIOGRÁFICAS}

ADAMS, N.; BOICE, R. A longitudinal study of dominance in an outdoor colony of domestic rats. J Comp Psychol, v. 97, n. 1, p. 24-33, 1983.

ASSOCIATION OF OFFICIAL ANALYTICAL CHEMISTS. . In: Horwitz W, editor. Official methods of analysis of Association of Official Analytical Chemists. 18th. ed. Maryland: AOAC International, 2006. [Current through revision 1]

BANAS, S.M.; ROUCH, C.; KASSIS, N.; MARKAKI, E.M.; GEROZISSIS, K. A dietary fat excess alters metabolic and neuroendocrine responses before the onset of metabolic diseases. Cell Mol Neurobiol, v. 29, p. 157-168, 2009.

BEUTLER, E. Red cell metabolism: a manual of biochemical methods. 2. ed. Nova lorque: Grune \& Stratton, 1975.

BUETTNER, R.; PARHOFER, K.G.; WOENCKHAUS, M.; WREDE, C.E.; KUNZSCHUGHART, L.A.; SCHÖLMERICH, J.; BOLLHEIMER, J.C. Defining hig-fat-diet rat models: metabolic and molecular effects of different fat types. J Mol Endocrionol, v. 36, p. 485-501, 2006.

CHENG G-W., WU H-L., HUANG Y-L. Simultaneous determination of malondialdehyde and ofloxacin in plasma using an isocratic high-performance liquid chromatography/fluorescence detection system. Anal Chim Acta, v. 616, p.230, 2008.

CINTRA, D.E.; ROPELLE, E.R.; MORAES, K.C.; PAULI, J.R.; MORARI, J.; DE SOUZA, C.T.; GRIMALDI, R.; STAHL, M.; CARVALHEIRA, J.B.; SAAD, M.J.; VELLOSO, L.A. Unsaturated fatty acids revert diet-induced hypothalamic inflammation in obesity. Plos One, v. 7, n. 1, p.e30571, 2012. 
DONATO Jr., J.; PEDROSA, R.G.; CRUZAT, V.F.; PIRES, I.S.O.; CHEM, B.; TIRAPEGUI, J. Effects of leucine supplementation on the body composition and protein status of rats submitted to food restriction. Nutr, v. 22, p. 520-527, 2006.

FEILLET-COUDRAY, C.; COUDRAY, C.; BRÛLÉ, F.; GUEUX, E.; MAZUR, A.; ABRAMS, S.A.; RAYSSIGUIER, Y. Exchangeable magnesium pool masses reflect the magnesium status of rats. J Nutr, v. 130, p. 2306-2311, 2000.

FISKE, C. H.; SUBBAROW, Y. The colorimetric determination of phosphorus. J Biol Chem, v. 66, p. 375-400, 1925.

FLOHÉ, L.; GUNZLER, W.A. Assays of glutathione peroxidase. Methods Enzymol, v. 105, p. 114-21, 1984.

FORD, E.S.; MOKDAD, A.H. Dietary magnesium intake in a national sample of U.S. adults. $\mathbf{J}$ Nutr, v. 133, p. 2879-2882, 2003.

GUSTAFSON, L.A; KUIPERS, F.; WIEGMAN, C.; SAUERWEIN, H.P.; ROMIJN, J.A.; MEIJER, A.J. Clofibrate improves glucose tolerance in fat-fed rats but decreases hepatic glucose consumption capacity. J Hepatol, v. 37, p. 425-431, 2002.

KIM, D.J.; XUN, P.; LIU, K.; LORIA, C.; YOKOTA, K.; JACOBS-JR, D.R.; HE, K. Magnesium intake in relation to systemic inflammation, insulin resistance, and the incidence of diabetes.

Diabetes Care, v. 33, p. 2604-2610, 2010.

KIRII, K.; ISO, H.; DATE, C.; FUKUI, M.; TAMAKOSHI, S.; JACC STUDY GROUP.

Magnesium intake and risk of self-reported type 2 diabetes among Japanese. J Am Coll Nutr, v. 29, 99-106, 2010.

LÄRSTAD M., LJUNGKVIST G., OLIN A-C., TORÉN K. Determination of malondialdehyde in breath condensate by high-performance liquid chromatography with fluorescence detection. $\mathbf{J}$ Chromat B, v.766, p.107, 2001.

LUNDBAEK, K. Intravenous glucose tolerance as a tool in definition and diagnosis of diabetes mellitus. Br Med J, v. 3, p. 1507-1513, 1962.

MATTHEWS, D.; HOSKER, J.; RUDENSKI, A.; NAYLOR, B.; TREACHER, D.; TURNER, R. Homeostasis model assessment: insulin resistance and $\beta$-cell function from fasting plasma glucose and insulin concentrations in man. Diabetologia, v. 28, p. 412-9, 1985.

NATIONAL RESEARCH COUNCIL. BOARD ON AGRICULTURE. COMMITTEE ON ANIMAL NUTRITION. SUBCOMMITTE ON LABORATORY ANIMAL NUTRITION. Nutrient requirements of the laboratory rat. In: _. Nutrient requirements of laboratory animals. 4. ed. Washington, D.C.: National Academy Press, 1995. Cap. 2, p. 11-79.

NETER, J.; KUTNER, M.; NACHTSHEIM, C.J.; LI, W. Applied linear statisctical models. 5. Ed. New York: McGral-Hill/Irwin, 2004.

PICKERING, C.; ALSIÖ, J.; HULTING, A.L.; SCHIÖTH, H.B. Withdrawal from free-choice high-fat high-sugar craving only in obesity-prone animals. Psychophamacology, v. 204, n. 3 , p. 431-443, 2009.

REEVES, P.; NIELSEN, F.; FAHEY Jr., G. Purified diets for laboratory rodents: final report of the American Institute of Nutrition ad hoc writing comittee on reformulation of the AIN-76A rodent diet. J Nutr, v. 123, n. 2, p. 1939-1951, 1993.

SALES, C.H.; PEDROSA, L.F.C.; LIMA, J.G.; LEMOS, T.M.A.M.; COLLI, C. Influence of magnesium status and magnesium intake on the blood glucose control in patients with type 2 diabetes. Clin Nutr, v. 30, p.359-64, 2011. 
SIES, H.; KOCH, O.R.; MARTINO, E.; BOVERIS, A. Increased billiary glutathione disulfide release in chronically ethanol-treated rats. Febs Letters, v. 23, n. 2, p. 287-90, 1979.

SOGAWA, M.; SEURA, T.; KOHNO, S.; HIRASAKA, K.; YAMAGUSHI, Y.; TAKAGAKI, R.; HARADA, A.; OKUMURA, Y.; YAMAMOTO, S.; KISHI, K.; NIKAWA, T. Awa (Tokushima) lactate-fermented tea as well as green tea enhance the effect of diet restriction on obesity in rats. J Med Invest. v. 56, n. 1-2, p. 42-48, 2009.

TORRES, L.H.L. Efeitos da inalação da fumaça do cigarro no estresse oxidativo do sistema nervoso central de camundongos jovens. 2009. Dissertação (Mestrado em Toxicologia e Análises Toxicológicas). Faculdade de Ciências Farmacêuticas da USP. São Paulo, 2009. 
APÊNDICE E - Formulário para observação de sinais de deficiência de magnésio

\section{Sinais}

ANEXO 8

Animal:

Grupo:

Data da observação:

\begin{tabular}{|c|c|c|}
\hline Sina & & Observações \\
\hline 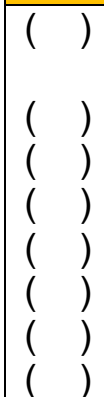 & $\begin{array}{l}\text { presença de hiperemia } \\
\text { das orelhas e pés } \\
\text { hiperirritabilidade } \\
\text { convulsão } \\
\text { tremores } \\
\text { alopecia } \\
\text { lesões na pele } \\
\text { edema } \\
\text { gengivas hipertróficas }\end{array}$ & \\
\hline
\end{tabular}

Responsável pela observação:

O animal permaneceu apresentado o(s) sinal(is) descrito? Fazer evolução caso haja alguma modificação. 

APÊNDICE F - Comparação dos resultados de determinação de magnésio plasmático e em amostras de sangue colhidas com citrato de sódio e heparina sódica

Para esta avaliação foi colhido sangue de nove ratos Wistar Hannover, provenientes do Biotério de Produção e Experimentação do Conjunto das Químicas da USP. Após anestesia por via intraperitoneal com solução de xilazina e quetamina (1:2, v/v), o sangue foi colhido, pela veia porta, e distribuído em três tubos: um contento citrato de sódio (Synth ${ }^{\circledR}$, São Paulo, Brasil) a $30 \%(10 \mu \mathrm{g}$ citrato/mL de sangue), outro contendo heparina sódica (50 UI heparina/mL de sangue) e outro sem anticoagulante. Este último tubo foi utilizado para obtenção de soro.

Os resultados foram submetidos à ANOVA seguido do post-hoc de Tukey para plasma/soro, e pelo teste t-Student pareado para eritrócitos

\section{Resultados}

Não houve diferenças estatísticas nos resultados de magnésio plasmático/sérico e eritrocitário quando o sangue foi colhido nas condições mencionadas (Figura F-1). No entanto, optou-se por usar heparina sódica como anticoagulante para as amostras para análises de magnésio, por ser o mais utilizado em estudos com animais.
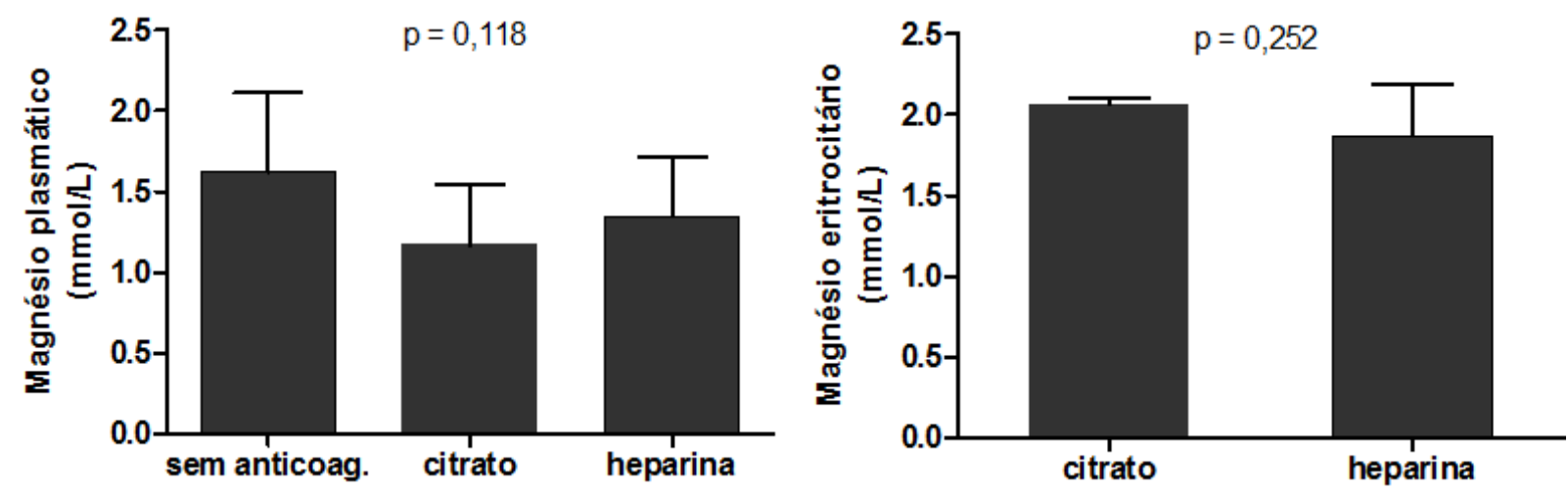

Figura F- 1 - Magnésio plasmático/sérico e eritrocitário de ratos Wistar $(n=9)$. Avaliação de uso de anticoagulantes. Médias \pm DP $(p>0,05)$. 

APÊNDICE G - Validação do método de determinação de ácidos graxos em fígados

Responsáveis pelos procedimentos:

Cassiana Ganem Achtschin e Cristiane Hermes Sales

Auxílio técnico: Rosângela Pavan Torres

\section{Método}

O método envolve a extração de lipídios (totais, saturados e insaturados) com éter após hidrólise ácida, e determinação por cromatografia a gás.

Foi preparado um homogenato de pool de fígados de ratos e feita a hidrólise ácida dos lipídios com o ácido pirogálico para minimizar a degradação oxidativa dos ácidos graxos (AG) durante a análise. Os lipídios foram extraídos com éter, e então metilados para ésteres metílicos de $A G$, usando trifluoreto de boro $\left(\mathrm{BF}_{3}\right)$ em metanol (7\%). Após remoção do solvente sobre fluxo de nitrogênio $\left(N_{2}\right)$, os ésteres metílicos foram ressuspendidos em clorofórmio e injetados em cromatógrafo a gás CG17A (Shimadzu, Kyoto, Japão), equipado com detector de ionização de chama ligado a um processadorintegrador C-30021 (CG Instrumentos Científicos Ltda, São Paulo, Brasil), nas seguintes condições de análise:

- Coluna cromatográfica de sílica fundida - Supelcowax 10 de $30 \mathrm{~m}$ x 0,25 mm de diâmetro e 0,2 $\mu \mathrm{m}$ de espessura da fase estacionária (Supelco Park, Bellefonte, Palo Alto, CA, EUA)

- Gás de arraste: hélio (1 mL/min)

- Programação de temperatura da coluna: aquecimento a $1^{\circ} \mathrm{C} / \mathrm{min}$ de $170 \stackrel{\circ}{ } \mathrm{C}$ até $225^{\circ} \mathrm{C}$, permanecendo nesta temperatura por $10 \mathrm{~min}$

- Temperatura do vaporizador: $250^{\circ} \mathrm{C}$

- Temperatura do detector: $270{ }^{\circ} \mathrm{C}$

- Tempo total de análise: 65 min

- Razão de divisão da amostra no injetor: 1/100

A identificação dos ésteres metílicos dos AG foi realizada comparando os tempos de retenção dos ésteres das amostras com os dos ácidos graxos padrão (mistura de 
padrões Sigma 189.19). A quantificação foi realizada relacionando a área dos picos com a área total (ácidos graxos totais foram fixados em $100 \%$ ), de acordo com a recomendação da AOAC (2006). Os valores foram expressos em percentual de AG.

O Procedimento Operacional Padrão - POP formulado para este método baseouse no método proposto pela AOAC (2006), com algumas modificações para adequar a quantidade de lipídios presente nessas amostras.

\section{Validação da extração}

A sensibilidade do método foi avaliada a partir da determinação dos limites de detecção (LD) e de quantificação (LQ). Para cálculo destes limites foram analisados 10 brancos sem amostra e sem padrão interno.

O LD foi calculado pela média obtida na leitura dos 10 brancos, somado ao produto da multiplicação do $\mathrm{t}_{(\mathrm{n}-1,1-\alpha)}$ (sinal/ruído) pelo desvio padrão de 10 leituras do branco. O LQ foi obtido da mesma forma, mas considerando a relação sinal/ruído de 10:1 (equações abaixo).

$$
\text { LD = média dos } 10 \text { brancos }+\left(t_{(n-1,1-\alpha)} \cdot \text { desvio padrão dos } 10 \text { brancos }\right)
$$

Onde, $\mathrm{t}$ = distribuição de Student, dependente do tamanho da amostra e do grau de confiança, neste caso, com 10 amostras, ou seja, com o grau de liberdade igual a nove e considerando limite de confiança $99 \%$, o sinal/ruído é de 2,821:1.

$$
\mathrm{LQ}=\text { média dos } 10 \text { brancos }+(10 \cdot \text { desvio padrão dos } 10 \text { brancos })
$$

A precisão foi calculada em termos de repetibilidade e reprodutibilidade dos resultados. Para esta avaliação foram realizadas, em três dias diferentes, a extração e metilação de cinco amostras do homogenato do pool de fígados, conforme recomendado no método, ou seja, usando o padrão interno $C_{13: 0}$ (triglicerídeo tritridecanoína $-C_{13: 0}$, Sigma $\left.{ }^{\circledR}\right)$. 
A precisão intra-ensaio foi avaliada pelo resultado das cinco determinações feitas no pool, em um mesmo ensaio. A reprodutibilidade inter-ensaio foi avaliada pela dispersão dos resultados das análises feitas em três dias distintos.

$$
\text { Precisão }(\%)=100-\left(\frac{\text { desvio padrão }}{\text { concentração média determinada }} \times 100\right)
$$

A exatidão foi avaliada através do erro relativo (ER), que é calculado através da equação abaixo, considerando a concentração obtida do padrão interno empregado no método (triglicerídeo tritridecanoína $-\mathrm{C}_{13: 0}$, Sigma ${ }^{\circledR}$ ) acrescentado nas amostras usadas para avaliar a precisão e no branco com padrão $C_{13: 0}$, e considerando os resultados obtidos do padrão Lipid Standards: fatty acid methyl ester mixtures (189-19) - Supelco ${ }^{\circledR}$.

$$
\mathbf{E R}=\frac{\mathrm{Xlab}-\mathrm{Xv}}{\mathrm{X} v} \times 100
$$

Onde: Xlab = média aritmética dos valores obtidos $\mathrm{X} v=$ valor aceito como verdadeiro

\section{Resultados}

\section{$\square$ Sensibilidade do método}

O limite de detecção do método foi de 249,7 e o de quantificação de 885,3 . Estes foram calculados com base nas áreas do AG palmítico (16:0), representado na Figura G1. O AG palmítico foi escolhido entre os que foram detectados por ter sido identificado em todas as replicatas feitas do branco, e por suas áreas diferirem do branco (zero), diferente do AG mirístico, que também identificado, e com maior coeficiente de variação em relação ao palmítico (Tabela G-1). 


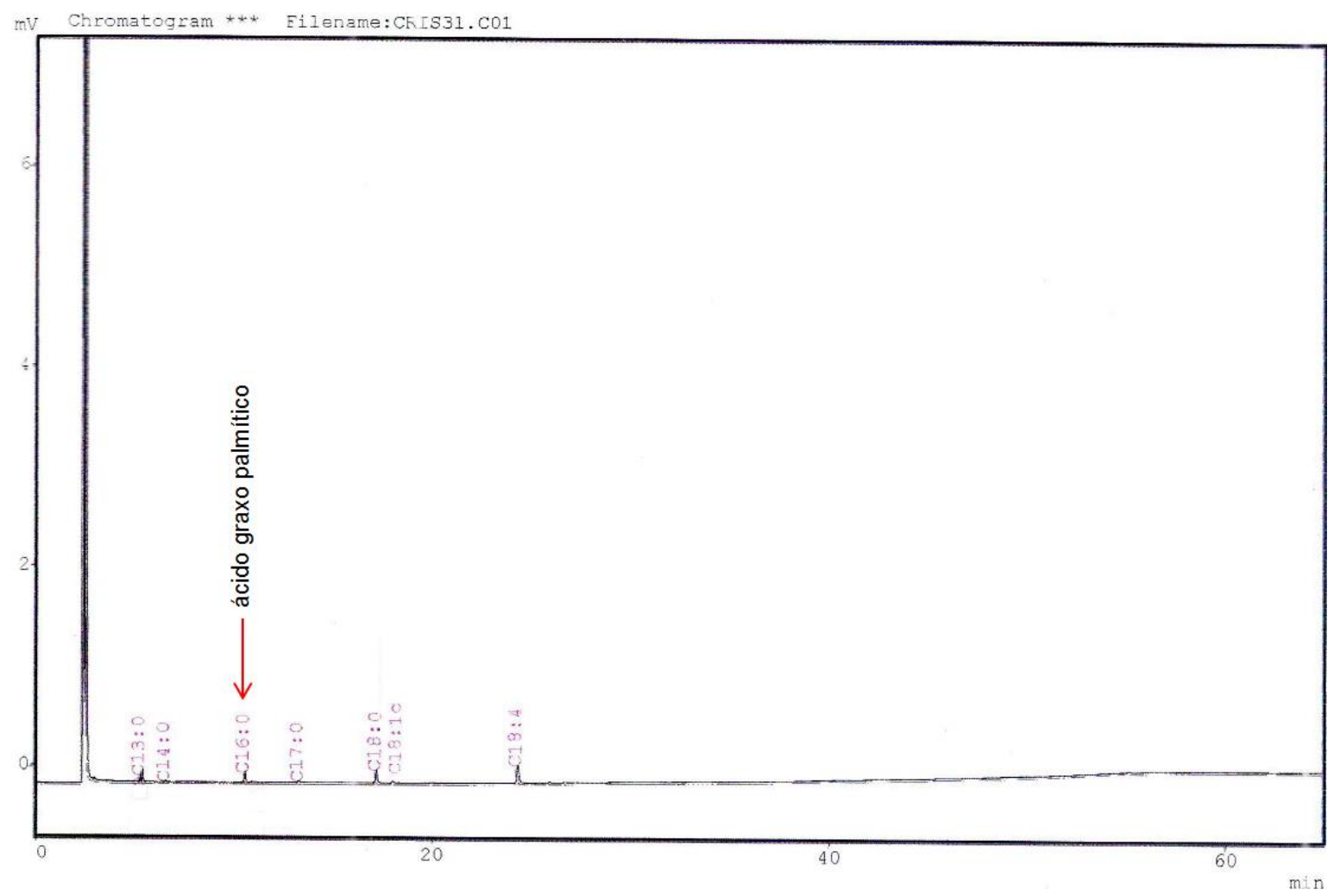

Figura G- 1 - Cromatograma representativo do branco utilizado no método: todos os reagentes sem amostra e sem padrão interno

Tabela G- 1 - Ácidos graxos quantificados nos brancos avaliados pelo método de hidrólise ácida durante a validação da extração de ácidos graxos em fígado de ratos Wistar

\begin{tabular}{lcccc}
\hline Variável & Branco & Ácido mirístico & Ácido palmítico & $\mathbf{p}$ \\
\hline Área do pico & $0,00 \pm 0,00^{\mathrm{a}}$ & $46,8 \pm 12,9^{\mathrm{a}}$ & $\mathbf{4 5 2 , 4} \pm \mathbf{8 8 , 5 ^ { \mathrm { b } }}$ & 0,000 \\
\hline
\end{tabular}

\section{■ Precisão e exatidão}

O método de extração apresentou boa precisão (Tabela G-2). Apesar disto, especialmente para os ácidos graxos capróico, pentadecanóico e oléico, ele não foi tão exato quanto desejável (Tabela G-1). Nas figuras G-2 e G-3 são apresentados cromatogramas representativos das análises do branco com padrão $C_{13: 0}$, do fígado e do padrão certificado 198.19. 
Tabela G- 2 - Precisões intra- e inter-ensaio do método de extração e metilação de ácidos graxos por hidrólise ácida em amostras de fígado de ratos Wistar

\begin{tabular}{|c|c|c|c|}
\hline \multicolumn{2}{|l|}{ Ácidos graxos (\%) } & $\begin{array}{l}\text { Precisão inter- } \\
\text { ensaio }\end{array}$ & $\begin{array}{l}\text { Precisão intra- } \\
\text { ensaio }\end{array}$ \\
\hline Totais & & $99,84-99,98$ & 99,89 \\
\hline Saturados & & $99,83-99,98$ & 99,89 \\
\hline Monossaturados & & 99,87 - 99,97 & 99,90 \\
\hline Poli-insaturados & & $99,83-99,98$ & 99,89 \\
\hline palmítico & 16:0 & $99,85-99,98$ & 99,89 \\
\hline esteárico & $18: 0$ & 99,82 - 99,99 & 99,89 \\
\hline palmitoléico & $18: 1$, cis -9 & 99,88 - 99,96 & 99,92 \\
\hline vacênico & $18: 1$ cis- 11 & $99,85-99,98$ & 99,88 \\
\hline linoléico & $18: 2$, cis- 9,12 & $99,85-99,98$ & 99,90 \\
\hline eicosadienóico & $20: 2$, cis- 11,14 & $99,84-99,97$ & 99,90 \\
\hline araquidônico & $20: 4$, cis-5,8,11,14 & $99,82-99,99$ & 99,88 \\
\hline docosapentaenóico & $22: 5$ & $99,82-99,99$ & 99,88 \\
\hline docosahexaenóico & $\begin{array}{l}22: 6, \text { cis- } \\
4,7,10,13,16,19\end{array}$ & $99,80-99,98$ & 99,86 \\
\hline
\end{tabular}

* análises realizadas em três dias diferentes $(n=5$ replicatas $/ \mathrm{d})$

Tabela G- 3 - Erro relativo do método de extração e metilação de ácidos graxos em fígados de ratos, por hidrólise ácida. Avaliação feita com padrão interno: triglicerídeo tritridecanoína $\left(\mathrm{C}_{13: 0}\right)$ Sigma $^{\circledR}$ (concentração esperada do padrão interno $=0,005 \mathrm{mg} / \mathrm{mL}$ )

\begin{tabular}{lcc}
\hline & Concentração recuperada $(\mathbf{m g} / \mathbf{m L})$ & Erro relativo $(\%)^{\star}$ \\
\hline branco com padrão interno & 0,0046 & $-8,36(0,06)$ \\
$1^{\circ}$ dia & 0,0046 & $-8,12(0,05)$ \\
$2^{\circ}$ dia & 0,0046 & $-8,42(0,03)$ \\
$3^{\circ}$ dia & 0,0046 & $-8,54(0,14)$ \\
\hline Média & & $-\mathbf{8 , 3 6}$ \\
DP & & $\mathbf{0 , 1 8}$ \\
CV (\%) & $\mathbf{- 2 , 1 2}$ \\
\hline
\end{tabular}

${ }^{*}$ Resultados em média(desvio padrão) 
Tabela G- 4 - Comparação dos resultados obtidos experimentalmente com o valor do material certificado de referência*

\begin{tabular}{|c|c|c|c|c|c|c|}
\hline \multirow{2}{*}{ Ácido graxo } & & \multicolumn{3}{|c|}{ Valor obtido (\%) } & \multirow{2}{*}{$\begin{array}{c}\text { Valor } \\
\text { certificado } \\
(\%)\end{array}$} & \multirow{2}{*}{ Erro relativo } \\
\hline & & média & SD & CV (\%) & & \\
\hline \multicolumn{7}{|l|}{ Gordura saturada } \\
\hline butírico ou butanóico & $04: 0$ & - & - & - & 4 & - \\
\hline capróico & 06:0 & 1,56 & 0,82 & 52,54 & 4 & $-61,01$ \\
\hline caprílico & 08:0 & 3,33 & 0,18 & 5,31 & 4 & $-16,77$ \\
\hline cáprico & $10: 0$ & 4,09 & 0,08 & 1,89 & 4 & 2,36 \\
\hline undecanóico & $11: 0$ & 2,07 & 0,03 & 1,62 & 2 & 3,71 \\
\hline láurico & $12: 0$ & 4,33 & 0,06 & 1,34 & 4 & 8,33 \\
\hline tridecanóico & $13: 0$ & 2,18 & 0,03 & 1,53 & 2 & 8,88 \\
\hline mirístico & 14:0 & 4,40 & 0,06 & 1,39 & 4 & 10,08 \\
\hline pentadecanóico & $15: 0$ & 2,18 & 0,04 & 1,65 & 4 & $-45,42$ \\
\hline palmítico & $16: 0$ & 6,85 & 0,10 & 1,41 & 6 & 14,13 \\
\hline heptadecanóico & $17: 0$ & 1,55 & 0,03 & 1,65 & 2 & $-22,65$ \\
\hline esteárico & 18:0 & 4,52 & 0,06 & 1,32 & 4 & 13,04 \\
\hline araquídico & $20: 0$ & 4,47 & 0,07 & 1,46 & 4 & 11,84 \\
\hline heneicosanóico & $21: 0$ & 2,25 & 0,03 & 1,53 & 2 & 12,36 \\
\hline beénico & $22: 0$ & 4,55 & 0,08 & 1,72 & 4 & 13,65 \\
\hline tricosanóico & 23:0 & 2,32 & 0,04 & 1,75 & 2 & 15,75 \\
\hline lignocérico & $24: 0$ & 4,70 & 0,09 & 1,83 & 4 & 17,39 \\
\hline TOTAL & & 55,17 & 0,61 & 1,10 & 60 & $-8,04$ \\
\hline \multicolumn{7}{|c|}{ Gordura monossaturada } \\
\hline miristoléico & $14: 1$, cis-9 & 2,23 & 0,03 & 1,22 & 2 & 11,30 \\
\hline pentadecenóico & $15: 1$, cis- 10 & 2,19 & 0,03 & 1,32 & 2 & 9,69 \\
\hline palmitoléico & $16: 1$, cis-9 & 2,23 & 0,03 & 1,19 & 2 & 11,52 \\
\hline heptadecenóico & $17: 1$, cis- 10 & 2,25 & 0,03 & 1,28 & 2 & 12,71 \\
\hline oléico & $18: 1$, cis-9 & 7,03 & 0,09 & 1,31 & 4 & 75,84 \\
\hline eicosenóico & $20: 1$, cis- 11 & 2,30 & 0,03 & 1,35 & 2 & 14,92 \\
\hline erúcico & $22: 1$, cis- 13 & 2,30 & 0,04 & 1,68 & 2 & 15,01 \\
\hline nervônico & $24: 1$, cis- 15 & 2,40 & 0,05 & 2,00 & 2 & 20,13 \\
\hline TOTAL & & 22,94 & 0,31 & 1,35 & 18 & 27,44 \\
\hline \multicolumn{7}{|c|}{ Gordura poli-insaturada } \\
\hline linoléico & $18: 2$, cis-9,12 & 2,15 & 0,02 & 0,97 & 2 & 7,73 \\
\hline$\gamma$-linolênico & 18:3, cis-6,9,12 & 1,99 & 0,03 & 1,46 & 2 & $-0,71$ \\
\hline linolênico & $18: 3$, cis- $9,12,15$ & 1,99 & 0,02 & 1,24 & 2 & $-0,52$ \\
\hline eicosadienóico & $20: 2$, cis- 11,14 & 2,14 & 0,02 & 1,05 & 2 & 7,19 \\
\hline eicosatrienóico & $20: 3$, cis- $11,14,17(n-3)$ & 1,87 & 0,03 & 1,36 & 2 & $-6,53$ \\
\hline eicosatrienóico & $20: 3$, cis- $8,11,14(n-6)$ & 1,90 & 0,02 & 1,17 & 2 & $-4,78$ \\
\hline araquidônico & $20: 4$, cis- $5,8,11,14$ & 1,84 & 0,03 & 1,42 & 2 & $-8,20$ \\
\hline eicosapentaenóico & $20: 5$, cis- $5,8,11,14,17$ & 1,69 & 0,02 & 1,43 & 2 & $-15,72$ \\
\hline docosadienóico & $22: 2$, cis- 13,16 & 2,17 & 0,03 & 1,49 & 2 & 8,34 \\
\hline docosahexaenóico & $22: 6$, cis- $4,7,10,13,16,19$ & 1,50 & 0,03 & 1,72 & 2 & $-24,84$ \\
\hline TOTAL & & 17,33 & 2,20 & 12,67 & 20 & $-13,36$ \\
\hline \multicolumn{7}{|l|}{ Gordura trans } \\
\hline elaídico & $18: 1$, trans-9 & - & - & - & 2 & - \\
\hline linolelaídico & $18: 2$, trans $-9,12$ & 2,22 & 0,02 & 0,79 & 2 & 11,09 \\
\hline TOTAL & & 2,22 & 0,02 & 0,79 & 4 & $-44,5$ \\
\hline
\end{tabular}

* padrão Lipid Standards: fatty acid methyl ester mixtures (189-19) - Supelco ${ }^{\circledR}$ 

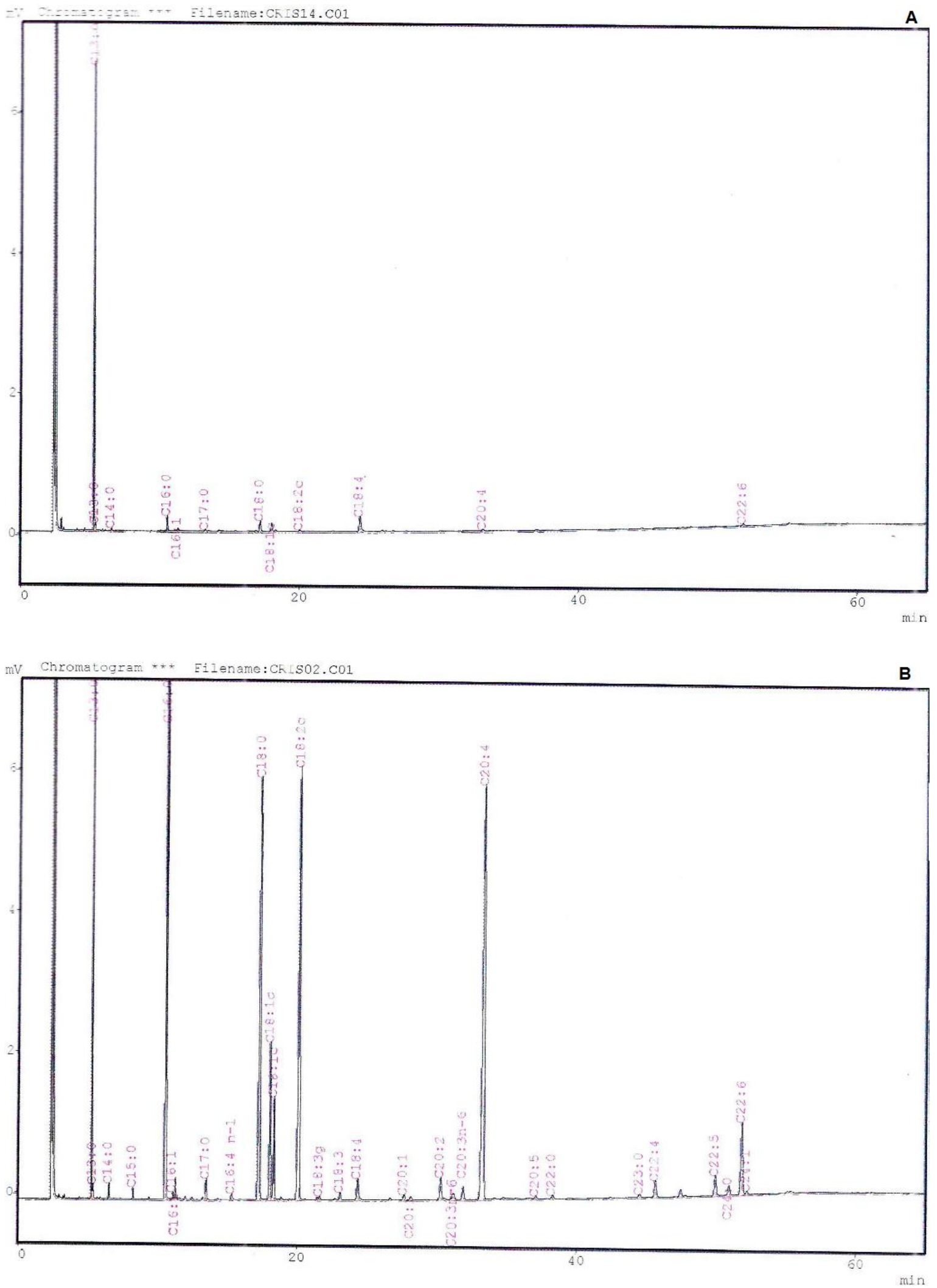

Figura G- 2 - Cromatogramas representativos das análises do branco com padrão $\mathrm{C}_{13: 0}$ (A) e das amostras de fígado de ratos Wistar (B) 


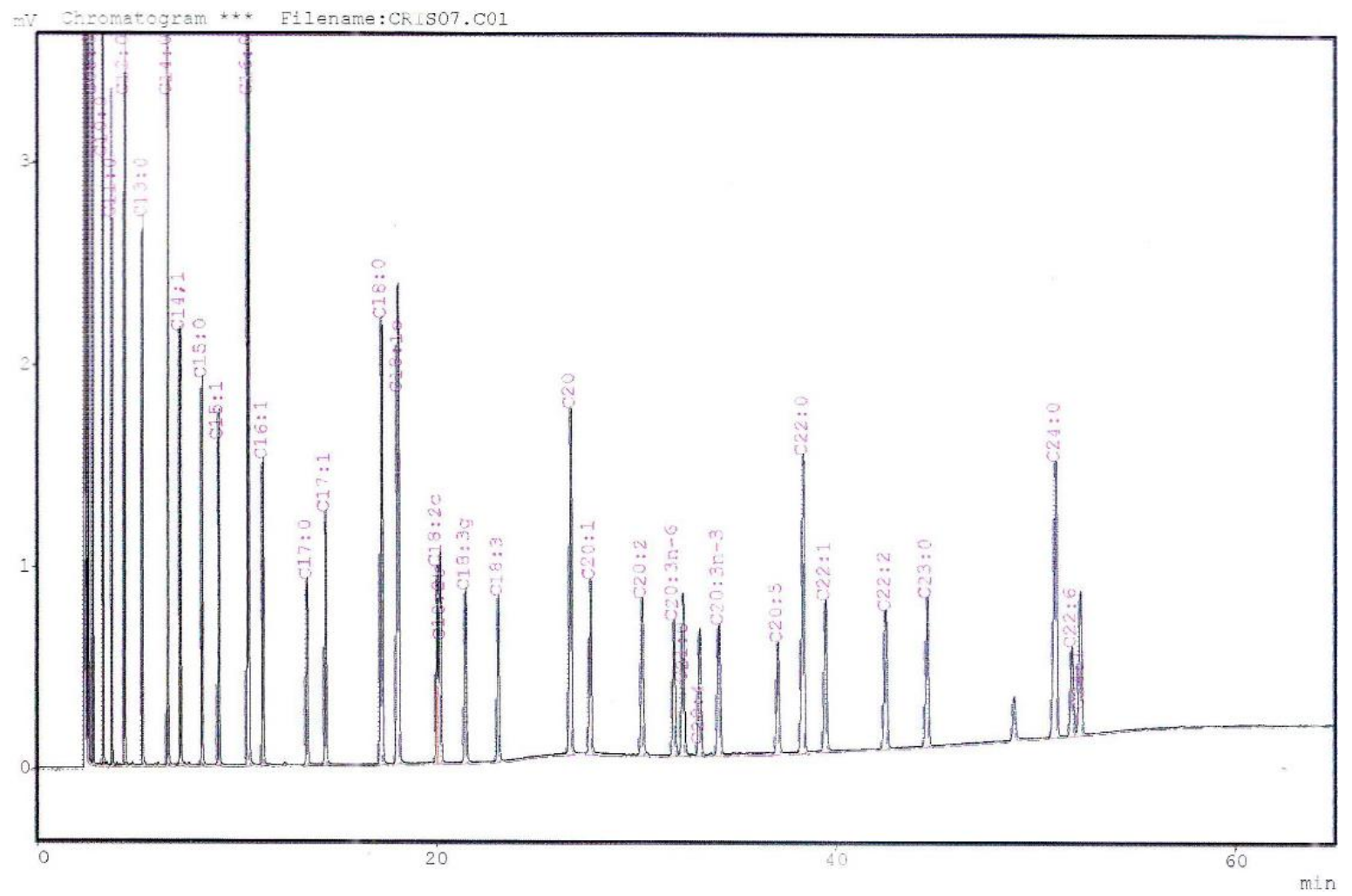

Figura G- 3 - Cromatograma representativo da análises do padrão Lipid Standards: fatty acid methyl ester mixtures (189-19) - Supelco ${ }^{\circledR}$

\section{REFERÊNCIAS CONSULTADAS}

ASSOCIATION OF OFFICIAL ANALYTICAL CHEMISTS. Official methods of analysis of Association of Official Analytical Chemists. 18. ed. Maryland: Current through Revision 1, 2006, Cap. 41 , p. $20-25$.

GUIMARÃES, A.R.P; KUGA. E.; TORRES. R.P.; COLQUHOUN, A.; CURI, R.; MANCINI FILHO, J. Composition of fatty acids in the liver and lymphoid organs of rats fed fatty acids-rich diets.

Biochem Mol Biol Int, v. 36, p. 451-461, 1995.

INSTITUTO NACIONAL DE METROLOGIA, NORMALIZAÇÃO E QUALIDADE INDUSTRIAL -

INMETRO. DOQ-CGCRE-008. Orientação sobre validação de métodos analíticos. Revisão 03. Fevereiro de 2010. Disponível em: http://www.inmetro.gov.br/Sidoq/Arquivos/CGCRE/DOQ/DOQCGCRE-8_03.pdf. Acesso em: 31 maio de 2010. 
APÊNDICE H - Representação da perda de pelos em estágio mais avançado, sem lesões, em animais do grupo hiperlipídico deficiente em magnésio. Estágio observado ao final do experimento. Do lado esquerdo temos um animal do grupo pareado.
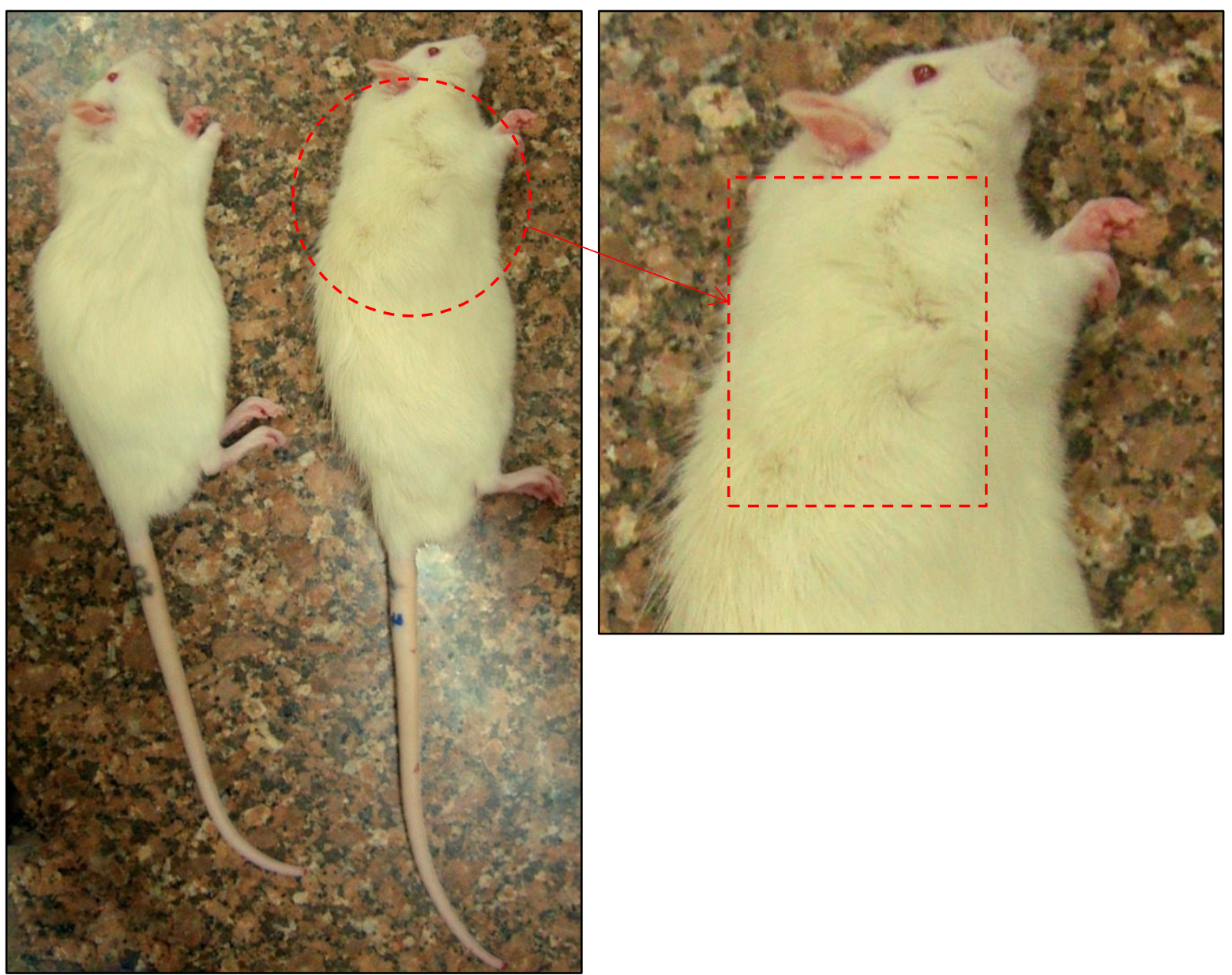
200 SALES, С.H. 
APÊNDICE I - Lesão apresentada por um animal do grupo hiperlipídico deficiente em magnésio
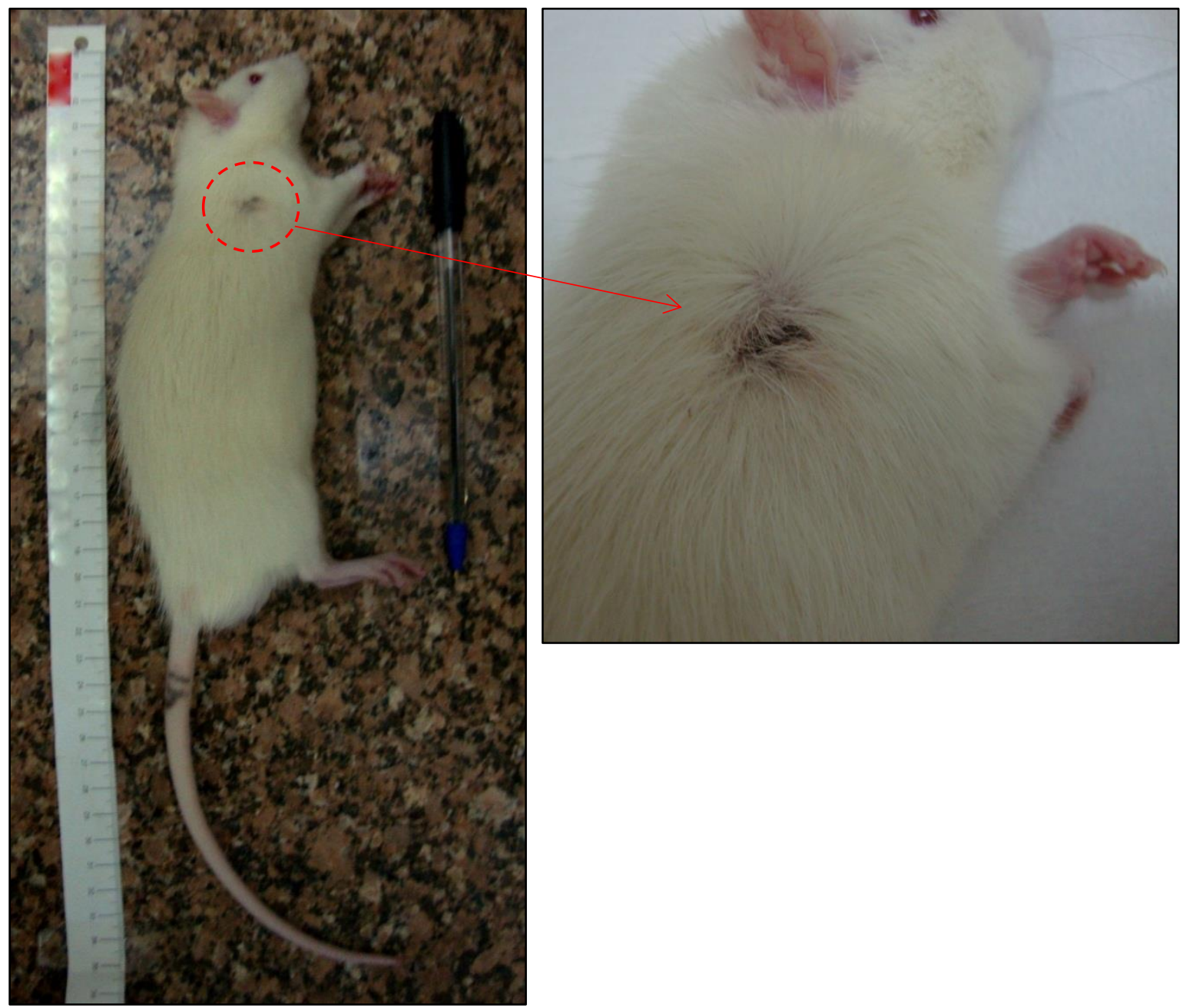

APÊNDICE J - Resultados de estresse oxidativo e inflamação obtidos no ensaio principal, e que não foram explorados no artigo apresentado na Parte II

Tabela J- 1 - Status oxidativo e inflamatório de ratos Wistar alimentados, durante 32 dias, com dieta controle, hiperlipídica ou hiperlipídica deficiente em magnésio

\begin{tabular}{|c|c|c|c|c|c|}
\hline Parâmetros & $\begin{array}{c}C T \\
(n=8)\end{array}$ & $\begin{array}{c}\text { PF } \\
(n=16)\end{array}$ & $\begin{array}{c}H F \\
(n=12)\end{array}$ & $\begin{array}{l}\mathrm{HFMg}^{-} \\
(\mathrm{n}=12)\end{array}$ & $\mathbf{p}^{\mathrm{a}}$ \\
\hline \multicolumn{6}{|l|}{ Status oxidativo } \\
\hline $\begin{array}{l}\text { Malondialdeído ( } \mu \mathrm{mol} / \mathrm{mg} \\
\text { proteína) }\end{array}$ & $17,9 \pm 9,03^{a}$ & $20,8 \pm 13,1^{a}$ & $25,1 \pm 13,1^{\mathrm{a}}$ & $26,0 \pm 21,4^{a}$ & 0,590 \\
\hline $\begin{array}{l}\text { Atividade da GSH-Px } \\
\text { (U/mg proteína) }\end{array}$ & $1,07 \pm 0,41^{\mathrm{a}}$ & $0,96 \pm 0,38^{a}$ & $1,03 \pm 0,58^{\mathrm{a}}$ & $1,23 \pm 0,49^{a}$ & 0,513 \\
\hline $\begin{array}{l}\text { Atividade da CAT (U/mg } \\
\text { proteína) }\end{array}$ & $1,85 \pm 0,67^{\mathrm{a}}$ & $2,37 \pm 1,10^{\mathrm{a}}$ & $2,08 \pm 1,10^{\mathrm{a}}$ & $2,41 \pm 1,19^{a}$ & 0,610 \\
\hline \multicolumn{6}{|l|}{ Status inflamatório } \\
\hline $\begin{array}{l}\text { interleucina } 6 \text { sérica } \\
(\mathrm{pg} / \mathrm{mL})\end{array}$ & ND & ND & ND & ND & - \\
\hline $\begin{array}{l}\text { interleucina } 1 \beta \text { sérica } \\
(\mathrm{pg} / \mathrm{mL})\end{array}$ & $22,6 \pm 24,1^{a}$ & $21,0 \pm 31,5^{\mathrm{a}}$ & $28,8 \pm 33,0^{\mathrm{a}}$ & $13,1 \pm 6,9^{a}$ & $0,368^{b}$ \\
\hline TNF- $\alpha$ sérico (pg/mL) & $2,06 \pm 3,16^{a}$ & $2,07 \pm 4,60^{\mathrm{a}}$ & $0,50 \pm 0,56^{a}$ & $3,04 \pm 7,21^{a}$ & $0,929^{b}$ \\
\hline PAl-1 total sérico $(\mathrm{pg} / \mathrm{mL})$ & $112 \pm 70,6^{a}$ & $71,6 \pm 75,3^{a}$ & $67,0 \pm 117^{\mathrm{a}}$ & $46,7 \pm 63,5^{a}$ & 0,226 \\
\hline $\begin{array}{l}\text { proteína C reativa } \\
(\mathrm{ng} / \mathrm{mL})\end{array}$ & $483 \pm 110^{a}$ & $567 \pm 74^{\mathrm{a}}$ & $478 \pm 107^{a}$ & $502 \pm 156^{a}$ & 0,191 \\
\hline TNF- $\alpha$ hepático & $0,80 \pm 0,32^{a}$ & $0,70 \pm 0,16^{a}$ & $0,86 \pm 0,37^{\mathrm{a}}$ & $0,80 \pm 0,38^{a}$ & 0,777 \\
\hline
\end{tabular}

Resultados expressos em média \pm desvio padrão

CT: grupo controle ad libitum; PF: grupo controle com alimentação pareada em gramas aos hiperlipídicos; HF: grupo hiperlipídico; $\mathrm{HFMg}^{-}$: grupo hiperlipídico e deficiente em magnésio; $\mathrm{GSH}$ Px: glutationa peroxidase; CAT: catalase; TNF: fator de necrose tumoral; PAI: inibidor do ativador de plasminogênio; ND: não determinado

${ }^{a}$ comparação das médias dos grupos feita pelo teste one-way ANOVA, seguido de post-hoc de Tukey. Letras diferentes na mesma linha correspondem a médias diferentes.

${ }^{\mathrm{b}}$ comparação das medianas dos grupos feita pelo teste Kruskal-Wallis 
Tabela J- 2 - Análise de regressão linear múltipla stepwise considerando os parâmetros de peroxidação lipídica, estresse oxidativo e inflamação como variáveis dependentes

\begin{tabular}{|c|c|c|c|c|}
\hline Variáveis dependentes $^{a}$ & $\begin{array}{c}\text { Variáveis } \\
\text { independentes }^{\mathrm{b}}\end{array}$ & $B \pm S E$ & $\mathbf{p}$ & $\mathbf{R}^{2}$ \\
\hline \multirow{2}{*}{$\begin{array}{l}\text { Malondialdeído }(\mu \mathrm{mol} / \mathrm{mg} \\
\text { proteína) }\end{array}$} & $\mathrm{Mg}$ eritrocitário $(\mathrm{mmol} / \mathrm{L})$ & $-18,81 \pm 8,73$ & 0,037 & \multirow[t]{2}{*}{0,095} \\
\hline & Constante & $65,92 \pm 20,04$ & 0,002 & \\
\hline \multirow[t]{2}{*}{ PAl-1 total $(\mathrm{pg} / \mathrm{mL})$} & Mg eritrocitário $(\mathrm{mmol} / \mathrm{L})$ & $-110,6 \pm 50,64$ & 0,034 & \multirow[t]{2}{*}{0,100} \\
\hline & Constante & $321,3 \pm 115,7$ & 0,008 & \\
\hline \multirow[t]{2}{*}{ Interleucina $1 \beta(\mathrm{pg} / \mathrm{mL})$} & Mg plasmático $(\mathrm{mmol} / \mathrm{L})$ & $53,38 \pm 17,79$ & 89,255 & \multirow[t]{2}{*}{0,173} \\
\hline & Constante & $-33,33 \pm 18,07$ & 4,106 & \\
\hline
\end{tabular}

B: coeficiente de regressão não padronizado; SE: erro padrão; $p$ : probabilidade; $R^{2}$ : coeficiente de determinação; Mg: magnésio

${ }^{a}$ variáveis independentes incluídas no modelo inicial: magnésio plasmático, magnésio eritrocitário, magnésio urinário, magnésio muscular, magnésio ósseo, consumo de magnésio, consumo de lipídios e índice de adiposidade.

Apesar de a peroxidação lipídica, o estresse oxidativo e a inflamação serem considerados fatores que podem ser influenciados pela deficiência de magnésio (RAYSSIGUIER et al., 2006; NIELSEN et al., 2007; BOPARAl et al., 2007; MAZUR et al., 2007), a ausência de alterações nestes parâmetros no presente estudo [ENSAIO PRINCIPAL] (Tabela J-1) indica que a influencia desse mineral possa ser posterior, considerando o nível de restrição de magnésio que foi imposto (66 \% da recomendação). Por outro lado, é possível que os parâmetros usados para avaliação do status oxidativo e inflamatório não reflitam de forma evidentes alterações que possam estar ocorrendo, possivelmente por tratar-se de um evento inicial.

Embora fraca, a associação inversa do MDA com o magnésio eritrocitário (Tabela J-2), indica que as concentrações intracelulares de magnésio influenciam na peroxidação lipídica, e provavelmente não se alteraram pelo controle das enzimas antioxidantes, que se mantiveram adequadas (Tabela $\mathbf{J}-\mathbf{1}$ ). Relata-se a deficiência de magnésio também pode induzir a peroxidação lipídica (BOPARAl et al., 2007), cuja indução seria, em parte, atribuída a redução do magnésio intracelular e aumento do cálcio citosólico, desencadeados por alterações na permeabilidade da membrana celular. Essas alterações iônicas induzem ao aumento da xantina oxidase e da hipoxantina dentro da célula, que quando não encontram concentrações adequadas de enzimas antioxidantes, 
permeiam que ocorra o acúmulo de $\mathrm{H}_{2} \mathrm{O}_{2}$ e $\mathrm{O}_{2}$, e assim induzem ao estresse e a peroxidação lipídica (MALPUECH-BRUGÈRE et al., 2000).

A inflamação também pareceu ter influencia das concentrações de magnésio. A relação inversa do magnésio eritrocitário como o PAl-1 total pode indicar que as concentrações intracelulares desse mineral podem influenciar na maior propensão a disfunção endotelial e maior agregação plaquetária, e assim propiciar a inflamação (RAYSSIGUIER et al., 2006; MAZUR et al., 2007). Por outro lado, a associação positiva da IL-1 $\beta$ com o magnésio plasmático não ficou muito clara. Contudo, existem relatos de que diante da modificação da resposta fagocítica das células, o organismo modifica a sua compartimentalização e induz ao aumento do magnésio plasmático para se proteger dos efeitos adversos da inflamação (MALPUECH-BRUGÈRE et al., 2000). É possível que isso ocorra como uma resposta inicial do organismo na tentativa de se defender, e possivelmente pode mudar ao longo do tempo.

\section{Referências}

Boparai RK, Kiran R, Bansal DD. Insinuation of exacerbated oxidative stress in sucrosefed rats with a low dietary intake of magnesium: evidence of oxidative damage to proteins. Free Radic Res. 2007; 41(9): 981-9. doi: 10.1080/10715760701447892

Mahfouz MM, Kummerow FA. Effect of magnesium deficiency on $\Delta 6$ desaturase activity and fatty acid composition of rat liver microsomes. Lipids 1989; 24: 727-32.

Malpuech-Brugère $C$, Nowacki W, Daveau M, Gueux E, Linard C, Rock E, et al. Inflammatory response following acute magnesium deficiency in the rat. Biochim Biophys Acta 2000; 1501(2-3): 91-8.

Mazur A, Maier JAM, Rock E, Gueux E, Nowacki W, Rayssiguier Y. Magnesium and the inflammatory response: potential physiopathological implications. Arch Biochem Biophys 2007; 458: 48-56.

Nielsen FH, Milne DB, Klevay LM, Gallagher S, Johnson L. Dietary magnesium deficiency induces heart rhythm changes, impairs glucose tolerance, and decreases serum cholesterol in post menopausal women. J Am Coll Nutr 2007; 26(2): 121-32.

Rayssiguier Y, Gueux E, Nowacki W, Rock E, Mazur A. High fructose consumption combined with low dietary magnesium intake may increase the incidence of the metabolic syndrome by inducing inflammation. Magnes Res 2006; 19(4): 237-43. 


ANEXo A - Aprovação do comitê de ética em experimentação animal

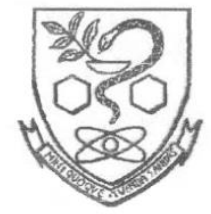

UNIVERSIDADE DE SÃO PAULO

FACULDADE DE CIÊNCIAS FARMACÊUTICAS

Comissão de Ética em Experimentação Animal

Oficio CEEA/FCF/ $31 / 2009$

\section{CERTIFICADO}

Certificamos que o Projeto "Efeito da deficiência dietética de magnésio na resistência insulínica e na resposta inflamatória em ratos alimentados com dieta hiperlipídica" (Protocolo $n^{\circ} 221$ ), de responsabilidade da pesquisadora Cristiane Hermes Sales sob a orientação da Profa. Dra. Célia Colli, está de acordo com os Princípios Éticos na Experimentação Animal adotado pelo Colégio Brasileiro de Experimentação Animal - COBEA e foi aprovado pela Comissão de Ética em Experimentação Animal - CEEA, desta Faculdade, em 11 de maio de 2009.

São Paulo, 12 de maio de 2009.

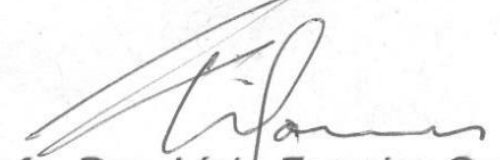

Profa. Dra. Lígia Ferreira Gomes

Presidente da Comissão de Ética em Experimentação Animal CEEA/FCF/USP 

ANEXo B - Rações experimentais usadas no ensaio piloto

Teklad Custom Research Diet Data Sheet

\section{TD.06416 Adjusted Calories Diet (10/Fat)}

\section{Formula}

Casein

L-Cystine

Corn Starch

Maltodextrin

Lard

Soybean Oil

Cellulose

Sucrose

Mineral Mix, AIN-93G-MX (94046)

Calcium Phosphate, dibasic

Vitamin Mix, AIN-93-VX (94047)

Choline Bitartrate

Yellow Food Color $\mathrm{g} / \mathrm{Kg}$

210.0

3.0

280.0

50.0

20.0

20.0

37.15

325.0

35.0

2.0

15.0

2.75

0.1
Key Features

- Purified Diet

- Diet Induced Obesity

- Control

\section{Key Planning Information}

- Products are made fresh to order

- Store product at $4^{\circ} \mathrm{C}$ or lower

- Use within 6 months (applicable to most diets)

- Box labeled with product name,

manufacturing date, and lot number

- Replace diet at minimum once per week More frequent replacement may be advised

- Lead time:

- 2 weeks non-irradiated

4 weeks irradiated

\section{Product Specific Information}

- $1 / 2$ " Pellet or Powder (free flowing)

- Minimum order $3 \mathrm{Kg}$

- Irradiation available upon request

\section{Options (Fees Will Apply)}

- Rush order (pending availability)

- Irradiation (see Product Specific Information)

- Vacuum packaging (1 and $2 \mathrm{Kg}$ )

Approximate fatty acid profile ( $\%$ of total fat): $29 \%$ saturated, $37 \%$

monounsaturated, $34 \%$ polyunsaturated.

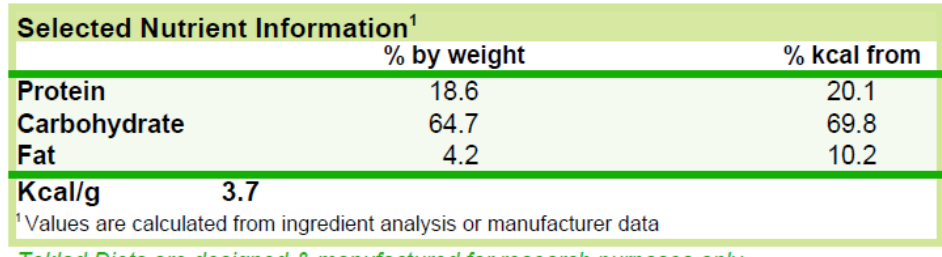

Teklad Diets are designed \& manufactured for research purposes only.

Speak With A Nutritionist

- (800) 483.5523

- askanutritionist@harlan.com

Harlan Laboratories · PO Box 44220 - Madison, WI 53744-4220

harlan"

International Inquiry

- Outside U.S.A. or Canada

- askanutritionist@harlan.com

Place Your Order (U.S.A. \& Canada)

Place Order - Obtain Pricing

Check Order Status

- (800) 483.5523

- (608) 277.2066 facsimile

- tekladinfo@harlan.com

Helping you do research better 


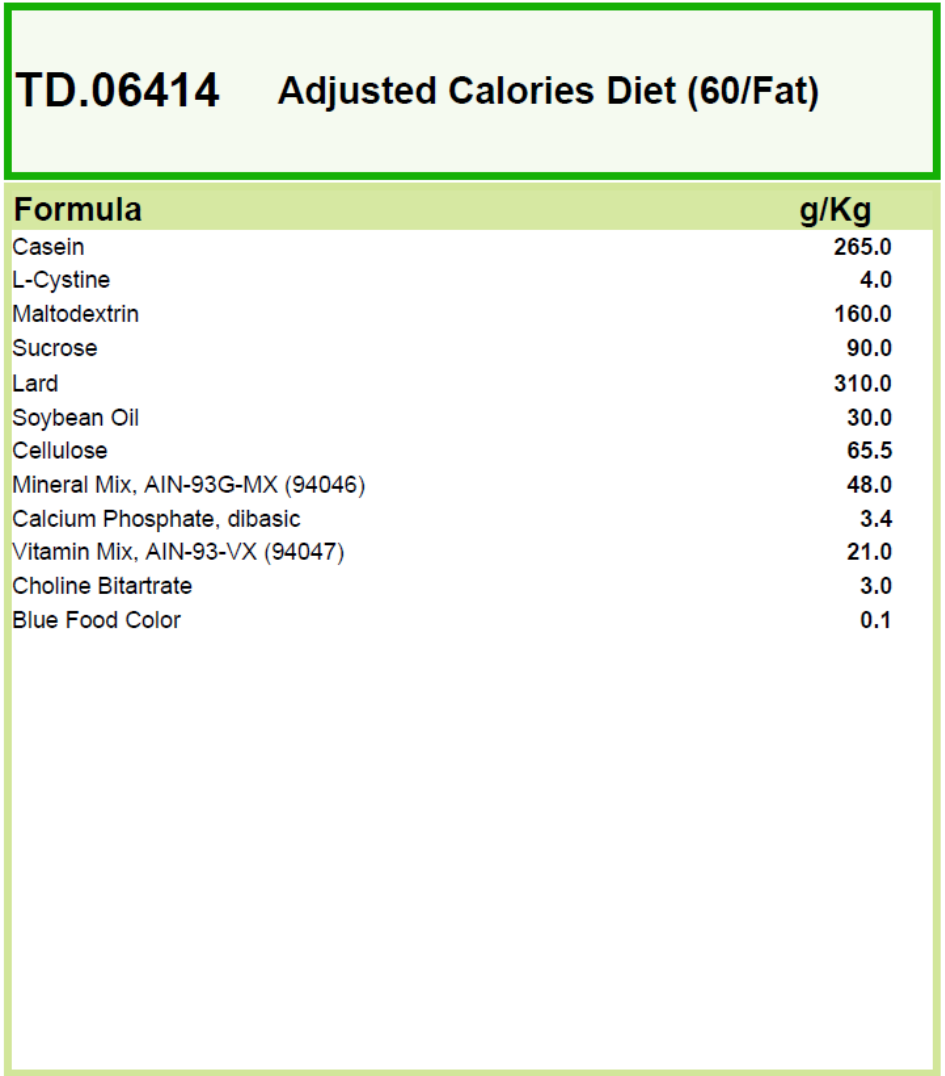

\section{Footnote}

Approx. $60 \%$ of total calories come from fat. Designed with similarities to Research Diets, Inc. formula D12492. For the series TD 06414-TD 06416. Approximate fatty acid profile ( $\%$ of total fat): $37 \%$ saturated, $47 \%$ monounsaturated, $16 \%$ polyunsaturated.

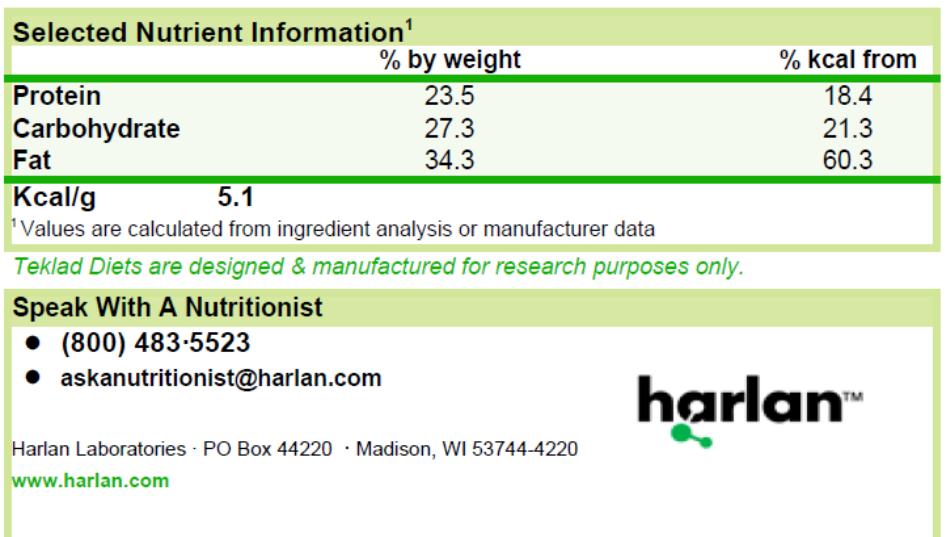

\section{Key Features}

\section{- Purified Diet}

- Diet Induced Obesity

- High Fat

\section{Key Planning Information}

- Products are made fresh to order

- Store product at $4^{\circ} \mathrm{C}$ or lower

- Use within 6 months (applicable to most diets)

- Box labeled with product name,

manufacturing date, and lot number

- Replace diet at minimum once per week More frequent replacement may be advised

- Lead time:

- 2 weeks non-irradiated

4 weeks irradiated

\section{Product Specific Information}

- 1/2" Pellet or Powder (free flowing)

- Minimum order $3 \mathrm{Kg}$

- Irradiation available upon request

Options (Fees Will Apply)

- Rush order (pending availability)

- Irradiation (see Product Specific Information)

- Vacuum packaging (1 and $2 \mathrm{Kg}$ )

International Inquiry

- Outside U.S.A. or Canada.

- askanutritionist@harlan.com

Place Your Order (U.S.A. \& Canada)

- Place Order - Obtain Pricing.

Check Order Status

- (800) 483.5523

- (608) 277.2066 facsimile

- tekladinfo@harlan.com

Helping you do research better 
ANEXO C - Rações experimentais usadas no ensaio principal

\section{TD.110294 7\% Soybean Oil Diet $(500 \mathrm{Mg})$}

$\begin{array}{lc}\text { Formula } & \mathbf{g} / \mathbf{K g} \\ \text { Casein } & 200.0 \\ \text { L-Cystine } & 3.0 \\ \text { Corn Starch } & 396.636 \\ \text { Maltodextrin } & 132.0 \\ \text { Sucrose } & 100.0 \\ \text { Soybean Oil } & 70.0 \\ \text { Cellulose } & 50.0 \\ \text { Mineral Mix (Mg Deficient) (05090) } & 35.0 \\ \text { Magnesium Oxide } & 0.85 \\ \text { Vitamin Mix, AIN-93-VX (94047) } & 10.0 \\ \text { Choline Bitartrate } & 2.5 \\ \text { TBHQ, antioxidant } & 0.014\end{array}$

\section{Footnote}

Diet is essentially AIN-93G, but uses a mineral mix without $\mathrm{Mg}$ and then adds

Mg back to level of approximately 500 mg/kg. Series TD.110294-TD.110299.

Selected Nutrient Information ${ }^{1}$

\begin{tabular}{lcc|}
\hline & \% by weight & \% kcal from \\
\hline Protein & 17.7 & 18.8 \\
Carbohydrate & 60.1 & 63.9 \\
Fat & 7.2 & 17.2 \\
\hline Kcal/g & $\mathbf{3 . 8}$ & \\
'Values are calculated from ingredient analysis or manufacturer data \\
\hline \multicolumn{2}{l}{ Teklad Diets are designed \& manufactured for research purposes only. }
\end{tabular}

\section{Speak With A Nutritionist}

- (800) 483.5523

- askanutritionist@harlan.com

Harlan Laboratories · PO Box 44220 - Madison. WI 53744-4220 www.harlan.com
Key Features

- Purified Diet

- AIN-93G Modification

- Magnesium Adjusted

- Series

\section{Key Planning Information}

- Products are made fresh to order

- Store product at $4^{\circ} \mathrm{C}$ or lower

- Use within 6 months (applicable to most diets)

- Box labeled with product name. manufacturing date, and lot number

- Replace diet at minimum once per week More frequent replacement may be advised

- Lead time:

- 2 weeks non-irradiated

4 weeks irradiated

\section{Product Specific Information}

- 1/2" Pellet or Powder (free flowing)

- Minimum order $3 \mathrm{Kg}$

- Irradiation not advised . Contact a nutritionist for recommendations

Options (Fees Will Apply)

- Rush order (pending availability)

- Irradiation (see Product Specific Information

- Vacuum packaging (1 and $2 \mathrm{Kg}$ )

International Inquiry

- Outside U.S.A. or Canada

- askanutritionist@harlan.com

Place Your Order (U.S.A. \& Canada)

Place Order - Obtain Pricing Check Order Status

- (800) 483.5523

- (608) 277.2066 facsimile

- tekladinfo@harlan.com

Helping you do research better 


\section{TD.110297 25\% Lard, 7\% SBO Diet (500 Mg)}

\section{Formula}

Casein

L-Cystine

Corn Starch

Maltodextrin

Sucrose

Lard

Soybean Oil

Cellulose

Mineral Mix (Mg Deficient) (05090)

Magnesium Oxide

Vitamin Mix, AIN-93-VX (94047)

Choline Bitartrate

$\mathrm{TBHQ}$, antioxidant

$\mathrm{g} / \mathrm{Kg}$
200.0
3.0
78.636
200.0
100.0
250.0
70.0
50.0
35.0
0.85
10.0
2.5
0.014

\section{Footnote}

Modification of AIN-93G with $25 \%$ lard added at the expense of starch. Uses a mineral mix without $\mathrm{Mg}$ and then adds $\mathrm{Mg}$ back to level of approximately 500 $\mathrm{mg} / \mathrm{kg}$. No adjustment is made to make protein, vitamins, or mineral levels proportional to kcal density. Series TD.110294-TD.110299.

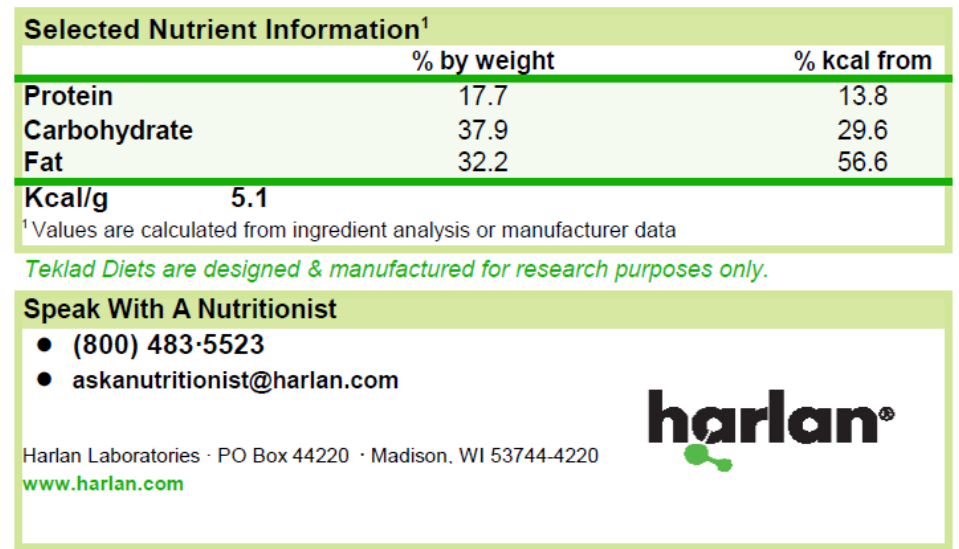

Key Features

- Purified Diet

- AIN-93G Modification

- High Fat - Lard

- Series

\section{Key Planning Information}

- Products are made fresh to order

- Store product at $4^{\circ} \mathrm{C}$ or lower

- Use within 6 months (applicable to most diets)

- Box labeled with product name,

manufacturing date, and lot number

- Replace diet at minimum once per week More frequent replacement may be advised

- Lead time:
2 weeks non-irradiated
4 weeks irradiated

\section{Product Specific Information}

- $1 / 2$ " Pellet or Powder (free flowing)

- Minimum order $3 \mathrm{Kg}$

- Irradiation not advised - Contact a nutritionist for recommendations

\section{Options (Fees Will Apply)}

- Rush order (pending availability)

- Irradiation (see Product Specific Information)

- Vacuum packaging (1 and $2 \mathrm{Kg}$ )

International Inquiry

- Outside U.S.A. or Canada.

- askanutritionist@harlan.com

Place Your Order (U.S.A. \& Canada)

Place Order - Obtain Pricing Check Order Status.

- (800) 483.5523

- (608) 277-2066 facsimile

- tekladinfo@harlan.com

Helping you do research better 


\section{TD.110299 25\% Lard, 7\% SBO Diet (150 Mg)}

\section{Formula}

Casein

L-Cystine

Corn Starch

Maltodextrin

Sucrose

Lard

Soybean Oil

Cellulose

Mineral Mix (Mg Deficient) (05090)

Magnesium Oxide

Vitamin Mix, AIN-93-VX (94047)

Choline Bitartrate

TBHQ, antioxidant $\mathrm{g} / \mathrm{Kg}$

200.0

3.0

79.226

200.0

100.0

250.0

70.0

50.0

35.0

0.26

10.0

2.5

0.014

Key Features

- Purified Diet

- AIN-93G Modification

- High Fat - Lard

- Series

\section{Key Planning Information}

- Products are made fresh to order

- Store product at $4^{\circ} \mathrm{C}$ or lower

- Use within 6 months (applicable to most diets)

- Box labeled with product name,

manufacturing date, and lot number

- Replace diet at minimum once per week More frequent replacement may be advised

- Lead time:

2 weeks non-irradiated

4 weeks irradiated

\section{Product Specific Information}

- $1 / 2$ " Pellet or Powder (free flowing)

- Minimum order $3 \mathrm{Kg}$

- Irradiation not advised - Contact a nutritionist for recommendations

\section{Footnote}

Modification of AIN-93G with $25 \%$ lard added at the expense of starch. Uses a mineral mix without $\mathrm{Mg}$ and then adds $\mathrm{Mg}$ back to level of approximately 150 $\mathrm{mg} / \mathrm{kg}$. No adjustment is made to make protein, vitamins, or mineral levels proportional to kcal density. Series TD.110294-TD.110299.

\begin{tabular}{|c|c|c|}
\hline \multicolumn{3}{|c|}{ Selected Nutrient Information ${ }^{1}$} \\
\hline & $\%$ by weight & $\%$ kcal from \\
\hline Protein & 17.7 & 13.8 \\
\hline Carbohydrate & 38.0 & 29.7 \\
\hline Fat & 32.2 & 56.5 \\
\hline \multicolumn{3}{|c|}{$\begin{array}{l}5.1 \\
\text { ed from ingredient analysis or manufacturer data }\end{array}$} \\
\hline
\end{tabular}

\section{Speak With A Nutritionist}

- (800) 483.5523

- askanutritionist@harlan.com

Harlan Laboratories - PO Box 44220 - Madison. WI 53744-4220

\section{harlan'} www.harlan.com

Harlan, Harlan Laboratories, Helping you do research better,

\section{Options (Fees Will Apply)}

- Rush order (pending availability)

- Irradiation (see Product Specific Information)

- Vacuum packaging (1 and $2 \mathrm{Kg}$ )

International Inquiry

- Outside U.S.A. or Canada.

- askanutritionist@harlan.com

Place Your Order (U.S.A. \& Canada)

- Place Order - Obtain Pricing.

Check Order Status

- (800) 483.5523

- (608) 277.2066 facsimile

- tekladinfo@harlan.com

Helping you do research better 

ANEXO D - Informações do programa de pós-graduação para os membros julgadores

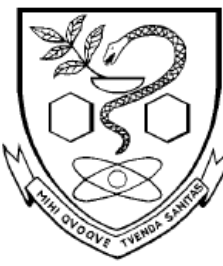

UNIVERSIDADE DE SÃO PAULO

Faculdade de Ciências Farmacêuticas Secretaria de Pós-Graduação

\section{Informações para os Membros de Bancas Julgadoras de Mestrado/Doutorado}

1. O candidato fará uma apresentação oral do seu trabalho, com duração máxima de 30 minutos.

2. Os membros da banca farão a arguição oral. Cada examinador disporá, no máximo, de 30 minutos para arguir o candidato, exclusivamente sobre o tema do trabalho apresentado, e o candidato disporá de 30 minutos para sua resposta.

2.1. Com a devida anuência das partes (examinador e candidato), é facultada a arguição na forma de diálogo em até 60 minutos por examinador.

2.2. Tempo máximo total de arguição: 3 horas para o mestrado e 5 horas para o doutorado.

3. A sessão de defesa será aberta ao público.

4. Terminada a arguição por todos os membros da banca, a mesma se reunirá reservadamente e expressará na ata (relatório de defesa) a aprovação ou reprovação do candidato, baseando-se no trabalho escrito e na arguição.

4.1. Será considerado aprovado o aluno que obtiver aprovação por unanimidade ou pela maioria da banca.

4.2. Caso algum membro da banca reprove o candidato, a Comissão Julgadora deverá emitir um parecer a ser escrito em campo exclusivamente indicado na ata.

5. Dúvidas poderão ser esclarecidas junto à Secretaria de Pós-Graduação: pgfarma@usp.br, (11) 30913621.

São Paulo, 26 de maio de 2011.

Profa. Dra. Bernadette D. G. M. Franco

Presidente da CPG/FCF/USP 

ANEXO E - Ficha do aluno

Janus - Sistema Administrativo da Pós-Graduação

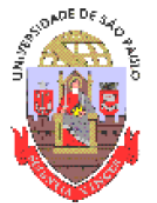

Universidade de São Paulo

Faculdade de Ciências Farmacêuticas

Documento sem validade oficial

FICHA DO ALUNO

9132 - 5763435/2 - Cristiane Hermes Sales

Email:

Data de Nascimento:

Cédula de Identidade:

Local de Nascimento:

Nacionalidade:

Graduação:

Nutricionista - Universidade Federal do Rio Grande do Norte - Rio Grande do Norte Brasil - 2005

Mestrado: $\quad$ Mestre em Ciência dos Alimentos - Área: Nutrição Experimental - Faculdade de Ciências Farmacêuticas - Universidade de São Paulo - São Paulo - Brasil - 2008

Curso:

Programa:

Área:

Data de Matrícula:

Início da Contagem de Prazo:

Data Limite:

Orientador:

Proficiência em Línguas:

Data de Aprovação no Exame de Qualificação:

Data do Depósito do Trabalho

Título do Trabalho:

Data Máxima para Aprovação da

Banca:

Data de Aprovação da Banca:

Data Máxima para Defesa:

Data da Defesa:

Resultado da Defesa:

Histórico de Ocorrências:

\section{Doutorado}

Ciência dos Alimentos

Nutrição Experimental

23/03/2009

23/03/2009

$25 / 03 / 2013$

Prof(a). Dr(a). Celia Colli - 23/03/2009 até o presente.

Inglês, Aprovado em 23/03/2009

Aprovado em 04/06/2012

Ingressou no Doutorado em 23/03/2009

Matrícula de Acompanhamento em 18/02/2013

Última ocorrência: Matrícula de Acompanhamento em 18/02/2013

Impresso em: 24/02/13 11:16:16 